\title{
Energy Savings and Economics of Advanced Control Strategies for Packaged Heat Pumps
}

\author{
W Wang \\ Y Huang \\ S Katipamula
}

October 2012

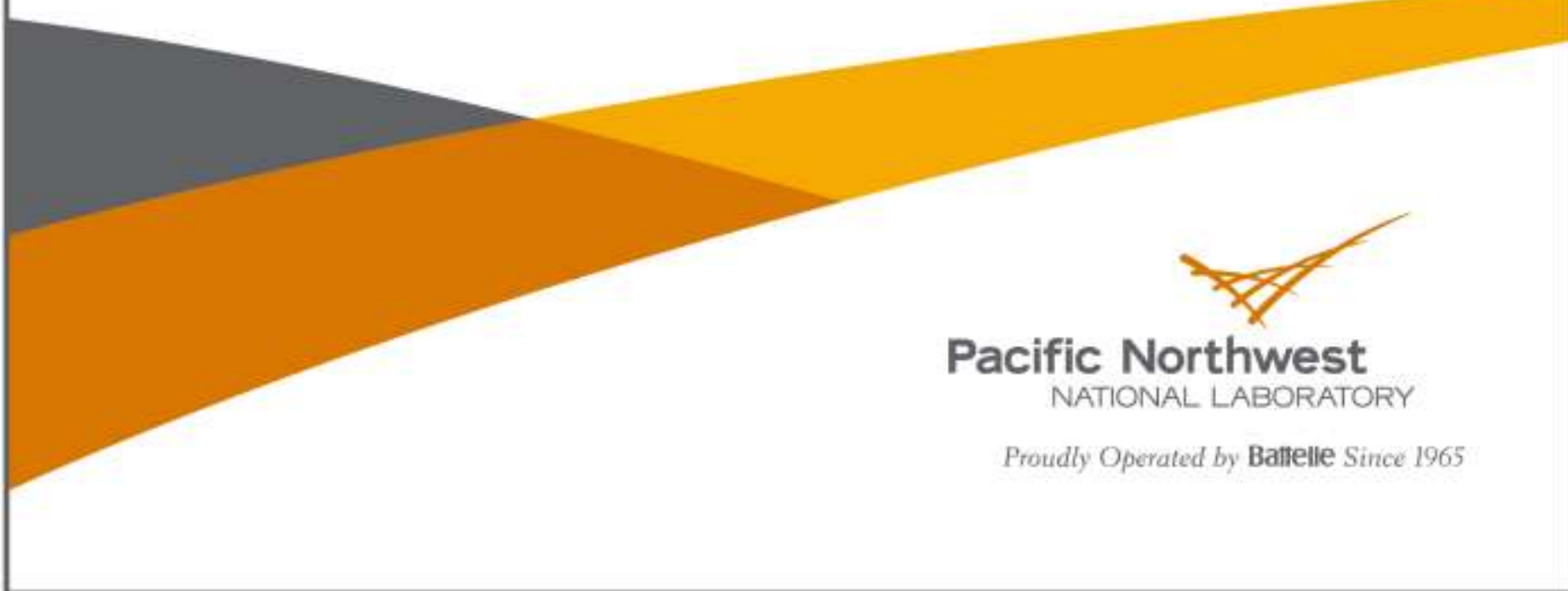




\title{
DISCLAIMER
}

This report was prepared as an account of work sponsored by an agency of the United States Government. Neither the United States Government nor any agency thereof, nor Battelle Memorial Institute, nor any of their employees, makes any warranty, express or implied, or assumes any legal liability or responsibility for the accuracy, completeness, or usefulness of any information, apparatus, product, or process disclosed, or represents that its use would not infringe privately owned rights. Reference herein to any specific commercial product. process, or service by trade name, trademark, manufacturer, or otherwise does not necessarily constitute or imply its endorsement, recommendation, or favoring by the United States Government or any agency thereof, or Battelle Memorial Institute. The views and opinions of authors expressed herein do not necessarily state or reflect those of the United States Government or any agency thereof.

\author{
PACIFIC NORTHWEST NATIONAL LABORATORY \\ operated by \\ BATTELLE \\ for the \\ UNITED STATES DEPARTMENT OF ENERGY \\ under Contract DE-AC05-76RLO1830
}

Printed in the United States of America

Avaliable to DOE and DOE contractors from the

Office of Scientific and Technical Information,

P.O. Box 62, Oak Ridge, TN 37831-0062;

ph: (865) 576-8401

fax: (865) $576-5728$

email: reports $a$ adonis.ssti.gov

\author{
Available to the public from the National Technical Information Service, \\ U.S. Department of Commerce, 5285 Port Royal Rd., Springfield, VA 22161 \\ ph: (800) 553-6847 \\ fax: (703) 605-6900 \\ email: orders $a$ ntis.fedworld.gov \\ online ordering: http://www.ntis.gov/ordering.htm
}


PNNL-21944

Energy Savings and Economics of Advanced Control Strategies for Packaged Heat Pumps

\author{
W Wang \\ Y Huang \\ S Katipamula
}

October 2012

Prepared for

U.S. Department of Energy

under Contract DE-AC05-76RL01830

Pacific Northwest National Laboratory

Richland, Washington 99352 


\section{Abstract}

Packaged cooling equipment, including packaged air-conditioning units and heat pumps, is used in $46 \%$ of all commercial buildings, serving over $60 \%$ of the commercial building floor space in the U.S. The annual electricity consumption associated with packaged equipment for cooling and ventilation is about 571 trillion Btus for site energy or 1,770 trillion Btus for source energy. Therefore, even a small increase in the part-load efficiency of these units can lead to significant reductions in energy use and cost. Pacific Northwest National Laboratory (PNNL), with funding from the U.S. Department of Energy's (DOE's) Building Technologies Program (BTP), evaluated a number of control strategies that can be implemented in an advanced controller, which can be retrofit into existing packaged heat pump units to improve their operational efficiency.

Using EnergyPlus simulations in 11 locations and in the two most promising building types, PNNL evaluated three individual control strategies, and combinations of those strategies, relative to a common base case, to estimate energy and cost savings potential. Those control strategies (shown in Table ES - 1) include use of a multi-speed fan (relative to constant speed fan), demand-controlled ventilation (relative to no demand control ventilation) and an integrated economizer (relative to an economizer that is not integrated).

Key findings of this analysis are shown in Figure ES - 1, Figure ES - 2, Figure ES - 3, Figure ES - 4 and Table ES - 2 and include the following:

- The individual control strategy with the greatest average savings impact is use of a multispeed fan (MSF). (This is primarily because fan energy consumption can be greater than the compressor energy consumption in many locations in the U.S. because it is running at constant speed all the time when the building is occupied to meet the ventilation requirements.) The savings range from $11 \%$ to $38 \%$ in the retail building, and $19 \%$ to $54 \%$ for the office building.

- The individual demand-controlled ventilation (DCV) control strategy has significant benefits in retail because of variable occupancy patterns, but not in offices as a result of their high and somewhat constant occupancy rates. Savings from the DCV controls range between $10 \%$ and $28 \%$ in retail buildings and $11 \%$ in office buildings.

- Integrated economizer savings are small $(0 \%$ to $7 \%)$ because the savings typically occur when the outdoor-air temperatures are between $50^{\circ} \mathrm{F}$ and $70^{\circ} \mathrm{F}$.

- A combination of MSF and DCV (Table ES - 2) can achieve very significant average electricity and electricity cost savings, approximately $40 \%$ in heating, ventilation and airconditioning (HVAC) energy for the two building types. In terms of average annual megawatt hour savings, the retail building would achieve $82 \mathrm{MWh}$ and the office 110 MWh, and costs savings are $\$ 12,000$ and $\$ 19,000$ per year, respectively.

- The range of the maximum acceptable installed cost with a 3-year payback for the retail building and the office building were also estimated (Figure ES - 3 and Figure ES - 4). The maximum total installed controller cost per packaged unit that will yield a 3-year payback period varies with the four scenarios. The controller cost can range between $\$ 4,180$ and $\$ 8,390$ for the retail building and between $\$ 1,560$ and $\$ 2,990$ for the office building. 


\section{Executive Summary}

Packaged cooling equipment, including packaged air-conditioning units and heat pumps, is used in $46 \%$ of all commercial buildings, serving over $60 \%$ of the commercial building floor space in the U.S. (Tables B40 and B41, EIA 2003). The annual electricity consumption associated with packaged equipment for cooling and ventilation is about 571 trillion Btus for site energy or 1,770 trillion Btus for source energy. Therefore, even a small increase in the part-load efficiency of these units can lead to significant reductions in energy use and cost. Pacific Northwest National Laboratory (PNNL), with funding from the U.S. Department of Energy's (DOE's) Building Technologies Program (BTP), evaluated a number of control strategies that can be implemented in an advanced controller, which can be retrofit into existing packaged heat pump units to improve their operational efficiency.

Many retrofit opportunities exist to improve the operational efficiency of packaged cooling equipment of rooftop units (RTUs). For example, building codes require that when a building is occupied, the supply fan on packaged units should operate continuously to meet the ventilation needs, irrespective of whether the unit is providing cooling or heating. Because the fan runs continuously, the fan energy consumption can be greater than the compressor energy consumption in many locations in the U.S. This implies that there exists a big potential to achieve energy savings from fan speed control while still meeting the ventilation needs. Similarly, packaged equipment with constant-speed supply fans is designed to provide ventilation at the design rate at all times when the fan is operating. Because there are a number of hours during the day when a building may not be fully occupied or the need for ventilation is lower than designed, potential opportunity exists to achieve energy savings from demand-based ventilation control. The significant saving potentials from multi-speed fan control and demandcontrolled ventilation (DCV) was demonstrated by the simulation results in our previous work for packaged air-conditioners with gas heat (Wang et al. 2011). As an extension of our previous work, this project focuses on packaged heat pumps.

The two primary objectives of this research project are to: 1) determine the range of national energy and cost savings achievable by retrofitting existing packaged heat pumps with advanced control strategies not ordinarily used in field installations for two building types in 11 locations with different climates, and 2) estimate the maximum installed cost of a replacement controller with the desired features in various regions of the U.S. to provide acceptable payback periods to owners.

\section{Analytic Approach}

The analytic approach consists of the following steps: specify advanced control options, determine the control sequence and control parameters, select representative buildings that predominately use packaged heat pumps, simulate the energy performance of the selected buildings in U.S. climate zones where heat pumps are predominately used, determine energy savings associated with changing base case controls to more advanced controls, and conduct the economic analysis. The energy savings are estimated based on detailed EnergyPlus (DOE 2010) simulations. Eight combinations of advanced control strategies are simulated for 2 building types in 11 locations with different climates. 


\section{Control Sequence of Operation for Packaged Heat Pumps}

In most packaged air-source heat pumps, a thermostat controls the operation of the compressor, depending on whether the zone calls for cooling or heating. In conventional control (base case), the compressor cycles to maintain the required zone temperature set point; and in heating mode, if the compressor is not able to meet all the heating needs, supplemental electric strip heating is used. The supply fan runs continuously when the building is occupied to provide required ventilation. The base case also assumes the use of non-integrated economizer, which is not used simultaneously with the mechanical cooling system.

Three additional control options that can be added to packaged heat pumps are analyzed or evaluated in this study, as shown in Table ES-1. These control options are:

- integrated airside economizer,

- supply-fan speed control, and

- demand-controlled ventilation.

For this study, the energy savings impacts of all three control strategies and their combinations were evaluated for packaged single-zone systems relative to the base case.

Table ES - 1: Advanced Control Options Considered for this Study

\begin{tabular}{|l|l|}
\hline Technology & Considered control options \\
\hline Air economizer & $\begin{array}{l}\text { Base Control Option: Differential dry-bulb, nonintegrated } \\
\text { Advanced Option: Differential dry-bulb, integrated }\end{array}$ \\
\hline Fan-speed control & $\begin{array}{l}\text { Base Control Option: Constant speed } \\
\text { Advanced Option: Multiple speed }\end{array}$ \\
\hline Ventilation control & $\begin{array}{l}\text { Base Control Option: Constant outdoor-air supply } \\
\text { Advanced Option: Demand-controlled ventilation }\end{array}$ \\
\hline
\end{tabular}

\section{Building Prototypes and Locations}

For this study, two prototype buildings that predominately use packaged heat pumps are chosen from the DOE's post-1980 commercial reference building models (Deru et al. 2011): medium office and stand-alone retail. Significant changes were made to the reference models to simulate the various control strategies that were evaluated using the EnergyPlus energy management controls module. The climate conditions and representative cities considered in this work follow those in the DOE's post-1980 reference models. However, the very hot climate (climate zone 1) and very cold climate (climate zones 6,7 and 8) were removed from the scope of analysis because heat pumps are not commonly used in those locations.

\section{Methodology}

To estimate the energy consumption of a prototype building with the baseline control option for packaged heat pumps and a modified prototype with advanced control options, a detailed simulation model is needed. An EnergyPlus model with the energy management system (EMS) feature was used to simulate the buildings and the various control options for the packaged heat pumps in two different prototype buildings and 11 locations, resulting in 176 simulation runs. 
For each simulation, EnergyPlus provides estimates of fan, cooling, heating and total energy consumption and electricity usage. Annual energy cost is simply calculated as the product of the electricity rates and the annual total electricity consumption.

\section{Energy and Cost Savings Results for Various Control Combinations}

Only HVAC energy uses are considered in estimating the energy and cost savings because the investigated control strategies do not affect the energy use for lighting, plug loads and service hot water. The annual total HVAC energy consumption, which is simply the sum of the electricity use for heating, cooling and fan operation, ranges between $94 \mathrm{MWh}$ and $323 \mathrm{MWh}$ for the retail building and 163 and $475 \mathrm{MWh}$ for the building. After normalization with the building area, the HVAC energy use intensities for the two building types range from 3.7 to $13 \mathrm{kWh} / \mathrm{ft}^{2} / y e a r(12.6$ to $44.3 \mathrm{kBtu} / \mathrm{ft}^{2} /$ year) for the retail building and from 3 to $8.8 \mathrm{kWh} / \mathrm{ft}^{2} /$ year $(10.2$ to $30 \mathrm{kBtu} /$ $\mathrm{ft}^{2} /$ year) for the office building.

Figure ES - 1 and Figure ES - 2 show the range in savings for all possible advanced control combinations relative to the baseline. The yellow point in the bar indicates the simple average of percentage savings across all 11 locations. Because electricity is the only fuel type for HVAC energy uses, the percentage saving is the same for both energy and cost. These two figures show that:

- For the three individual advanced control options, replacement of constant-speed fan control with multi-speed fan control yields the most energy savings: $11 \%$ to $38 \%$ for the retail building and $19 \%$ to $54 \%$ for the office building.

- $\quad$ DCV is also a highly effective control strategy for energy and cost savings, especially for the retail building. Using DCV yields $10 \%$ to $28 \%$ of HVAC energy and cost savings for the retail building and up to $11 \%$ savings for the office building. In comparison with multispeed fan control and DCV, enabling the integrated airside economizer with mechanical cooling has relatively small energy and cost savings (less than 6\%).

- Combining multi-speed fan control and DCV leads to 35\% to 47\% savings across all 11 locations for the retail building and $20 \%$ to $57 \%$ savings for the office building. Adding an integrated economizer on top of other controls has negligible impact on energy and cost savings. For example, in comparison with the combination of multi-speed fan control and DCV, the combination of all three control strategies has an additional $0 \%$ to $6.6 \%$ savings, depending on the building type and location. 


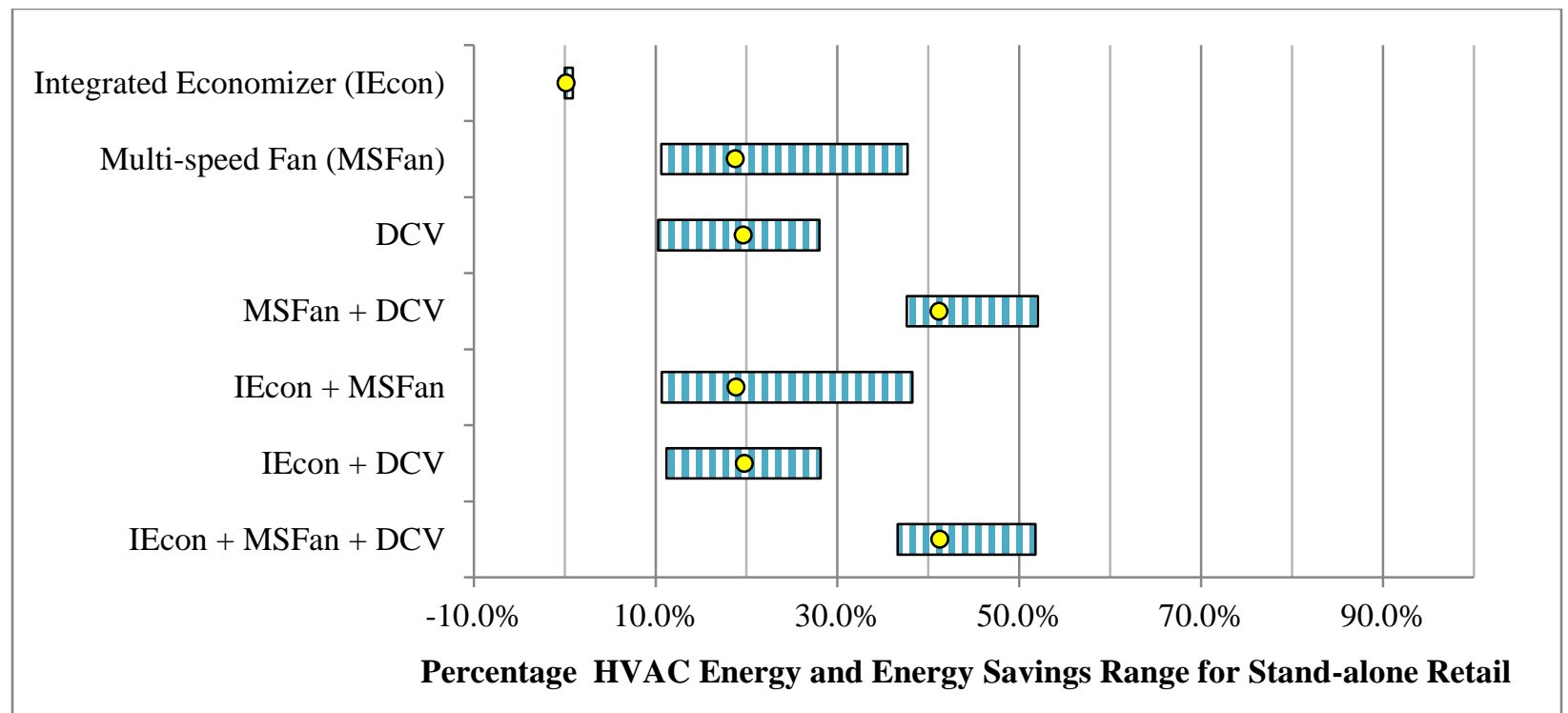

Figure ES - 1: Percentage HVAC Energy and Cost Savings Range for the Stand-alone Retail Building for All Seven Different Combinations of Advanced Control Options, Relative to the Base Case (yellow dot is a simple average across 11 locations)

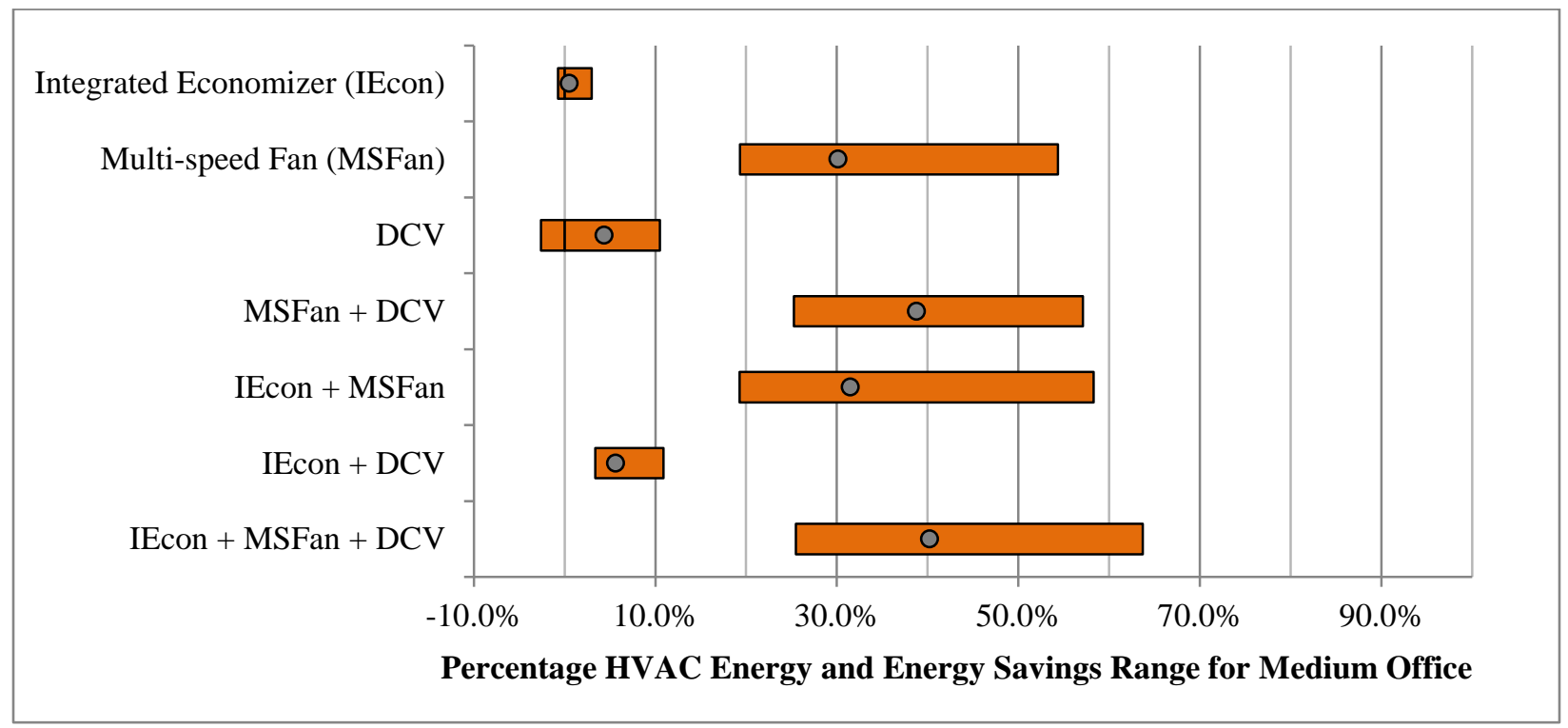

Figure ES - 2: Percentage HVAC Energy and Cost Savings Range for the Medium Office Building for All Seven Different Combinations of Advanced Control Options, Relative to the Base Case (yellow dot is a simple average across 11 locations)

For the combination of multi-speed fan control and DCV, Table ES - 2 summarizes the energy and cost savings including maximum, minimum and average savings. The key findings include:

- Relative to the base case with constant-speed supply fan and no DCV, retrofitting packaged heat pumps by adding multi-speed supply fan and DCV has the maximum percentage saving in Los Angeles (3B) for the retail building (51\%) and in San Francisco (3C) for the office 
building (57\%). The minimum percentage saving occurs in Houston (2A) for the retail building (37\%) and in Phoenix (2B) for the office building (25\%).

- The simple average of HVAC energy and cost savings across all 11 locations is $41 \%$ for the retail building and $39 \%$ for the office building.

Table ES - 2: Summary of HVAC Energy and Cost Savings from Replacing ConstantSpeed Supply Fan and Constant Ventilation with Multi-speed Supply-Fan Control and DCV

\begin{tabular}{|c|c|c|}
\hline & \multicolumn{2}{|c|}{ Building Type } \\
\hline & Stand-alone retail & Medium office \\
\hline Building Floor Area & $25,000 \mathrm{ft}^{2}$ & $53,600 \mathrm{ft}^{2}$ \\
\hline \multirow{2}{*}{ Maximum percentage savings } & $51 \%$ & $57 \%$ \\
\hline & in Los Angeles (3B) & in San Francisco (3C) \\
\hline \multirow{2}{*}{ Minimum percentage savings } & $37 \%$ & $25 \%$ \\
\hline & in Houston $(2 \mathrm{~A})$ & in Phoenix (2B) \\
\hline Average percentage savings & $41 \%$ & $39 \%$ \\
\hline \multirow{2}{*}{$\begin{array}{l}\text { Maximum absolute energy } \\
\text { savings }\end{array}$} & $122 \mathrm{MWh} /$ year & $125 \mathrm{MWh} /$ year \\
\hline & in Chicago (5A) & in Chicago (5A) \\
\hline \multirow{2}{*}{$\begin{array}{l}\text { Minimum absolute energy } \\
\text { savings }\end{array}$} & $48 \mathrm{MWh} /$ year & $93 \mathrm{MWh} /$ year \\
\hline & in Los Angeles (3B) & in San Francisco (3C) \\
\hline Average absolute energy savings & $82 \mathrm{MWh} /$ year & $110 \mathrm{MWh} /$ year \\
\hline \multirow{2}{*}{ Maximum absolute cost savings } & $\$ 17,633$ /year & $\$ 33,230 /$ year \\
\hline & in Chicago (5A) & in Chicago (5A) \\
\hline \multirow{2}{*}{ Minimum absolute cost savings } & $\$ 6,335$ /year & $\$ 6,700 /$ year \\
\hline & in Los Angeles (3B) & in San Francisco (3C) \\
\hline Average absolute cost savings & $\$ 11,800 /$ year & $\$ 19,000$ /year \\
\hline
\end{tabular}

\section{Controller Cost}

The maximum installed cost of advanced controllers that will yield a specific simple payback period is important for potential users to evaluate the financial merits of installing advanced controllers but also for vendors and developers in pricing their advanced control products.

Because an add-on controller is usually associated with each packaged heat pump unit, the total energy cost savings for a whole building needs to be normalized before calculating the maximum acceptable controller installed cost.

Controllers with different combinations of advanced control capabilities are likely to have different manufacturing and installation costs. Controllers with greater functionality will likely cost more. On the other hand, the examined control strategies have different degrees of impact on energy and cost savings in different locations in the country. Controllers with greater 
functionality usually provide greater energy and cost savings. Therefore, analysis of the savings provided by a controller relative to its cost is important. This is examined by determining the maximum total installed cost per controller that yields a 3-year simple payback for controllers with different combinations of control functionality. A total of four scenarios are considered:

- Scenario 1: the advanced controller with only multi-speed supply-fan control is retrofit to an existing packaged unit having a base case controller with only non-integrated differential dry-bulb economizer.

- Scenario 2: the advanced controller with only DCV is retrofit to an existing packaged unit having a base case controller.

- $\quad$ Scenario 3: the advanced controller with both multi-speed fan control and DCV is retrofit to an existing packaged unit having a base case controller.

- Scenario 4: the advanced controller with an integrated differential dry-bulb economizer control, multi-speed supply-fan control, and DCV is retrofit to an existing packaged unit having a base case controller.

Figure ES - 3 and Figure ES - 4 show the range of the maximum acceptable installed cost with a 3-year payback for the retail building and the office building, respectively. These figures show the following:

- The maximum total installed controller cost per packaged unit that will yield a 3-year payback period varies with the four scenarios. For both building types, Scenarios 3 and 4 have the largest maximum cost per controller for all 11 locations. The controller cost can range between $\$ 4,180$ and $\$ 8,390$ for the retail building and between $\$ 1,560$ and $\$ 2,990$ for the office building. Combining multi-speed fan control with DCV (Scenario 3) shows almost the same range of cost as the full control package (Scenario 4).

- For multi-speed fan control alone (Scenario 1), the controller cost is about half of that from the full package. In the retail building, the maximum installed cost per unit for adding multispeed fan control can range from $\$ 1,500$ to $\$ 3,600$. In the medium office building, the maximum installed cost per unit for adding multi-speed fan control can range from $\$ 1,200$ to $\$ 2,600$.

- For DCV only (Scenario 2), the maximum installed cost per unit ranges from $\$ 1,000$ to $\$ 5,000$, except for Los Angeles with a lower acceptable cost at about $\$ 1,000$. In the medium office building, the maximum installed cost per unit for DCV only ranges from 0 to $\$ 600$.

\section{Conclusion}

Individual control strategies have different degrees of impact on energy and cost savings. The simulation results indicate that multi-speed supply-fan control and DCV are the two control strategies contributing the most to energy and cost savings for packaged heat pumps. Relative to the baseline, adding multi-speed supply-fan control alone yields between $15 \%$ and $38 \%$ HVAC energy and cost savings for the retail building and between $18 \%$ and $54 \%$ savings for the medium office building. 


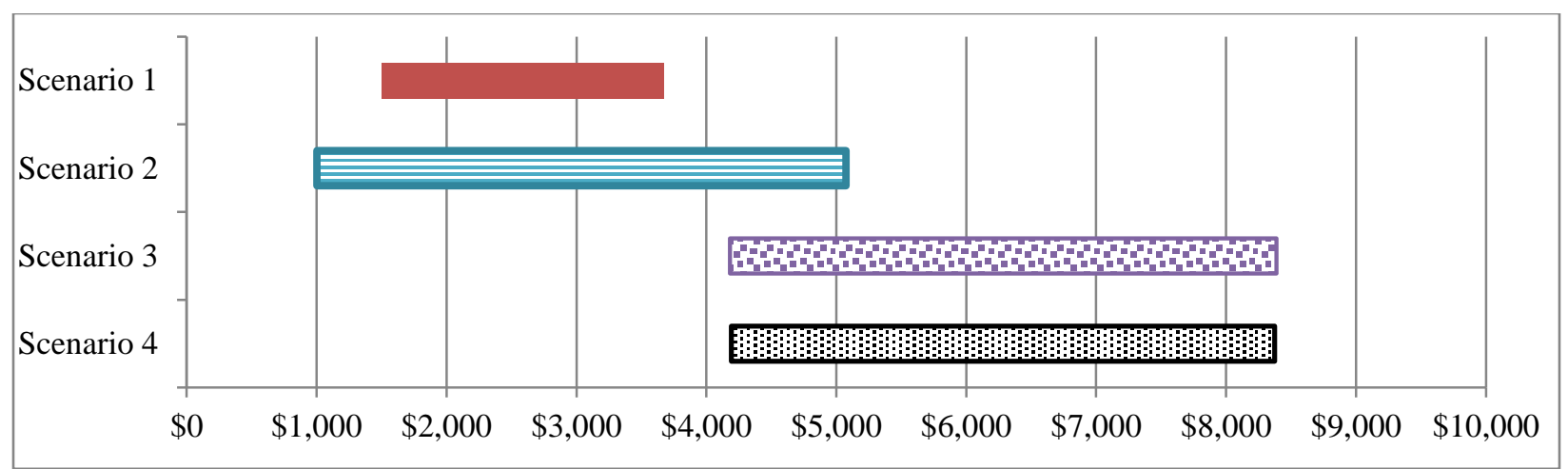

Figure ES - 3: Range of Maximum Total Installed Cost per Controller Unit that will Yield a 3-year Payback for the Stand-alone Retail Building

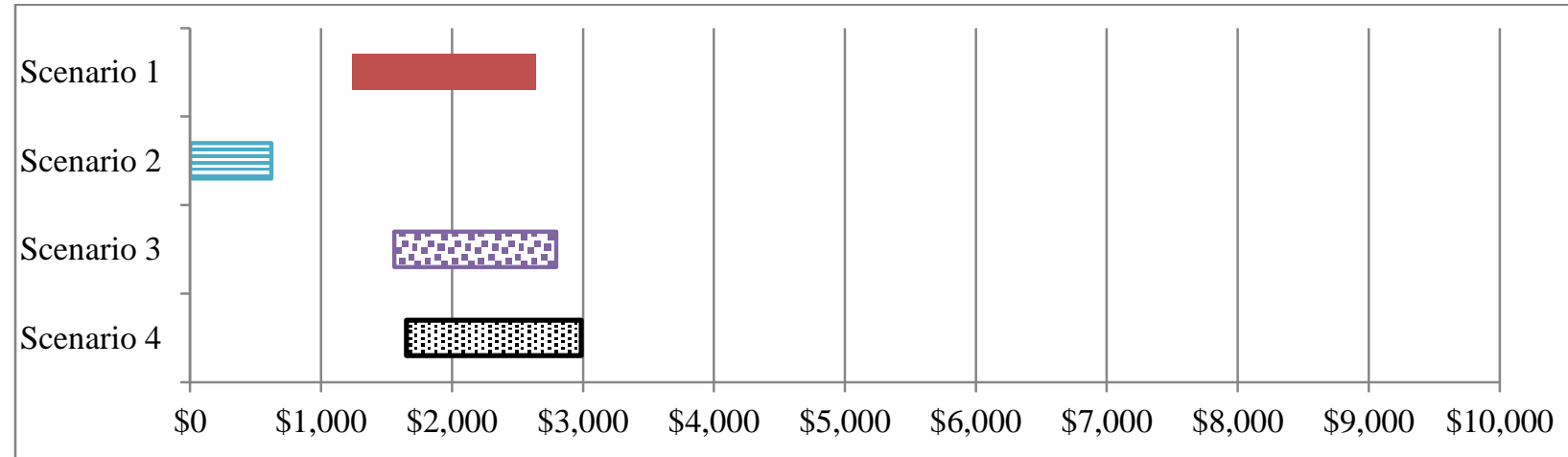

Figure ES - 4: Range of Maximum Total Installed Cost per Controller Unit will Yield a 3year Payback for the Medium Office Building

DCV contributes significantly more savings for the retail building than for the office building. DCV can achieve between $10 \%$ and $27 \%$ of HVAC energy and cost savings for the retail building, while it can achieve the maximum of $11 \%$ savings for the office building. Enabling the integration of an airside economizer with mechanical cooling has makes a very small contribution to the overall HVAC energy and energy cost savings. The one exception is the office building in locations with mild climates (e.g., Los Angeles),

For the combination of multi-speed fan control and DCV, the annual absolute energy cost savings relative to the base case lies in the approximate range between $\$ 6,300$ and $\$ 17,600$ for the stand-alone retail building and between $\$ 6,700$ and $\$ 33,230$ for the medium office building. Based on the number of heat pump units in the 2 building prototypes ( 4 in the retail building and 15 in the medium office building), the maximum total installed controller cost per packaged unit providing a 3-year payback period ranges from $\$ 4,150$ to $\$ 8,350$ for the retail building and from $\$ 1,550$ to $\$ 2,800$ for the medium office building. 


\section{Acknowledgement}

The authors would like to acknowledge the Buildings Technologies Program of the U.S.

Department of Energy Office of Energy Efficiency and Renewable Energy for supporting the research and analysis effort. The authors would also like to thank Alan Schroeder and Jason Koman, Technology Development Managers; Linda Sandahl for providing the project management and guidance; Ron Underhill and Andrew Nicholls for providing technical review; and Sue Arey for editorial support. 


\section{Contents}

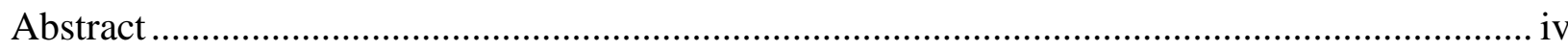

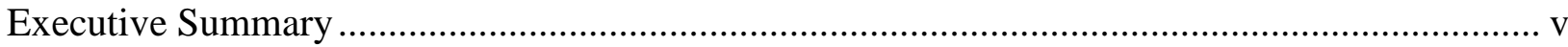

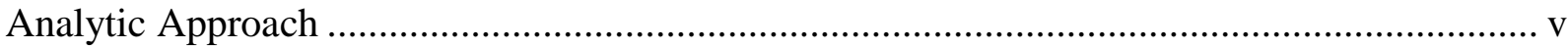

Control Sequence of Operation for Packaged Heat Pumps......................................................... vi

Building Prototypes and Locations ......................................................................................... vi

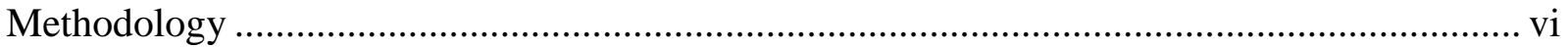

Energy and Cost Savings Results for Various Control Combinations....................................... vii

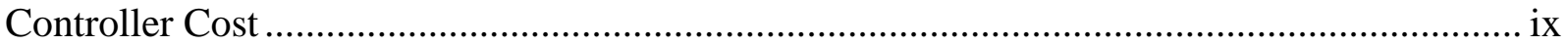

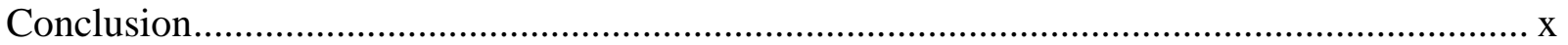

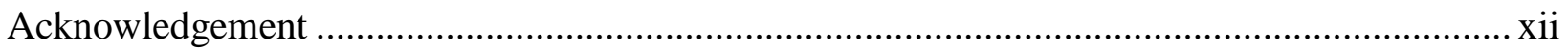

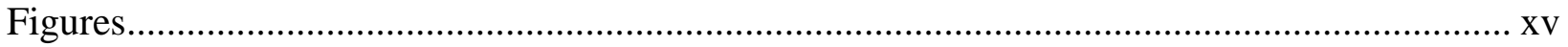

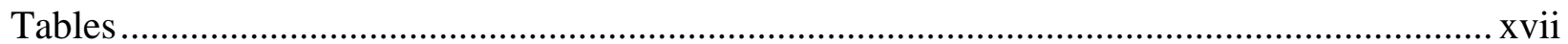

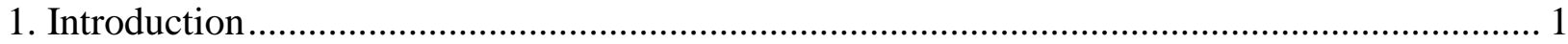

2. Control Sequence of Operation for Packaged Heat Pumps ........................................................ 3

2.1 Conventional Control Options for Packaged Heat Pumps ..................................................... 3

2.2 Advanced Control Options for Packaged Heat Pumps ........................................................... 3

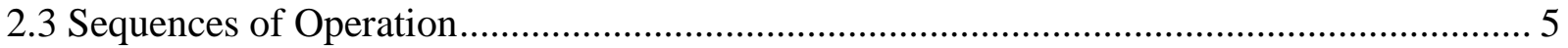

3. Choice of Building Types, Climates and Locations ………...................................................... 9

3.1 Representative Buildings........................................................................................... 9

3.2 Climates and Locations ................................................................................................. 11

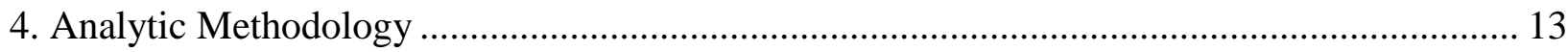

4.1 Energy Use Estimation Methodology …………………............................................ 13

4.2 Economic Analysis Methodology …………………….................................................. 15

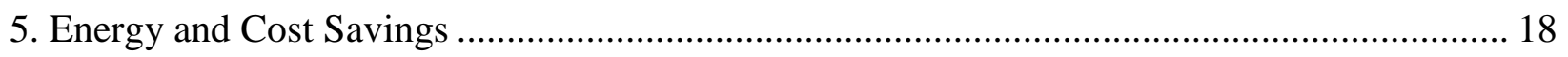

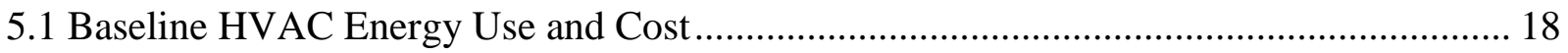

5.2 Impact Assessment of Individual Control Strategies ........................................................ 20

5.3 Energy and Cost Savings from Combined Control Strategies ............................................. 29

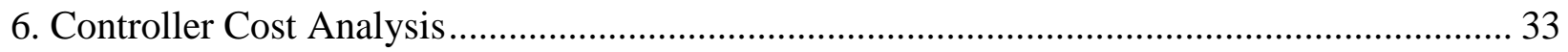

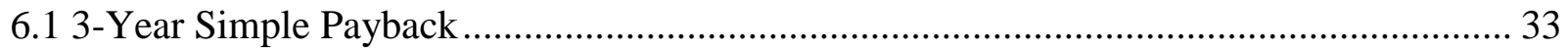

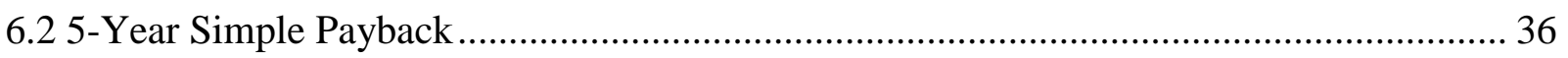




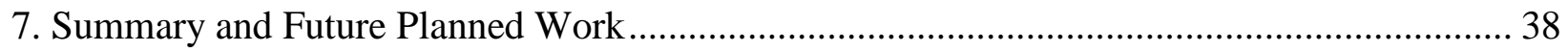

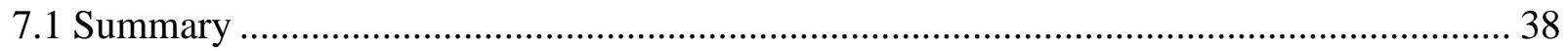

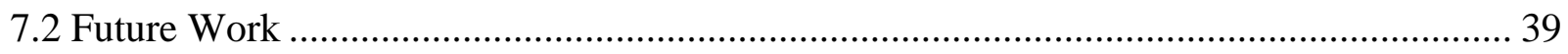

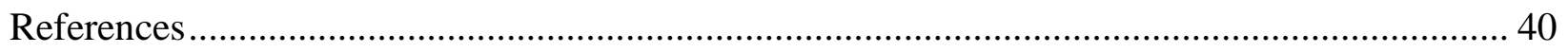

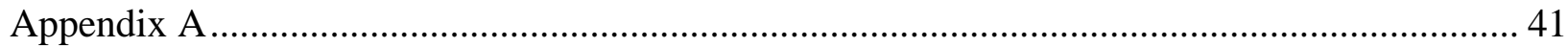

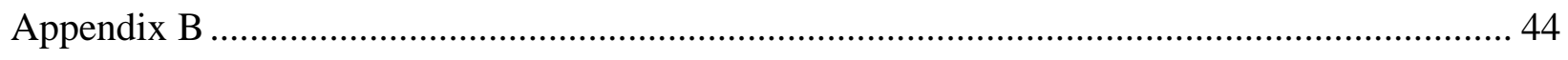

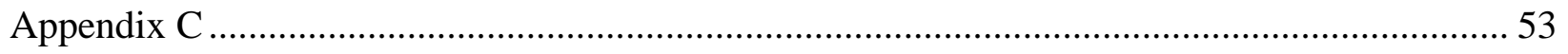

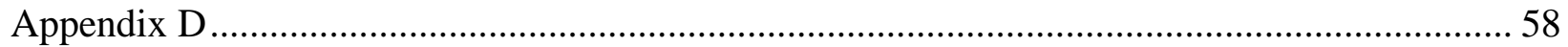




\section{Figures}

Figure ES - 1: Percentage HVAC Energy and Cost Savings Range for the Stand-alone Retail

Building for All Seven Different Combinations of Advanced Control Options,

Relative to the Base Case (yellow dot is a simple average across 11 locations) ....... viii

Figure ES - 3: Percentage HVAC Energy and Cost Savings Range for the Medium Office

Building for All Seven Different Combinations of Advanced Control Options,

Relative to the Base Case (yellow dot is a simple average across 11 locations) ....... viii

Figure ES - 4: Range of Maximum Total Installed Cost per Controller Unit that will Yield a 3-

year Payback for the Stand-alone Retail Building ................................................... xi

Figure ES - 5: Range of Maximum Total Installed Cost per Controller Unit will Yield a 3-year

Payback for the Medium Office Building............................................................ xi

Figure 1: Illustration of the Typical Control Sequence for Rooftop Units in Single-Zone HVAC

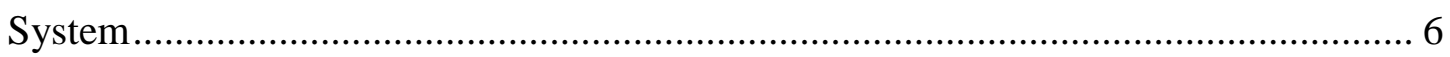

Figure 2: Axonometric View of Stand-alone Retail Building .............................................. 10

Figure 3: Axonometric View of Medium Office Building ................................................... 10

Figure 4: Annual HVAC Energy Use and Cost for Baseline (Case 1) Control Package of the

Stand-alone Retail Building .............................................................................. 19

Figure 5: Annual HVAC Energy Use and Cost for Baseline (Case \#1) Control Package of the

Medium Office Building ...................................................................................... 19

Figure 6: HVAC Energy Percentage Savings from the Use of Integrated Airside Differential

Dry-Bulb Economizer Controls (Case 2) Compared to the Baseline with Non-

Integrated Airside Differential Dry-bulb Economizer (Case 1) .............................. 21

Figure 7: Absolute HVAC Energy Savings from the Use of Integrated Airside Differential Dry-

Bulb Economizer Controls (Case 2) Compared to the Baseline with Non-integrated

Airside Differential Dry-bulb Economizer (Case 1)............................................. 21

Figure 8: HVAC Absolute Energy Cost Savings from the Use of Integrated Airside Differential

Dry-Bulb Economizer Controls (Case 2) Compared to the Baseline with Non-

integrated Airside Differential Dry-bulb Economizer (Case 1).............................. 22

Figure 9: Percentage of HVAC Savings from the Use of Multi-speed Supply-Fan Control (Case

3) Compared to the Base Case with Constant-Speed Fan Control (Case 1) ............... 23

Figure 10: HVAC Energy Savings from the Use of Multi-speed Supply-Fan Control (Case 3)

Compared to the Base Case with Constant-Speed Fan Control (Case 1) ................... 24

Figure 11: HVAC Cost Savings from the Use of Multi-speed Supply-Fan Control (Case 3)

Compared to the Base Case with Constant-Speed Fan Control (Case 1) ................... 24

Figure 12: Percent HVAC Energy and Cost Savings from the Use of DCV Control (Case 4)

Compared to the Baseline with no DCV Control (Case 1) ..................................... 25

Figure 13: HVAC Energy Savings from the Use of DCV Control (Case 4) Compared to the

Baseline with no DCV Control (Case 1) ................................................................ 26 
Figure 14: HVAC Energy Cost Savings from the Use of DCV Control (Case 4) Compared to the Baseline with no DCV Control (Case 1)............................................................. 26

Figure 15: Weekday Occupancy Schedules for the Four Building Types ................................ 27

Figure 16: Range of Percentage Savings from Individual Control Strategies Across All 11

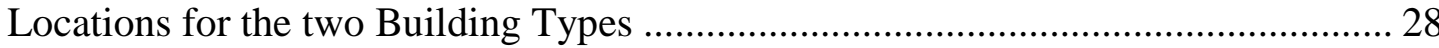

Figure 17: Range of Absolute Energy Savings from Individual Control Strategies Across All 11 Locations for the two Building Types 28

Figure 18: Range of Absolute Energy Cost Savings from Individual Control Strategies Across All 11 Locations on the Two Building Prototypes

Figure 19: HVAC Energy Savings from Multi-speed Fan and DCV Controls for the Stand-alone Retail Building (Case 1 vs. Case 5) 30

Figure 20: HVAC Energy Savings from Multi-speed Fan and DCV Controls for the Medium

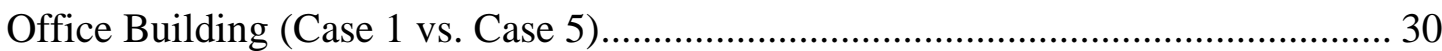

Figure 21: HVAC Cost Savings from Multi-speed Fan and DCV Controls for the Stand-alone Retail Building (Case 1 vs. Case 5)

Figure 22: HVAC Cost Savings from Multi-speed Fan and DCV Controls for the Medium Office Building (Case 1 vs. Case 5) ............................................................................ 31

Figure 23: Percentage Savings Range for combinations of each case for all locations............... 32

Figure 24: Maximum Total Installed Cost per Controller Unit to Achieve a Payback Period of 3 Years for the Stand-alone Retail ............................................................................. 34

Figure 25: Maximum Total Installed Cost per Controller Unit to Achieve a Payback Period of 3 Years for the Medium Office

Figure 26: Range of Maximum Total Installed Cost per Controller Unit to Achieve 3-year Payback for Stand-alone Retail 35

Figure 27: Range of Maximum Total Installed Cost per Controller Unit to Achieve 3-year Payback for Medium Office. 36

Figure 28: Maximum Total Installed Cost per Controller Unit to Achieve a Payback Period of 5 Years for the Stand-alone Retail

Figure 29: Maximum Total Installed Cost per Controller Unit to Achieve a Payback Period of 5 Years for the Medium Office 


\section{Tables}

Table ES - 1: Advanced Control Options Considered for this Study .... vi

Table ES - 2: Summary of HVAC Energy and Cost Savings from Replacing Constant-Speed Supply Fan and Constant Ventilation with Multi-speed Supply-Fan Control and DCV ix

Table 1: Advanced Control Options Considered for this Study ............................................ 5

Table 2: Building Types Studied ...................................................................................... 11

Table 3: Selected Climates and Corresponding Representative Locations Used for the Current

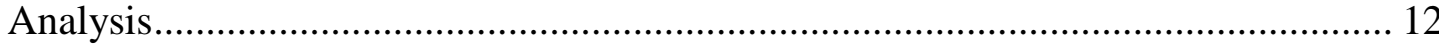

Table 4: Combinations of Control Packages ............................................................................. 13

Table 5: Efficiency of Air-cooled Heat Pump and Fan Systems ............................................ 14

Table 6: Default Values of the Key Control Parameters ........................................................ 15

Table 7: Electricity Prices by Location in the Year of 2010 (EIA 2011) .................................. 16

Table 8: Cases Represent Individual Impacts of Three Control Strategies ............................... 20

Table A- 1: Key Geometric, Envelope, HVAC, Water Heating and Internal Load Characteristics for the Stand-alone Retail Building Prototype.

Table A- 2: Key Geometric, Envelope, HVAC, Water Heating and Internal Load Characteristics for the Medium Office Building Prototype

Table B-1: HVAC Energy Uses Break Down for the Stand-alone Retail Building in Climate Zones $2 \mathrm{~A}$ and $3 \mathrm{~B}$

Table B-2: HVAC Energy Uses Break Down for the Stand-alone Retail Building in Climate Zones $3 \mathrm{~B}$ and $4 \mathrm{~B}$

Table B-3: HVAC Energy Uses Break Down for the Stand-alone Retail Building in Climate Zones $4 \mathrm{C}$ and $5 \mathrm{~B}$

Table B-4: HVAC Energy Uses Break Down for the Medium Office in Climate Zones 2A and 3B.

Table B-5: HVAC Energy Uses Break Down for the Medium Office in Climate Zones 3B and $4 \mathrm{~B}$.

Table B-6: HVAC Energy Uses Break Down for the Medium Office in Climate Zones 4C and $5 \mathrm{~B}$.

Table B-7: HVAC Total Energy Cost for the Stand-alone Retail Building .............................. 51

Table B- 8: HVAC Total Energy Cost for the Medium Office Building .................................. 52 
Table C- 1: Total HVAC Energy Savings Compared to Case 1 for the Stand-alone Retail

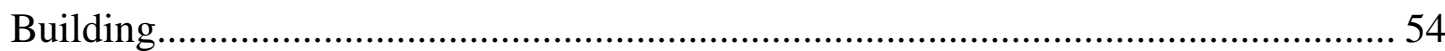

Table C- 2: Total HVAC Energy Savings Compared to Case 1 for the Medium Office Building

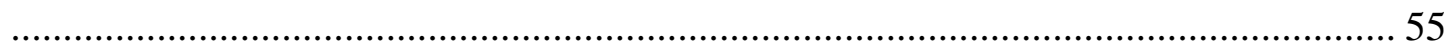

Table C-3: HVAC Energy Cost Savings Compared to Case 1 for the Stand-alone Retail Building

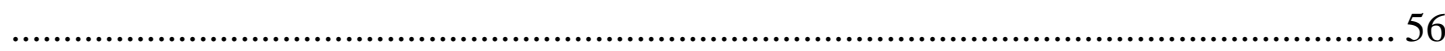

Table C-4: HVAC Energy Cost Savings Compared to Case 1 for the Medium Office Building. 57

Table D-1: Maximum Controller Installed Cost per Unit Supporting Different Retrofits for the Stand-alone Retail Building Based on the Payback Period of 3 Years and the Original

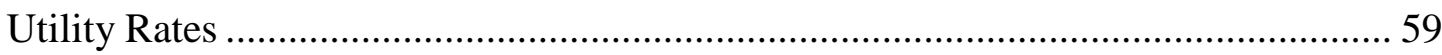

Table D-2: Maximum Controller Installed Cost per Unit Supporting Different Retrofits for the Medium Office Building Based on the Payback Period of 3 Years and the Original

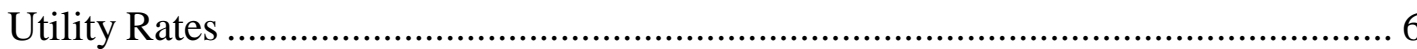




\section{Introduction}

Packaged cooling equipment, including packaged air-conditioning units and heat pumps, is used in $46 \%$ of all commercial buildings, serving over $60 \%$ of the commercial building floor space in the U.S. (Tables B40 and B41, EIA 2003). The annual electricity consumption associated with packaged equipment for cooling and ventilation is about 571 trillion Btus for site energy or 1,770 trillion Btus for source energy. Therefore, even a small increase in the part-load efficiency of these units can lead to significant reductions in energy use and cost. Pacific Northwest National Laboratory (PNNL), with funding from the U.S. Department of Energy's (DOE's) Building Technologies Program (BTP), evaluated a number of control strategies that can be implemented in an advanced controller, which can be retrofit into existing packaged heat pump units to improve their operational efficiency.

In 2011, PNNL, at the direction of the U.S. DOE's Building Technologies Program, evaluated a number of control strategies that can be implemented in a controller to improve the operational efficiency of existing packaged air-conditioners with gas furnaces. The results from detailed simulation analysis show that retrofitting packaged units with advanced control packages can achieve significant energy and cost savings (Wang et al. 2011). Based on the simulation of 4 building types in 16 climate locations and advanced controls (including airside economizer control, multi-speed supply-fan control, demand-controlled ventilation, and two-stage cooling capacity control) the heating, ventilation and air-conditioning (HVAC) energy reduced by between $14 \%$ and $56 \%$, and the cost savings were between $27 \%$ and $67 \%$, relative to a base case with no advanced control options and with a constant-speed supply fan. The simulation results indicated that multi-speed supply-fan control and DCV are the two control strategies contributing most of the savings.

The previous work (Wang et al. 2011) was focused on packaged air-conditioning units with a gas furnace for heating. Because heat pumps with electric heating are commonly used packaged units in many buildings and locations, PNNL is extending the analysis to include the impact of advanced controls on packaged heat pumps.

The two primary objectives of this research project are to: 1) determine the range of national energy and cost savings achievable by retrofitting existing packaged heat pumps with advanced control strategies not ordinarily used in field installations for two building types in 11 climate locations, and 2) estimate the maximum installed cost of a replacement controller with the desired features in various regions of the U.S. to provide acceptable payback periods to owners.

Based on our previous study, PNNL chose three strategies for evaluation:

- multi-speed fan control,

- demand-controlled ventilation (DCV), and

- integrated outdoor-air economizer.

Existing packaged heat pumps are usually equipped with constant-speed supply fans. By modulating the fan speed for different modes (such as ventilation, cooling, heating), a significant percentage of fan energy could be saved. For times when the building is not fully occupied and ventilation requirements are minimal, reducing the amount of outside-air intake for ventilation can save significant energy (Brandemuehl and Braun 1999, Roth et al. 2003). In a few mild climates, where free-cooling from the fresh air is possible, economizers can save significant 
cooling energy. When economizer operation is integrated with mechanical cooling control, it can provide additional energy savings.

In this study, the savings are estimated based on detailed EnergyPlus (DOE 2010) simulation. A total of 2 building types, 11 climate locations, and 3 advanced control strategies (along with their combinations) are simulated.

The report is organized as follows. The advanced control strategies and how they differ from conventional controls is summarized in Section 2. Two building types that predominantly use packaged RTUs are considered for this analysis: stand-alone retail and medium office. Detailed descriptions of the building types, the climate zones and representative locations used for the analysis are described in Section 3. The methodology used in estimating the energy consumption, energy cost and maximum total cost of the controller is described in Section 4. Section 5 provides results for the energy and cost savings for the various combinations of control strategies by building type and location. Based on the cost savings, the maximum installed costs of advanced controllers that will yield a specific simple payback period are calculated in Section 6. Conclusions and discussion of potential future work are provided in Section 7. Detailed results are tabulated in the Appendix. 


\section{Control Sequence of Operation for Packaged Heat Pumps}

Packaged air-source heat pumps are self-contained, factory-packed units comprising a number of off-the-shelf components available in standard design and cooling capacities. Usually, a packaged air-source heat pump consists of a fan and filter section, a reversible vapor compression cycle section, and a supplemental heating section. In an air-source heat pump, the outdoor air coil rejects heat to outside air in cooling mode and extracts heat from outside air in heating mode. Electric heaters are commonly used to supplement heat during defrost cycles and during periods when the compressor-heat generated from the compression cycle cannot meet the heating load.

For existing buildings served by packaged rooftop units (RTUs), RTU controller retrofit is usually a promising cost-effective solution to increase operational efficiency. RTU controller retrofit may include one or several technologies, such as economizer controls, supply-fan speed controls, optimal start and stop controls, and demand-controlled ventilation. This study investigates the energy and cost savings associated with three of these advanced control options for packaged heat pumps individually and in various combinations. The savings are estimated by comparing annual estimated energy consumption of the unit when using an advanced control option with the energy use for the unit with the base case controls. The base case control options and the advanced control options are discussed in this section, together with the sequences of operations considered for this work.

\subsection{Conventional Control Options for Packaged Heat Pumps}

In most packaged air-source heat pumps, a thermostat controls the operation of the compressor, depending on whether the zone calls for cooling or heating. In conventional control (base case), the compressor cycles to maintain the required zone temperature set point; and in heating mode if the compressor is not able to maintain the required zone temperature set point, electric strip heating is used. The supply fan runs continuously when the building is occupied to provide required ventilation. The base case also assumes the use of a non-integrated economizer. A nonintegrated economizer does not operate simultaneously with the mechanical cooling system. When the outdoor-air condition is favorable and sufficient to meet all the cooling demand, the economizer provides all necessary cooling; otherwise, the outdoor-air damper returns to its minimum position. In an integrated economizer operation, when the outdoor-air condition is favorable, the cooling demand is met with outdoor air; however, when use of the outside air alone is not able to meet the cooling demand, mechanical cooling is provided to supplement the cooling provided by outside air.

\subsection{Advanced Control Options for Packaged Heat Pumps}

There are three additional control options that might be added to packaged heat pumps including: integrated airside economizers, supply-fan speed controls and demand-controlled ventilation. For this study, the impact of all three control strategies and their combinations on energy and cost savings was evaluated for a packaged single-zone system compared to the same system with base case controls. 


\subsubsection{Integrated Airside Economizer Control}

Airside economizers use cool outdoor air (OA) to reduce energy use for mechanical cooling when OA cooling is favorable. It was observed from our previous work (Wang et al. 2011) that different economizer controls have minor differences in their impact on energy savings. Therefore, only the economizer control based on differential dry-bulb temperature is investigated in this study. This control opens the OA damper greater than the minimum position when the return-air dry-bulb temperature is warmer than the OA dry-bulb temperature in the cooling mode. Airside economizers displace the need for some or all mechanical cooling and reduce energy consumption by the unit.

In relation to the base case using a non-integrated economizer, the advanced control enables the integration of an airside economizer with mechanical cooling. With integrated economizer control, the OA damper can be modulated to provide as much cool air as possible, even if it the $\mathrm{OA}$ is not sufficient to meet the cooling load alone.

\subsubsection{Fan-Speed Control}

Generally, a packaged heat pump serving a single zone has three fan control options: constant- speed control, multi-speed control, and variable -speed control.

- With a constant fan-speed control, the supply fan runs at its design speed as long as the packaged heat pump is on or as long as the building is occupied. This is the base case option.

- With a multi-speed fan control, the supply fan runs at different speeds depending on the space load and the heat pump operation mode. For example, the fan may run at a reduced speed when neither cooling nor heating is requested (ventilation mode), or with a multi-stage heating/cooling unit, the fan speed can also be discretely changed at different stages of cooling or heating. Modulating the fan to a lower speed can reduce fan energy consumption and improve dehumidification control in the space. Many advanced control scenarios simulated for this study use the multiple supply-fan speed option.

- With variable-speed fan control, the supply-fan speed is modulated in proportion to the difference between the actual space temperature and the temperature set point. Meanwhile, the heating or cooling output is adjusted through staging or capacity modulation to satisfy the discharge-air temperature set point. This option is not evaluated in this study.

\subsubsection{Ventilation Control}

Depending on whether the outdoor-air flow rate is dynamically reset based on the ventilation needs, the following two ventilation control strategies can be considered in a packaged heat pump:

- The first strategy maintains a fixed minimum outdoor-air intake rate during system operation. The fixed rate at which outdoor air is brought in is based on the design occupancy of the space served, which is usually larger than the actual occupancy during many operating hours. Therefore, excess outdoor air is supplied to the space whenever the space is partially occupied. This is the base case option.

- The second strategy, referred to as demand-controlled ventilation (DCV), adjusts the amount of outdoor air based on the number of occupants and the corresponding ventilation demand. 
Although a number of options such as direct people counting, time-of-day schedule tracking, and measuring $\mathrm{CO}_{2}$ concentration are available to estimate the actual occupancy of spaces, $\mathrm{CO}_{2}$-based DCV is by far the most commonly implemented measure when outdoor-air ventilation is dynamically reset (Stanke 2006). $\mathrm{CO}_{2}$-based DCV relies on sensed $\mathrm{CO}_{2}$ concentrations in the space (usually measured in the return air) to regulate the ventilation rate. Assuming that the $\mathrm{CO}_{2}$ generation rate is proportional to the number of occupants, the minimum required outdoor-air flow rate for single-zone systems can be calculated from the space $\mathrm{CO}_{2}$ concentration set point and the difference between indoor and outdoor $\mathrm{CO}_{2}$ concentrations (ASHRAE 2010). By reducing outdoor-air intake, DCV has the potential to reduce the energy associated with conditioning the outdoor air. In this study, only one $\mathrm{CO}_{2}$ sensor is used to measure the $\mathrm{CO}_{2}$ concentration in the zone and compared to a predefined threshold.

Table 1 summarizes the control options for each control technology applied to rooftop units for this study.

Table 1: Advanced Control Options Considered for this Study

\begin{tabular}{|l|l|}
\hline Technology & Considered control options \\
\hline Air economizer & $\begin{array}{l}\text { Base control option: differential dry-bulb, nonintegrated } \\
\text { Advanced option: differential dry-bulb, integrated }\end{array}$ \\
\hline Fan-speed control & $\begin{array}{l}\text { Base control option: constant speed } \\
\text { Advanced option: multiple speed }\end{array}$ \\
\hline Ventilation control & $\begin{array}{l}\text { Base control option constant outdoor-air supply } \\
\text { Advanced option: demand-controlled ventilation }\end{array}$ \\
\hline
\end{tabular}

\subsection{Sequences of Operation}

The sequence of operation for packaged rooftop units varies with the control options selected. Figure 1 illustrates the typical control sequence for rooftop units in single-zone HVAC systems. Some details, such as the control limits for safe equipment operations, are not shown. The control sequence presented below assumes that the packaged heat pumps have two-stage mechanical cooling. The previous report (Wang et al. 2011) can be referred to for the case of single-stage cooling. Based on the sensed space temperature $T$, the rooftop unit has four basic operation modes: idle (off), ventilation (fan on), heating (compressor and fan on), and cooling (compressor and fan on).

Idle mode. The rooftop unit is in the idle mode if 1) the sensed space temperature lies between the heating and cooling set points, that is, $T_{\text {Heats }} \leq T \leq T_{\text {CoolsP }}$ and 2) the space is unoccupied. In the idle mode, the fan, the heating and the cooling are all off. Note that the heating and cooling set points during occupied and unoccupied modes may be different.

Ventilation mode. The rooftop unit operates in the ventilation mode if 1) the sensed space temperature lies between the heating and cooling set points, that is, $T_{\text {HeatSP }} \leq T \leq T_{\text {CoolsP }}$ and 2) the space is occupied. In the ventilation mode, the fan runs at the speed of Fan $_{V e n}$ but both the heating and the cooling are off. In this study, the supply fan runs at $100 \%$ of the design speed 
$\left(F a n_{V e n}=100 \%\right)$ in the ventilation mode for the control option with a constant fan speed, while it runs at $40 \%$ of the design speed $\left(F a n_{V e n}=40 \%\right)$ for the control option with multiple fan speeds.

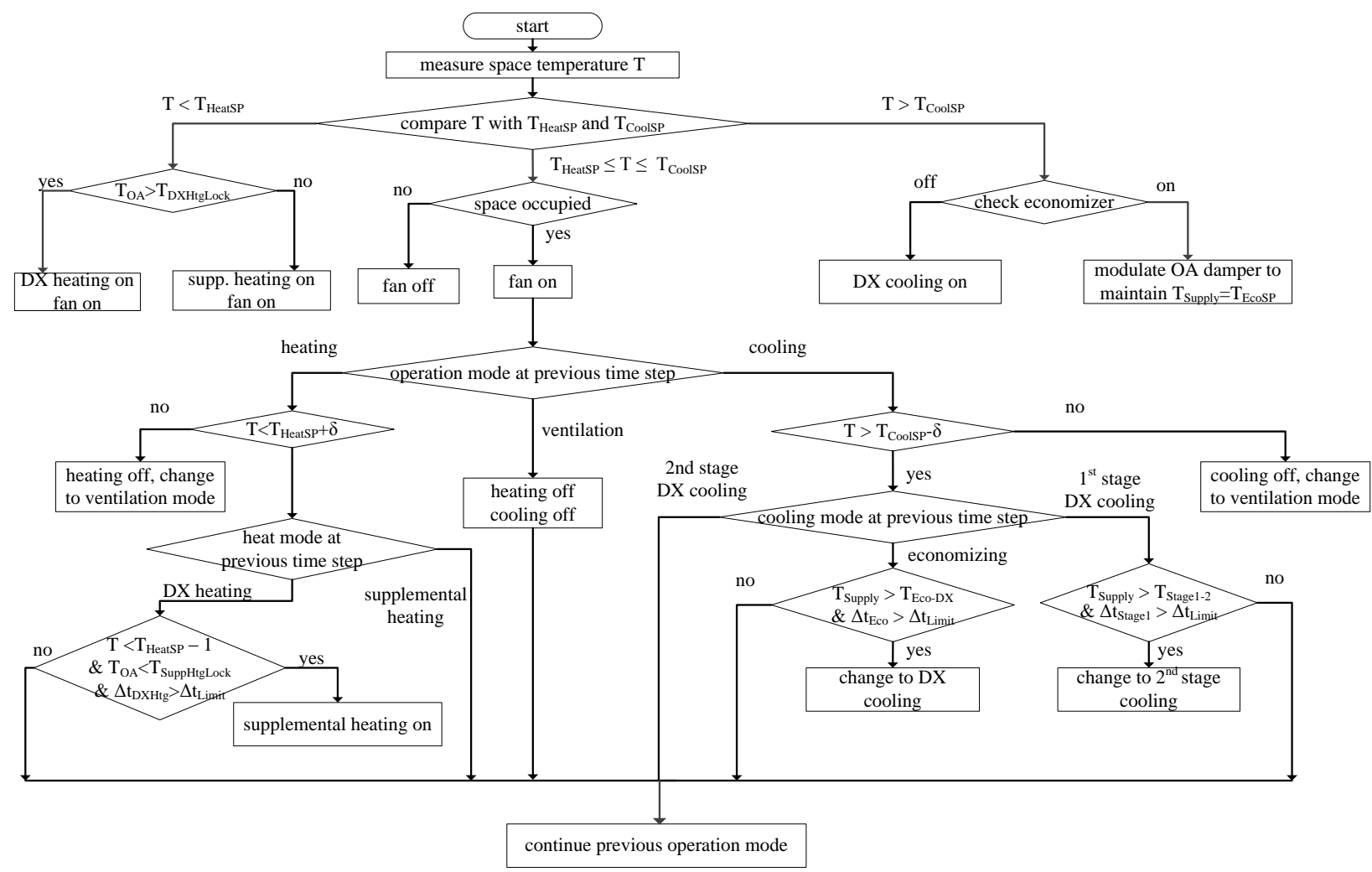

\section{Figure 1: Illustration of the Typical Control Sequence for Rooftop Units in Single-Zone HVAC System}

Heating mode. The rooftop unit operates in the heating mode if the sensed space temperature is less than the heating set point $\left(T<T_{\text {HeatSP }}\right)$. Depending on the status of electrical resistance for supplemental heating, the heat pump unit may work in two different sub modes: direct expansion (DX) heating mode and supplemental heating mode. Once heating is initiated, it continues until the space temperature rises above the heating set point plus a differential, $T>T_{\text {HeatSP }}+\delta$, where $\delta$ is the differential. In the heating mode, the fan runs at the speed Fan $_{\text {Heat }}$, which takes the value of $100 \%$ for the two considered options of fan-speed control.

- DX heating mode. Right after the heating mode is initiated, the heat pump unit enters the DX heating mode if the outdoor-air temperature is greater than the compressor heat lockout temperature $\left(\mathrm{T}_{\mathrm{DXHtgLock}}\right)$. In this mode, the supplemental heating remains off if the outdoorair temperature is greater than the supplemental heating lockout set point $\left(\mathrm{T}_{\text {SuppHtgLock }}\right)$. Otherwise, if the outdoor-air temperature lies in between the compressor lockout and the supplemental heating lock out temperatures (i.e, $\mathrm{T}_{\mathrm{DXH} \text { tgLock }}<T_{\mathrm{OA}}<\mathrm{T}_{\text {SuppHtgLock }}$ ), the supplemental heating will be triggered on after the time in DX heating mode exceeds the interstage delay (i.e., $\Delta \mathrm{t}_{\mathrm{DXHtg}}>\Delta \mathrm{t}_{\text {Limit }}$ ) and the space temperature is $1^{\circ} \mathrm{F}$ below the heating set point. Following conventional practice, both DX heating stages are enabled once the heat pump unit enters the DX heating mode. 
- Supplemental heating mode. The unit runs in the supplemental heating mode in two situations. First, right after the heating mode is initiated, the heat pump unit enters the supplemental heating mode if the outdoor-air temperature $\left(\mathrm{T}_{\mathrm{OA}}\right)$ is less than the compressor heat lockout temperature $\left(\mathrm{T}_{\mathrm{DXH} \text { tgLock }}\right)$. In this case, the compressor is locked out from operating. Second, the unit enters the supplemental heating mode from the DX heating mode if the compressor cannot heat up the space temperature fast enough, as discussed above in the DX heating mode. In this case, the compressor and the supplemental heating may run simultaneously.

Cooling mode. The rooftop unit operates in the cooling mode if the sensed space temperature is greater than the cooling set point $\left(T>T_{\text {CoolSP }}\right)$. Depending on the economizer and mechanical cooling stage control status, the rooftop unit may work in three different sub modes: economizing only, mechanical cooling only or both (integrated).

- Economizing (OA cooling) mode. Right after the cooling mode is initiated, the system controller determines whether the outdoor air is suitable for free cooling. If the outdoor air is favorable for cooling, the OA damper is modulated to maintain the supply-air temperature at the economizer supply-air set point, i.e., $T_{\text {Supply }}=T_{E c o S P}$. The economizing mode is used as long as the space temperature lies between the cooling set point and the cooling set point minus the differential, i.e., $T_{\text {CoolsP }}-\delta \leq T \leq T_{\text {CoolsP }}$. Otherwise, if $T<T_{\text {CoolsP }}-\delta$, the economizer is off and the outdoor-air damper returns to the ventilation-only position. The controller initiates mechanical cooling if the time in economizing mode, $\Delta \mathrm{tEco}$, exceeds the interstage delay time limit, $\Delta$ tLimit (i.e., $\Delta t_{E c o}>\Delta t_{\text {Limit }}$ ) and the supply-air temperature is greater than the threshold of changeover from OA cooling to mechanical cooling $\left(T_{\text {Supply }}>T_{E c o-D X}\right.$ ). In the economizing mode, the mechanical cooling is off and the supply fan operates at the speed $F_{F a n}$, which takes the value of $100 \%$ for the constant fan-speed control and $75 \%$ for the control option with multiple fan speeds. The economizing mode occurs only if an airside economizer is available.

- Mechanical cooling mode. The unit runs stage-one cooling first. Cooling continues with only the first stage operating as long as the space temperature lies between the cooling set point and the cooling set point minus the differential, i.e., $T_{\text {CoolsP }}-\delta \leq T \leq T_{\text {CoolsP }}$. Otherwise, the mechanical cooling is discontinued when $T<T_{\text {CoolsP }}-\delta$. The rooftop unit triggers the second stage mechanical cooling if the time in stage-one cooling mode exceeds the interstage delay time limit (i.e., $\Delta t_{\text {Stagel }}>\Delta t_{\text {Limit }}$ ) and the supply-air temperature is greater than the threshold of changeover between cooling stages $\left(T_{\text {Supply }}>T_{\text {Stagel-2 }}\right)$. After the rooftop unit initiates the second stage of cooling, both stages are on until the space is cooled to a temperature below $T_{\text {CoolsP }}-\delta$. In the mechanical cooling mode, if an integrated economizer is used and the OA condition is favorable for cooling, the control system fully opens the OA damper; otherwise, the controls keep the OA damper at the minimum position required by ventilation. The supply fan runs at the speed of $\mathrm{Fan}_{\text {Stagel }}$ and $\mathrm{Fan}_{\text {Stage } 2}$, respectively for first stage and second

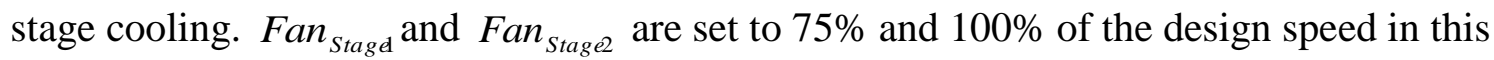
study for the control option with multiple fan speeds. 
If DCV control is available, the OA damper can be modulated depending on the sensed $\mathrm{CO}_{2}$ concentration $\left(C_{\mathrm{CO}_{2} S}\right)$ in the return air. The OA damper is modulated further toward fully closed if $C_{C O 2, S}$ is less than the space $\mathrm{CO}_{2}$ set point $\left(C_{C O 2, S P}\right.$ ), while it is opened further if $C_{C O 2, S}$ is greater than $C_{C O 2, S P}$. An absolute lower limit for OA ventilation is usually applied to ensure adequate ventilation to dilute air contaminants from non-occupant-related sources, such as building materials, furnishings, and finishes. This lower limit is reflected by the OA rate per area, as indicated in ASHRAE Standard 62.1-2010 (ASHRAE 2010). For example, in office spaces, the outdoor air flow rate per space area is required to be $0.06 \mathrm{cfm} / \mathrm{ft}^{2}$. It needs to be noted that when both an airside economizer and DCV controls are active, the economizer control takes precedence over DCV control. 


\section{Choice of Building Types, Climates and Locations}

For this study, 2 building types and 11 locations across 4 major climate zones where packaged heat pumps are predominantly used are analyzed. The selected building types and locations are presented below.

\subsection{Representative Buildings}

The U.S. DOE developed 16 commercial building EnergyPlus reference models. The inputs for these models came from different sources, such as surveys, databases, studies, manufacturer inputs, and several rounds of public reviews (Deru et al. 2011). These commercial reference buildings cover about $70 \%$ of the commercial building stock in terms of square footage, including office, restaurants, retail, schools, healthcare, supermarkets, lodgings, high rise apartments and warehouses. Every prototype has three versions with different vintages: new construction, post-1980 construction, and pre-1980 construction. The models with different vintages differ with respect to envelope insulation levels, lighting power densities, and HVAC equipment types and efficiencies. Because significant effort went into creating the reference building models that represent realistic building characteristics and construction practices, the reference models are usually used as the starting point for energy efficiency research (Field et al. 2010; Fumo et al. 2010; Wang et al. 2011).

Because packaged equipment is typically used on small and medium-sized buildings $(<50,000$ sf), PNNL chose medium office and stand-alone retail buildings and post-1980 set in this study. However, changes were made to the HVAC systems to tailor the models to the objectives of this work. In the original post-1980 reference model, for example, the medium office has three multizone variable-air-volume systems served by packaged air conditioners with gas heat. They were changed to 15 single-zone systems, each of which is served by a packaged heat pump unit. For the retail building, the original post-1980 reference model uses four packaged air-conditioning units with gas heat, which were changed to four packaged heat pumps in this work. The two building prototypes are discussed briefly below.

\section{3,1,1 Stand-alone Retail Building}

The stand-alone retail prototype shown in Figure 2 represents a retail box store with a total floor area of about $25,000 \mathrm{ft}^{2}$. Based on the space usage and the location, the store is divided into five areas: front entry $(0.5 \%)$, storage space $(16.5 \%)$, core retail $(70 \%)$, front retail $(6.5 \%)$, and cashier area $(6.5 \%)$, where the number in parenthesis indicates the percentage of the zone space area. Each space area is regarded as one thermal zone. Except for the front entry served by a unit heater, each of the other thermal zones is equipped with a packaged heat pump unit with electrical resistance for supplemental heating. Key building characteristics of the stand-alone building are shown in Table A- 1 in Appendix A. 


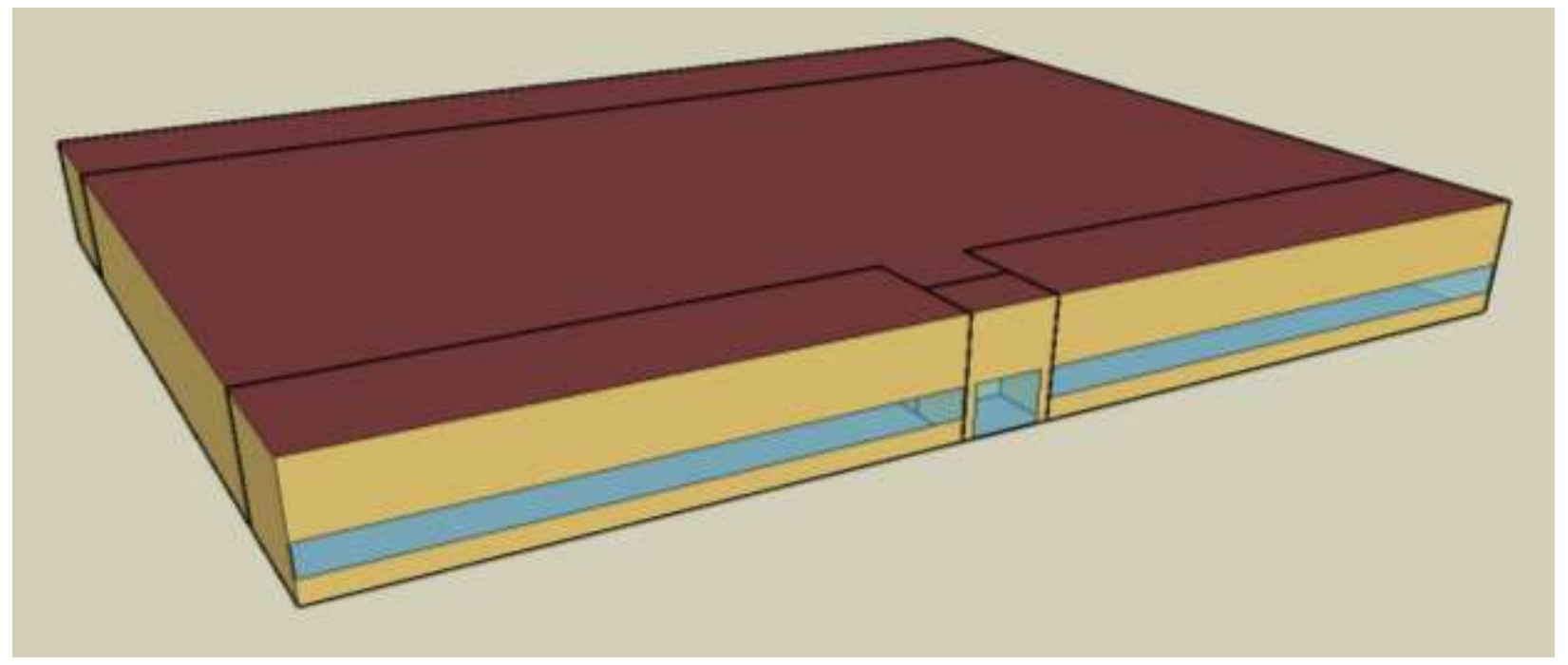

Figure 2: Axonometric View of Stand-alone Retail Building

\subsubsection{Medium Office Building}

The medium office building model shown in Figure 3 has three above-ground floors with a total floor area of 53,600 $\mathrm{ft}^{2}$. The building has a rectangular shape with aspect ratio of 1.5. The total window-to-wall ratio is about 33\%. Every floor has four perimeter zones with 15 feet depth from the exterior wall, and a core zone in the center. Each thermal zone is served by a packaged heat pump unit with electrical supplemental heating. Key building characteristics of the medium office building are listed in Table A- 2: Key Geometric, Envelope, HVAC, Water Heating and Internal Load Characteristics for the Medium Office Building Prototype in Appendix A.

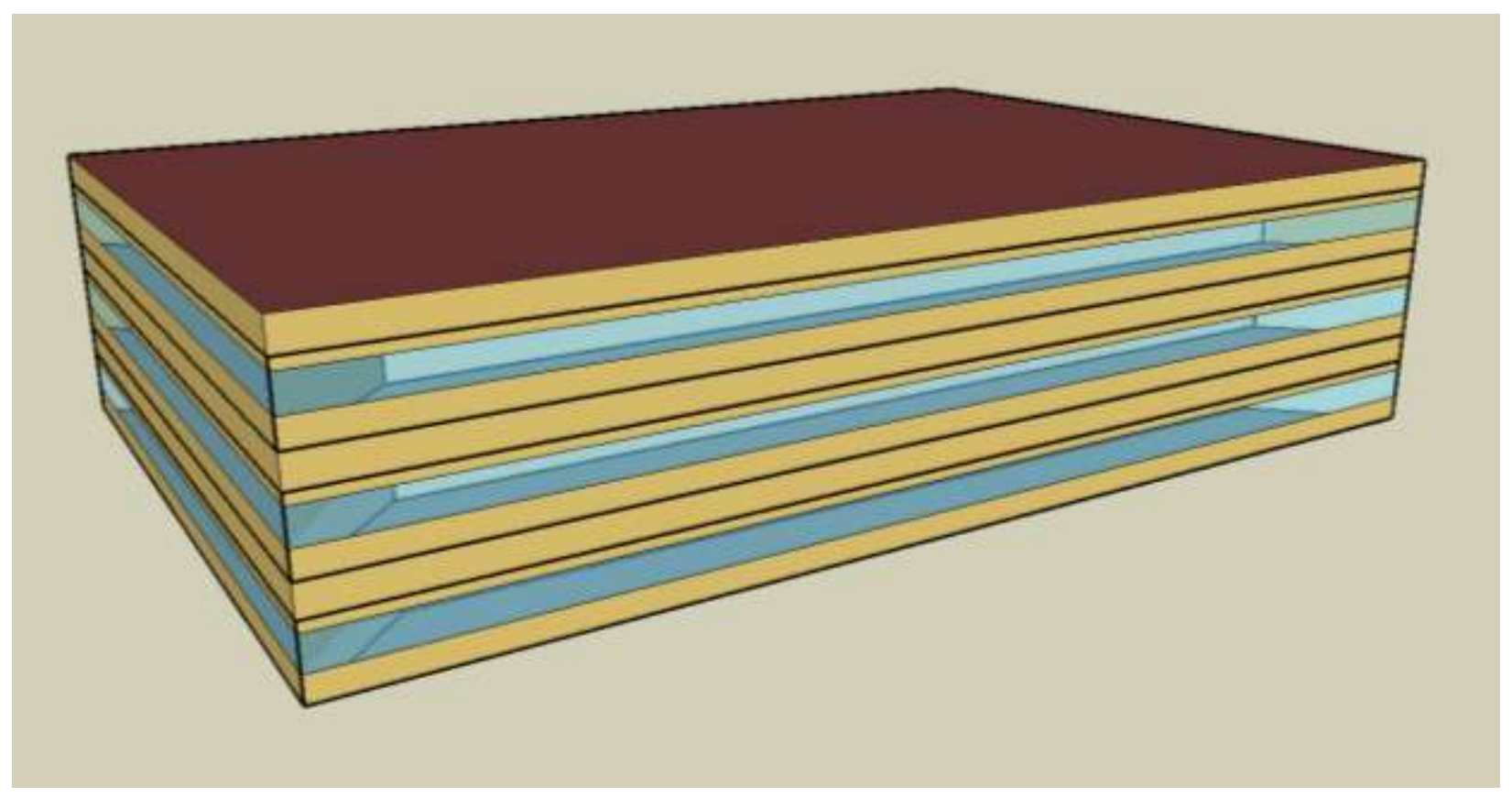

Figure 3: Axonometric View of Medium Office Building 
Table 2 summarizes the floor area, number of packaged systems, unit weekly operation hours and ventilation requirement for each building type. Because these buildings are modeled as post1980 construction, the ventilation requirements for different spaces are set according to ASHRAE Standard 62.1-1999 (ASHRAE 1999).

Table 2: Building Types Studied

\begin{tabular}{|c|c|c|c|c|}
\hline Building Type & Floor Area & $\begin{array}{c}\text { Number of } \\
\text { Packaged } \\
\text { Systems }\end{array}$ & $\begin{array}{c}\text { Unit Operation } \\
\text { Hours per Week }\end{array}$ & Ventilation Rate \\
\hline Medium Office & $53,600 \mathrm{ft}^{2}$ & 15 & $92 \mathrm{Hours}$ & $20 \mathrm{cfm} /$ person \\
\hline Stand-alone Retail & $25,000 \mathrm{ft}^{2}$ & 4 & $91 \mathrm{Hours}$ & $\begin{array}{c}0.15 \mathrm{cfm} / \mathrm{sf} \text { (storage) } \\
0.3 \mathrm{cfm} / \mathrm{sf} \text { (sales) }\end{array}$ \\
\hline
\end{tabular}

\subsection{Climates and Locations}

The energy saving potential from adding advanced controls to packaged heat pump units varies with climate conditions. The climate conditions and representative cities are basically the same as those used in our previous analysis (Wang et al. 2011). The only differences are that in this work, very hot climate (climate zone 1A) and very cold climate (climate zones 6, 7 and 8) are not used in the current analysis for the following two reasons. First, a heat pump unit normally has slightly lower cooling efficiency than its equivalent air-conditioning unit with gas heat, the system type we analyzed previously. Hence, there is no advantage of using heat pumps in very hot climates with negligible heating hours and where heat pumps are not used. Second, the heating efficiency and capacity of heat pump usually drops significantly at low outdoor-air temperature when heating is required. Therefore, packaged heat pumps are rarely used in very cold climate zones. Table 3 shows the climates and the representative cities used in this study. 
Table 3: Selected Climates and Corresponding Representative Locations Used for the Current Analysis

\begin{tabular}{|c|c|c|c|}
\hline $\begin{array}{c}\text { Climate } \\
\text { Zone }\end{array}$ & Climate Type & Representative City & Thermal Criteria \\
\hline 2A & Hot, humid & Houston, TX & $3500<\mathrm{CDD} 50^{\circ} \mathrm{F} \leq 5000$ \\
\hline 2B & Hot, dry & Phoenix, AZ & $3500<\mathrm{CDD} 50^{\circ} \mathrm{F} \leq 5000$ \\
\hline 3A & Warm, humid & Atlanta, GA & $2500<\mathrm{CDD} 50^{\circ} \mathrm{F} \leq 3500$ \\
\hline 3B & Warm, coastal & Los Angeles, CA & $2500<\mathrm{CDD} 50^{\circ} \mathrm{F} \leq 3500$ \\
\hline 3B & Warm, dry & Las Vegas, NV & $2500<\mathrm{CDD} 50^{\circ} \mathrm{F} \leq 3500$ \\
\hline 3C & Warm, marine & San Francisco, CA & HDD $65^{\circ} \mathrm{F} \leq 2000$ \\
\hline 4A & Mixed, humid & Baltimore, MD & $\begin{array}{c}\text { CDD50 } \\
\text { HD } \leq 2500\end{array}$ \\
\hline 4B & Mixed, dry & Albuquerque, NM & $\begin{array}{c}\text { CDD50 }{ }^{\circ} \mathrm{F} \leq 3000 \\
\mathrm{HDD} 65^{\circ} \mathrm{F} \leq 3000\end{array}$ \\
\hline 4C & Mixed, marine & Seattle, WA & $2000<\mathrm{HDD} 65^{\circ} \mathrm{F} \leq 3000$ \\
\hline 5A & Cool, humid & Chicago, IL & $3000<\mathrm{HDD} 65^{\circ} \mathrm{F} \leq 4000$ \\
\hline 5B & Cool, dry & Denver, CO & $3000<\mathrm{HDD} 65^{\circ} \mathrm{F} \leq 4000$ \\
\hline
\end{tabular}

CDD: cooling-degree-days; HDD: heating-degree-days 


\section{Analytic Methodology}

The methodology used to assess the energy and cost impact from advanced control strategies for heat pumps is similar to the methodology used in our previous work on packaged air conditioners with gas heat (Wang et al. 2011). Based on the simulated energy uses for different cases, the impact of using the advanced control package can be determined by taking the difference in energy use of the building with packaged heat pumps units with the base case control and the advanced control package. Energy costs savings are estimated by multiplying the energy savings of each of the energy sources by the corresponding energy price. Blended rates that essentially combine demand charges with usage charges are used for electricity. This section provides some details on the analytic methodology with emphasis on the differences from the previous work (Wang et al. 2011).

\subsection{Energy Use Estimation Methodology}

The EnergyPlus simulation software with the energy management system feature (DOE 2010) is used to simulate energy usage using typical meteorological weather for each location.

Simulations were performed for 2 prototype buildings, 11 locations (within 10 climate zones), and 8 control packages resulting in a total of 176 different simulation runs. The 2 building prototypes and 11 locations were discussed in Section 3. Table 4 lists the eight control packages.

Table 4: Combinations of Control Packages

\begin{tabular}{|c|l|c|c|c|}
\hline $\begin{array}{c}\text { Case } \\
\text { No }\end{array}$ & Case Name & $\begin{array}{c}\text { Economizer } \\
\text { Type } \\
\text { NIEcon or } \\
\text { IEcon) }\end{array}$ & $\begin{array}{c}\text { Fan-Speed } \\
\text { Control } \\
\text { (SSFan or } \\
\text { MSFan) }\end{array}$ & $\begin{array}{c}\text { Demand } \\
\text { Controlled } \\
\text { Ventilation } \\
\text { (DCV0 or } \\
\text { DCV1) }\end{array}$ \\
\hline 1 & NIEcon.SSFan.DCV0 (Baseline) & No & Constant & No \\
\hline 2 & IEcon.SSFan.DCV0 & Yes & Constant & No \\
\hline 3 & NIEcon.MSFan.DCV0 & No & Multiple & No \\
\hline 4 & NIEcon.SSFan.DCV1 & No & Constant & Yes \\
\hline 5 & NIEcon.MSFan.DCV1 & No & Multiple & Yes \\
\hline 6 & IEcon.MSFan.DCV0 & Yes & Multiple & No \\
\hline 7 & IEcon.SSFan.DCV1 & Yes & Constant & Yes \\
\hline 8 & IEcon.MSFan.DCV1 & Yes & Multiple & Yes \\
\hline
\end{tabular}

- The case number and case name are used as identifiers in this report. The case name is composed of three dot-separated fields to indicate the control strategies adopted in each case. The following abbreviations are used to designate the control features in each case: nonintegrated economizer (NIEcon), integrated economizer (IEcon), single-speed fan (SSFan), multi-speed fan (MSFan), DCV control (DCV1), and no DCV control (DCV0). Differential dry-bulb economizer control is considered in all the cases. Differential enthalpy control was 
not used because the difference in annual energy consumption between differential dry-bulb and differential enthalpy was small (Wang et al, 2011).

- In comparison with our previous work (Wang et al, 2011), the number of control combinations is reduced from 22 to 8 . The reduction comes from eliminating the variations of economizer control and staged cooling control. In this work, two-stage cooling is assumed for all cases, which is reasonable for the size of equipment serving the conditioned zones in the two building prototypes.

- The baseline case has a constant-speed supply fan, non-integrated airside economizer and no DCV. This baseline is assumed to be typical for many existing light commercial heat pump units.

Following the original DOE commercial building reference models (Deru et al. 2011), both the heat pump and the supplemental electrical heating coil are sized automatically by EnergyPlus according to the design day information of each location. As shown in Table 5, the equipment efficiencies vary with the equipment capacities (Deru et al. 2011).

\section{Table 5: Efficiency of Air-cooled Heat Pump and Fan Systems}

\begin{tabular}{|c|c|c|c|}
\hline Equipment & Capacity & Performance Metric & Value \\
\hline \multirow{4}{*}{$\begin{array}{l}\text { Air-Source } \\
\text { Heat Pump } \\
\text { (Cooling } \\
\text { Mode) }\end{array}$} & $<65 \mathrm{kBtu} / \mathrm{h}$ & SEER & 9.7 \\
\hline & $\geq 65 \mathrm{kBtu} / \mathrm{h}$ and $<135 \mathrm{kBtu} / \mathrm{h}$ & EER & 8.9 \\
\hline & $\geq 135 \mathrm{kBtu} / \mathrm{h}$ and $<760 \mathrm{kBtu} / \mathrm{h}$ & EER & 8.2 \\
\hline & $\geq 760 \mathrm{kBtu} / \mathrm{h}$ & EER & 8 \\
\hline \multirow{4}{*}{$\begin{array}{l}\text { Air-Source } \\
\text { Heat Pump } \\
\text { (Heating } \\
\text { Mode) }\end{array}$} & $<65 \mathrm{kBtu} / \mathrm{h}$ & HSPF & 6.6 \\
\hline & $\geq 65 \mathrm{kBtu} / \mathrm{h}$ and $<135 \mathrm{kBtu} / \mathrm{h}$ & $\mathrm{COP}$ & 2.8 \\
\hline & $\geq 135 \mathrm{kBtu} / \mathrm{h}$ and $<760 \mathrm{kBtu} / \mathrm{h}$ & $\mathrm{COP}$ & 2.8 \\
\hline & $\geq 760 \mathrm{kBtu} / \mathrm{h}$ & $\mathrm{COP}$ & 2.8 \\
\hline \multirow{6}{*}{ Fan } & \multirow{2}{*}{$<7,487 \mathrm{cfm}$} & Pressure rise & 2.5 in. w.c. ${ }^{*}$ \\
\hline & & Mechanical efficiency & $65 \%$ \\
\hline & \multirow{2}{*}{$\geq 7,487 \mathrm{cfm}$ and $<20,000 \mathrm{cfm}$} & Pressure rise & 4.46 in. w.c. \\
\hline & & Mechanical efficiency & $65 \%$ \\
\hline & \multirow{2}{*}{$>20,000 \mathrm{cfm}$} & Pressure rise & 4.09 in. w.c. \\
\hline & & Mechanical efficiency & $65 \%$ \\
\hline
\end{tabular}

*w.c. - water column

The sequence of heat pump unit operation considered in this work requires specialized control of packaged single-zone systems. Traditional controls built into EnergyPlus are not capable of modeling many control options, for example, the temperature set point differential and variation of fan speed with operation modes. To address the challenge, the energy management system (EMS) feature in EnergyPlus (DOE 2010) is used to provide the ability to customize controls. The EMS provides a variety of sensors and actuators much like the actual building automation 
system. The sequences of operations embedded in the EnergyPlus input files are used to override the traditional control and to add the desired control functionality into the simulation.

A number of control parameters need to be defined for the EMS control. Table 6 lists the control parameters that are independent of climate, location, and building type. The table shows that the constant-speed fan runs at its design speed, and the multi-speed fan runs at different speeds in different operation modes: $40 \%$ of the design speed in ventilation mode, $75 \%$ of the design speed in economizing mode, $75 \%$ and $100 \%$ of the design speed in first and second stage cooling modes, respectively.

Table 6: Default Values of the Key Control Parameters

\begin{tabular}{|c|c|}
\hline Parameter & Value \\
\hline Heating and cooling set point differential $(\delta)$ & $1.8^{\circ} \mathrm{F}$ \\
\hline Economizer supply-air temperature set point $\left(\mathrm{T}_{\mathrm{EcoSP}}\right)$ & $55^{\circ} \mathrm{F}$ \\
\hline Interstage delay time limit $\left(\Delta \mathrm{t}_{\text {Limit }}\right)$ & $9 \mathrm{~min}$ \\
\hline $\begin{array}{l}\text { Temperature threshold for changeover from OA } \\
\text { economizer cooling to DX cooling }\left(\mathrm{T}_{\mathrm{Eco}-\mathrm{DX}}\right)\end{array}$ & $58^{\circ} \mathrm{F}$ \\
\hline $\begin{array}{l}\text { Temperature threshold for changeover from first to } \\
\text { second stage } \mathrm{DX} \text { cooling }\left(\mathrm{T}_{\mathrm{DX} \_ \text {Stage }}\right)\end{array}$ & $58^{\circ} \mathrm{F}$ \\
\hline Fan speed in ventilation mode $\left(\right.$ Fan $\left._{V e n}\right)$ & $\begin{array}{l}100 \% \text { (constant speed) } \\
40 \% \text { (multi-speed) }\end{array}$ \\
\hline Fan speed in economizing mode $\left(\mathrm{Fan}_{\mathrm{Eco}}\right)$ & $\begin{array}{l}100 \% \text { (constant speed) } \\
75 \%(\text { multi-speed })\end{array}$ \\
\hline Fan speed in cooling $\left(\mathrm{Fan}_{\text {Stage } 1}\right)$ & $100 \%$ (constant speed) \\
\hline Fan speed in heating mode $\left(\right.$ Fan $\left._{\text {Heat }}\right)$ & $100 \%$ \\
\hline $\begin{array}{l}\text { Heat pump supplemental heating lock out OA } \\
\text { temperature }\end{array}$ & $40^{\circ} \mathrm{F}$ \\
\hline $\begin{array}{l}\text { Minimum OA temperature for compressor on for } \\
\text { heating }\end{array}$ & $10^{\circ} \mathrm{F}$ \\
\hline Ambient $\mathrm{CO}_{2}$ concentration & 400 ppm (ASHRAE 2010) \\
\hline Space $\mathrm{CO}_{2}$ concentration set point $\left(C_{C O 2, S P}\right)$ & 1000 ppm (ASHRAE 2010) \\
\hline $\mathrm{CO}_{2}$ generation rate from people & $0.0084 \mathrm{cfm} / \mathrm{met}$ (ASHRAE 2010) \\
\hline
\end{tabular}

\subsection{Economic Analysis Methodology}

For each simulation, EnergyPlus provides estimates of fan electricity consumption, cooling electricity consumption, heating electricity consumption, and total energy (electricity) consumption. The total energy consumption is the sum of all three end uses. Annual energy cost is simply calculated from the electricity rates and the annual energy consumption using the equation:

$$
\begin{aligned}
A E C & =r_{\text {elec }} \times Q_{\text {elec }} \\
& =r_{\text {elec }} \times\left(Q_{\text {cooling }}+Q_{\text {heating }}+Q_{\text {fan }}\right)
\end{aligned}
$$


where $A E C$ represents annual energy cost; $r_{\text {elec }}$ is the electricity utility rate (i.e., prices); and $Q_{\text {elec }}, Q_{\text {cooling, }}, Q_{\text {heating }}, Q_{\text {fan }}$ are the annual total electricity consumption, cooling electricity consumption, heating electricity consumption, and fan electricity consumption in $\mathrm{kWh}$.

Average blended electricity prices (energy and peak charges) from EIA (2011) are used for the analysis. EIA provides the historical data on monthly utility rates in all states back to the 1970s. For each location, the corresponding state average price in the year of 2010 is used as the applicable price for a whole year. Table 7 lists the electricity prices for all 11 locations, located in 10 different climate zones.

Table 7: Electricity Prices by Location in the Year of 2010 (EIA 2011)

\begin{tabular}{|c|c|c|c|}
\hline Climate Zone & City & State & $\begin{array}{c}\text { Electricity } \\
\mathbf{( \$ / k W h )}\end{array}$ \\
\hline 2A & Houston & TX & 0.092 \\
\hline 2B & Phoenix & AZ & 0.094 \\
\hline 3A & Atlanta & GA & 0.091 \\
\hline 3B & Los Angeles & CA & 0.138 \\
\hline 3B & Las Vegas & NV & 0.099 \\
\hline 3C & San Francisco & CA & 0.138 \\
\hline 4A & Baltimore & MD & 0.116 \\
\hline 4B & Albuquerque & NM & 0.086 \\
\hline 4C & Seattle & WA & 0.073 \\
\hline 5A & Chicago & IL & 0.088 \\
\hline 5B & Denver & CO & 0.090 \\
\hline
\end{tabular}

The maximum total installed cost of retrofitting an advanced control package on an existing rooftop unit equals the annual energy cost savings times the payback period. This initial installed cost, which is the sum of the initial capital cost of the advanced controller equipment and the cost of installation, is a function of annual savings and the simple payback period desired by the consumer (ordinarily the building owner). Having the annual energy cost for a given advanced control package in case $i$, the maximum acceptable initial cost can be calculated as:

$$
\begin{aligned}
I C_{i, \text { max }} & =\left(I C_{i, \text { capital }}+I C_{i, \text { installation }}\right)_{\text {max }} \\
& =\left(A E C_{i}-A E C_{\text {base }}\right) * N_{s p p}
\end{aligned}
$$

where, $I C_{i, \max }$ is the maximum acceptable total installed cost of the advanced controller with case i for a building in $\$ ; I C_{i, \text { capital }}$ is the corresponding capital cost of the controller; $I C_{i, \text { installation }}$ is the installation cost; $N_{s p p}$ is the simple payback period in years; and the subscripts $i$ and base refer to the $i$-th case and the baseline case, respectively. Note that $I C$ is the total installed cost 
for a building. Therefore, if the building has a number of units, then per unit cost can be estimated by dividing $I C$ by the number of units to obtain the maximum acceptable total initial cost for a single advanced controller. 


\section{Energy and Cost Savings}

The energy savings from different advanced control packages for heat pump units are presented and discussed in this section. The baseline HVAC energy use and cost are presented first. Then, in Section 5.2, the impact of each individual control strategy on HVAC energy and cost savings is investigated. Section 5.3 shows the impact of combined control strategies.

\subsection{Baseline HVAC Energy Use and Cost}

The baseline models have the following changes from the DOE reference models to simulate the packaged heat pump systems. The DX (direct expansion) cooling coils with gas heating coils in the reference models are changed to heat pump systems with electrical heating coils. Nonintegrated economizers on the airside are added in the baseline.

The investigated control strategies do not affect the energy use for lighting, plug loads and service hot water. Therefore, only HVAC energy uses (i.e., ventilation, cooling, and heating) are considered. Figure 4 and Figure 5 show the annual HVAC energy use for heating, cooling and fan across all 11 locations. These figures lead to the following observations:

- $\quad$ The annual HVAC energy consumption lies between 93 and $320 \mathrm{MWh}$ for the retail building and 160 and $475 \mathrm{MWh}$ for the office building. After normalization with the building area (Table 2), the HVAC energy use intensities for the two building types are in the following ranges: 3.7 to $13 \mathrm{kWh} / \mathrm{ft}^{2} /$ year for the retail buildings, and 3 to 8.8 $\mathrm{kWh} / \mathrm{ft}^{2} /$ year for the office buildings.

- Mild climates (such as Los Angeles in 3B, San Francisco in 3C, and Seattle in 4C) have the lowest energy consumptions in both prototypes. Retail in Chicago (5A) and Office in Phoenix (2B) have the highest energy consumptions. The office building has a more cooling-dominated load profile than the retail building.

- In comparison with heating and cooling energy, fan energy has smaller variation with different locations. This is mainly because fan running hours are the same for all locations. The small variation of fan energy comes from different fan sizes including the design flow rate and pressure rise. Fans consume from 25\% (Chicago) to 60\% (Los Angeles) of the total HVAC energy in Retail, and from 37\% (Phoenix) to $83 \%$ (San Francisco) in Office. The precise fractions depend on the climates. Generally fan energy use accounts for larger fractions in mild climates and smaller fractions in extreme climates.

- Cooling energy accounts for 3\% to $56 \%$ of total HVAC energy in the stand-alone retail building and $9 \%$ to $60 \%$ in the office building. Heating energy accounts for $12 \%$ to $65 \%$ of total HVAC energy in the retail building and $1 \%$ to $33 \%$ in the office building.

- The annual energy cost varies from $\$ 12,061$ to $\$ 28,514$ for retail buildings, and $\$ 14,493$ to $\$ 44,458$ for office buildings. Because the two vertical axis scales (in Figure 4 and Figure 5) were chosen to correspond to $0.1 \$ / \mathrm{kWh}$, the position of the blue dot indicates whether cost of electricity in that location is above or below $0.1 \$ / \mathrm{kWh}$. If the blue dot is above the top of the energy bar (i.e., Los Angeles, San Francisco, and Baltimore), the electricity price for that location is more than $0.1 \$ / \mathrm{kWh}$; otherwise, the electricity price is lower than $0.1 \$ / \mathrm{kWh}$. 


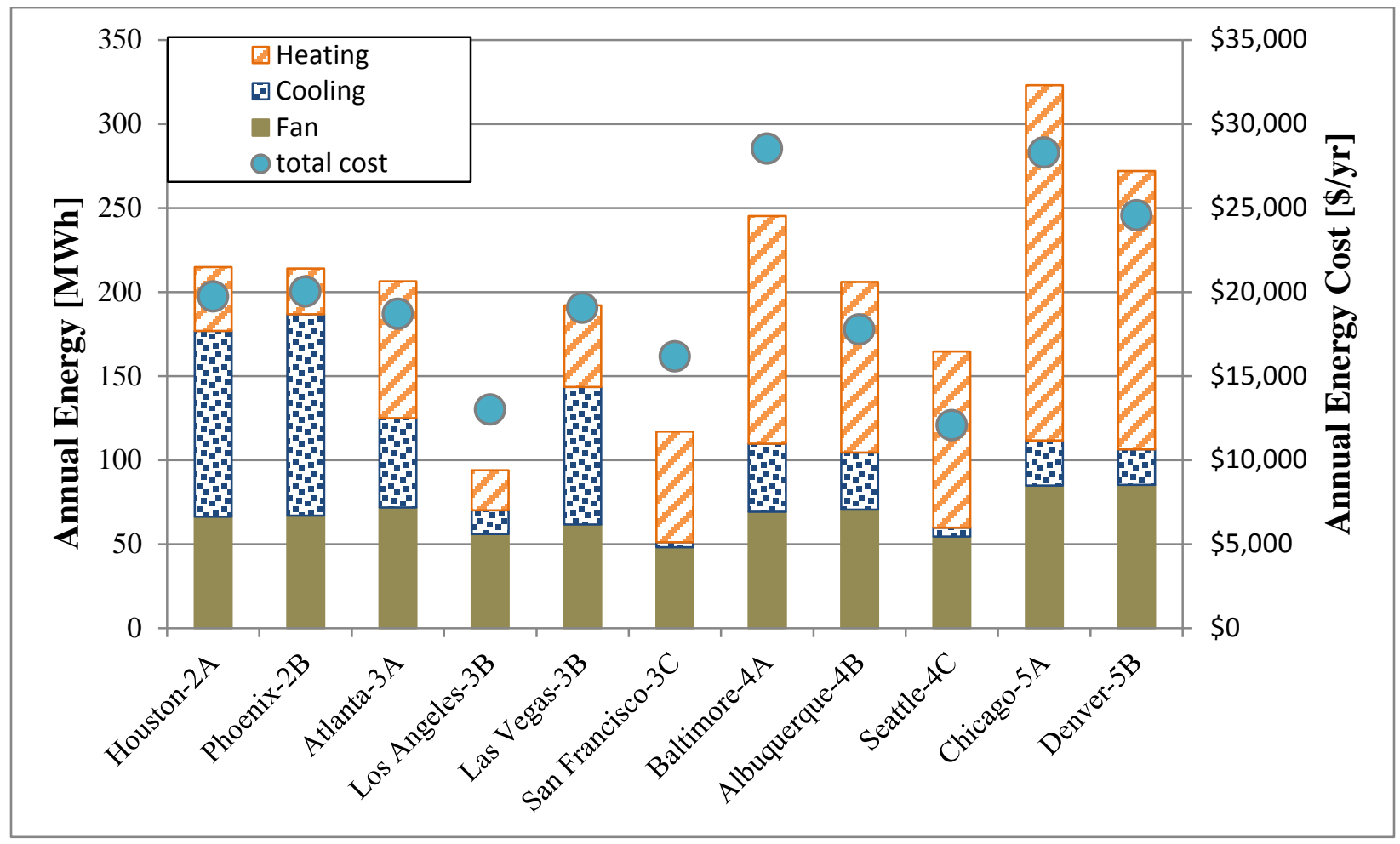

Figure 4: Annual HVAC Energy Use and Cost for Baseline (Case 1) Control Package of the Stand-alone Retail Building

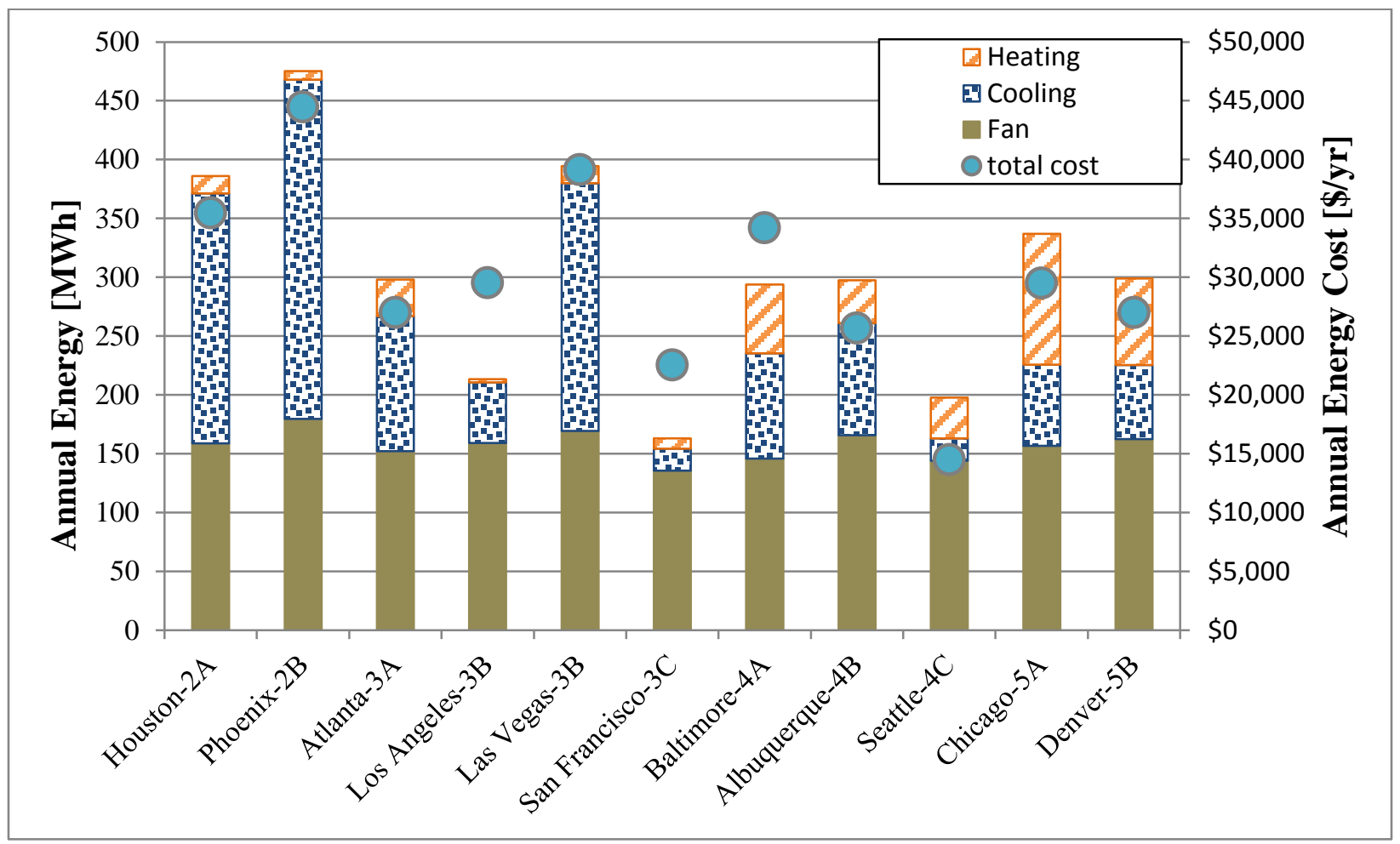

Figure 5: Annual HVAC Energy Use and Cost for Baseline (Case \#1) Control Package of the Medium Office Building 
For ease of reference, the annual HVAC energy use for the base case and all other eight advanced control packages are also tabulated in Appendix B for the two building types.

\subsection{Impact Assessment of Individual Control Strategies}

Three advanced control configurations including airside integrated economizers, multi-speed fan controls, and DCVs are evaluated individually in this section. Their individual impact is determined by comparing the energy consumption for the baseline (Case 1) with Case 2, Case 3, and Case 4, respectively (see Table 8).

Both absolute and percent savings are provided for energy savings. Because electricity is the only fuel type used for HVAC systems, the percent savings for HVAC energy and cost are the same. Therefore, only absolute savings are provided for the cost. A full list of the results is presented in Appendix B.

\section{Table 8: Cases Represent Individual Impacts of Three Control Strategies}

\begin{tabular}{|l|l|}
\hline Case 1: NIEcon.SSFan.DCV0 & Baseline \\
\hline Case 2: IEcon.SSFan.DCV0 & Baseline + Integrated Economizer \\
\hline Case 3: NIEcon.MSFan.DCV0 & Baseline + Multi-speed Fan \\
\hline Case 4: NIEcon.SSFan.DCV1 & Baseline + DCV \\
\hline
\end{tabular}

\subsubsection{Integrated Economizer}

Comparing Case 2 with the baseline shows the energy savings resulting from use of integrated economizer control. The integrated economizer control maximizes free cooling and allows use of mechanical cooling to meet any additional cooling load that cannot be met by the economizer alone. This configuration takes maximum advantage of the free cooling from the outdoor air without compromising occupant comfort. Figure 6, Figure 7 and Figure 8 show the impact of enabling an airside integrated economizer, where the following observations can be made:

- A maximum 3\% of HVAC energy and cost savings is achieved in Los Angeles for the medium office building. There are more savings in mild climates such as Los Angeles (3B) and San Francisco (3C). The benefits come from long hours of suitable weather and a big portion of these hours when outdoor air alone cannot fulfill all zone cooling loads. Appendix B shows that most of the savings from an integrated economizer come from cooling energy reductions.

- In hot and humid climates such as Houston (2A) and Atlanta (3A), enabling integrated economizer control based on differential dry-bulb temperature increases HVAC energy consumption. This energy increase can occur because 1) the control logic based on differential dry-bulb temperature may cause the outdoor-air damper to fully open when the outdoor-air dry-bulb temperature may be lower than the return-air temperature but the enthalpy of the outdoor air could be greater than the enthalpy of the return air (Taylor and Cheng 2010), and 2) the use of an integrated economizer increases the frequency at which this incorrect control decision occurs (Taylor and Cheng 2010).

- In those locations where integrated economizer control decreases energy consumption for both building types, the office building has higher percentage of energy savings than the retail building. This is because cooling takes a larger fraction of HVAC energy use in the office building than it does in the retail building. The higher percentage of cooling energy 
means the cooling extends to lower outdoor-air temperatures when an economizer is beneficial.

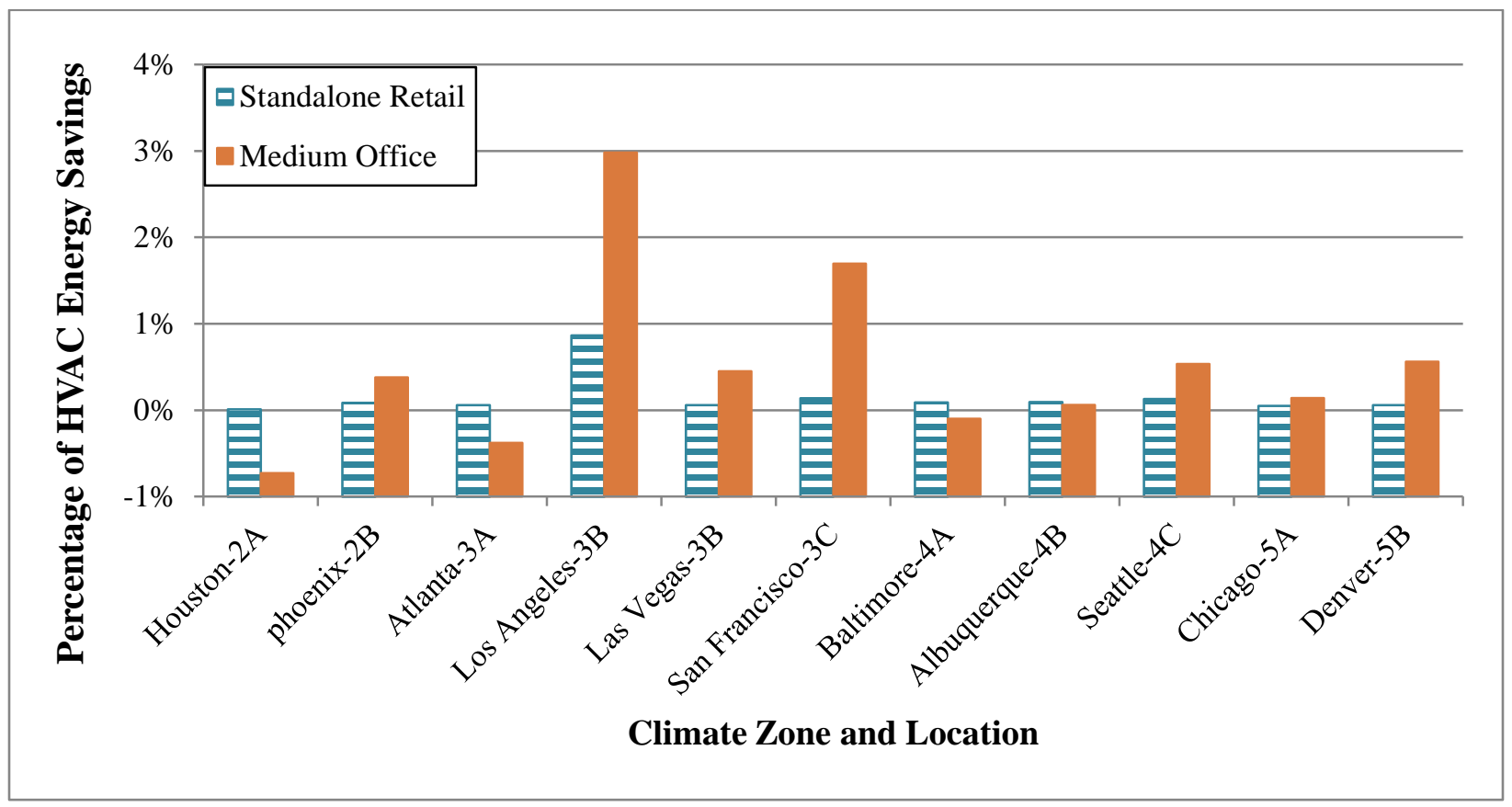

Figure 6: HVAC Energy Percentage Savings from the Use of Integrated Airside Differential Dry-Bulb Economizer Controls (Case 2) Compared to the Baseline with NonIntegrated Airside Differential Dry-bulb Economizer (Case 1)

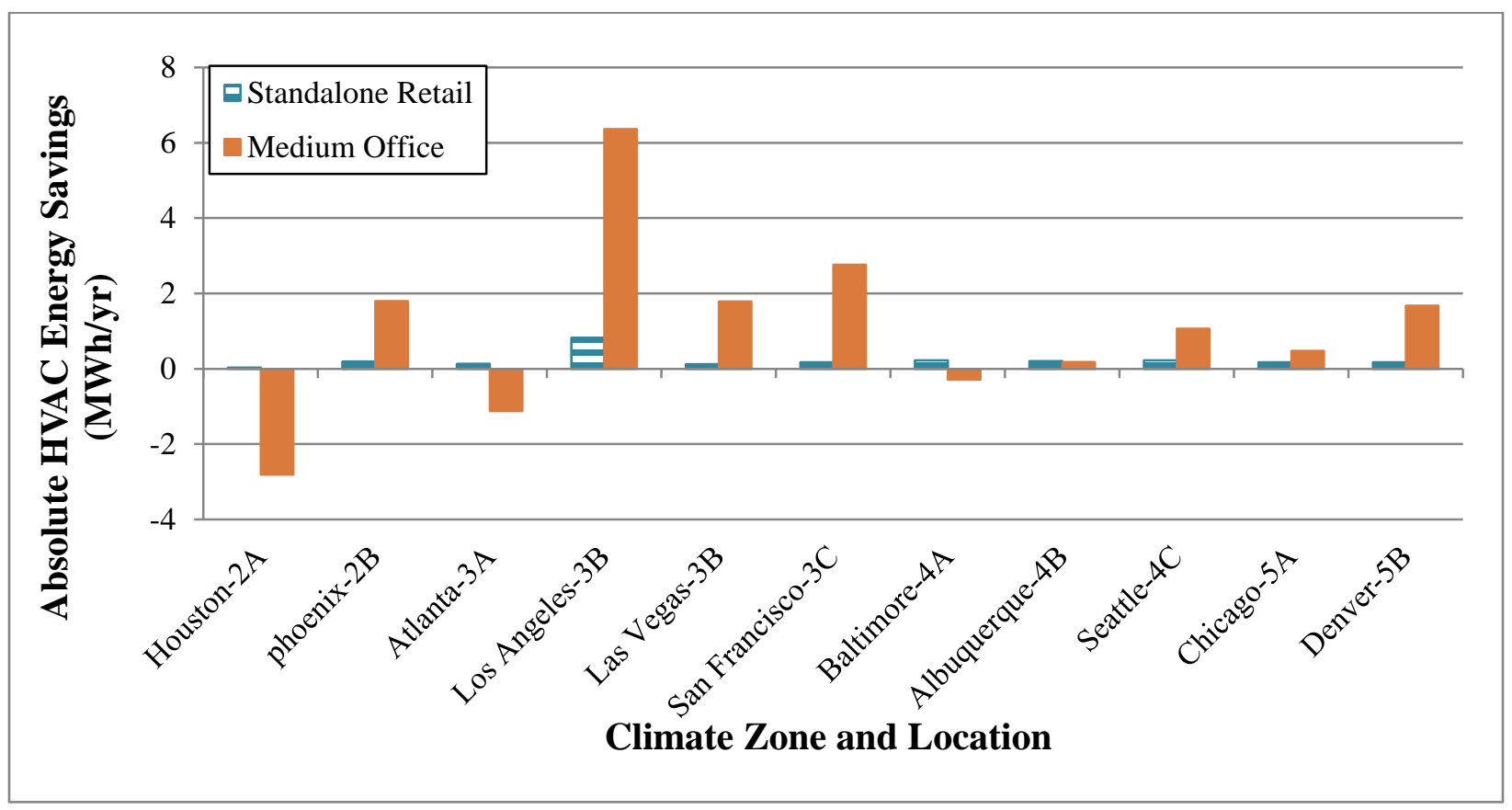

Figure 7: Absolute HVAC Energy Savings from the Use of Integrated Airside Differential Dry-Bulb Economizer Controls (Case 2) Compared to the Baseline with Non-integrated Airside Differential Dry-bulb Economizer (Case 1) 


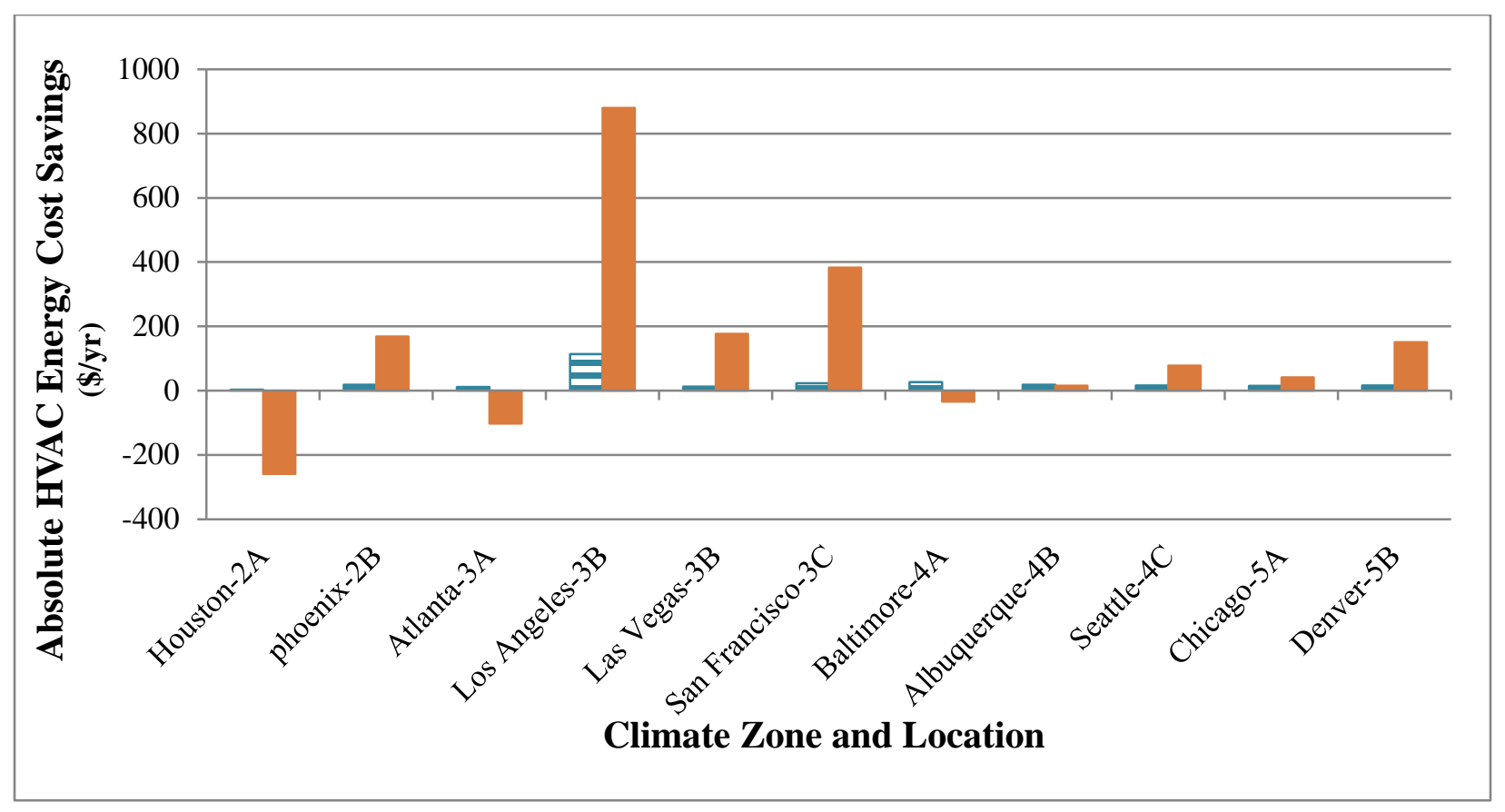

Figure 8: HVAC Absolute Energy Cost Savings from the Use of Integrated Airside Differential Dry-Bulb Economizer Controls (Case 2) Compared to the Baseline with Nonintegrated Airside Differential Dry-bulb Economizer (Case 1)

- In general, enabling integrated economizer control has small impact on energy and cost savings. In locations with positive savings from an integrated economizer, the absolute savings range from $0.03 \mathrm{MWh} / \mathrm{yr}$ to $0.81 \mathrm{MWh} / \mathrm{yr}$ for retail, and $0.18 \mathrm{MWh} / \mathrm{yr}$ to $6.37 \mathrm{MWh} / \mathrm{yr}$ for office (Figure 7). This yields a whole-building cost savings from $\$ 2 / \mathrm{yr}$ to $\$ 112 / y r$ for retail, and $\$ 15 / y r$ to $\$ 880 / y r$ for office (Figure 8 ). 


\subsubsection{Multi-speed Fan}

Case 3 differs from the baseline (Case 1) in supply-fan control: single-speed fan control is used in the baseline while multi-speed fan control is used in Case 3. Thus, comparing Case 3 with the baseline shows the resulting savings from adding multi-speed fan control, as shown in Figure 9 through Figure 11. These figures indicate the following:

- Adding multi-speed fan control results in $15 \%$ to $38 \%$ of the total HVAC energy and cost savings for the retail building. The percentage of savings increases to $18 \%$ to $54 \%$ for the office buildings.

- The retail building saves $27 \mathrm{MWh}$ to $41 \mathrm{MWh}$ of electricity per year from the multi-speed fan control, and the office building saves $70 \mathrm{MWh}$ to $95 \mathrm{MWh}$ per year. The absolute fan energy savings are proportional to the fan size. Because the total fan flow rates in the retail building are about $40 \%$ of those in the office building, the absolute fan energy savings in the retail building are about $40 \%$ of that in the office building.

- The retail building saves between $\$ 2,000 / \mathrm{yr}$ and $\$ 4,900 / \mathrm{yr}$ from the multi-speed fan control and office building savings are between $\$ 6,200 / \mathrm{yr}$ to $\$ 13,200 / \mathrm{yr}$ (Figure 11).

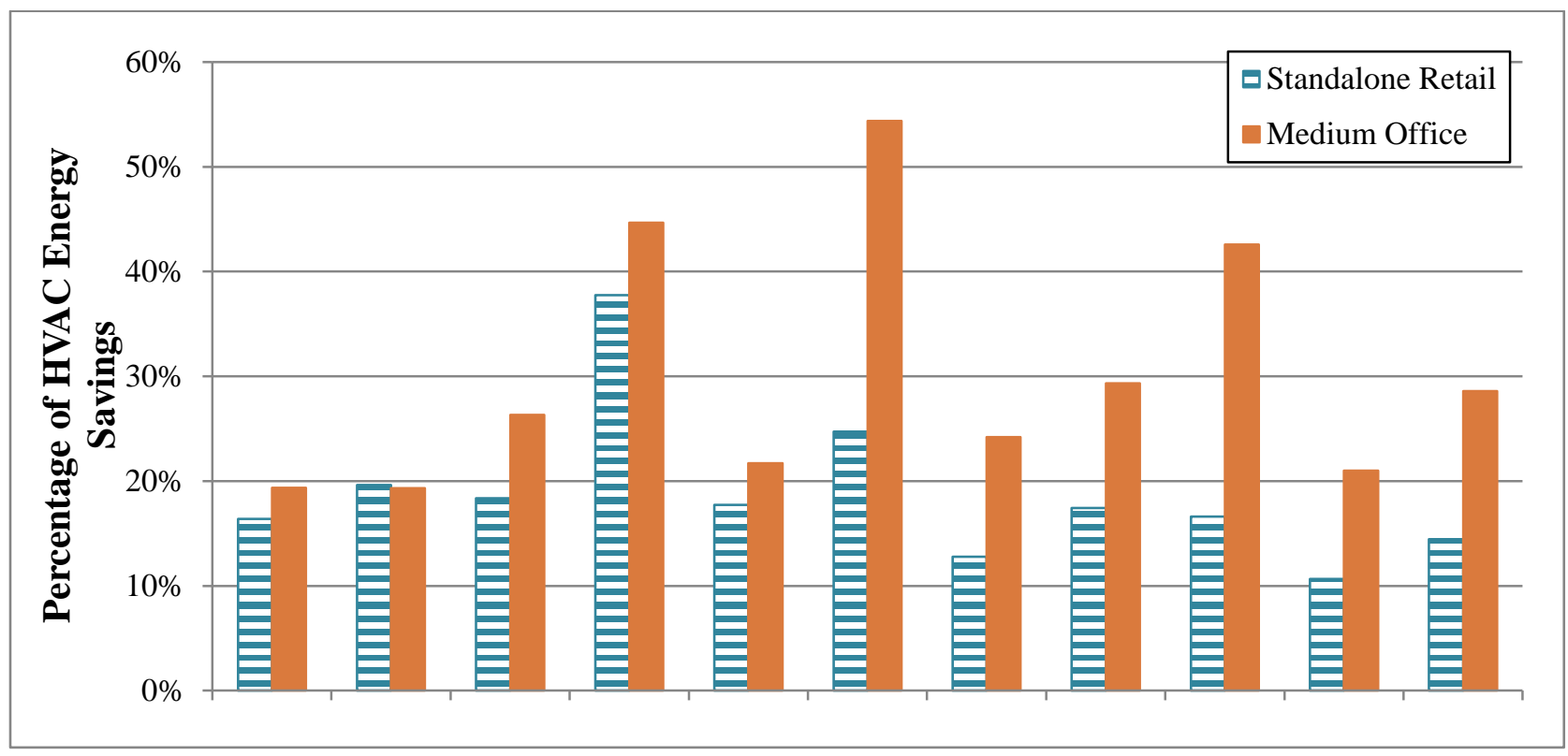

Figure 9: Percentage of HVAC Savings from the Use of Multi-speed Supply-Fan Control (Case 3) Compared to the Base Case with Constant-Speed Fan Control (Case 1) 


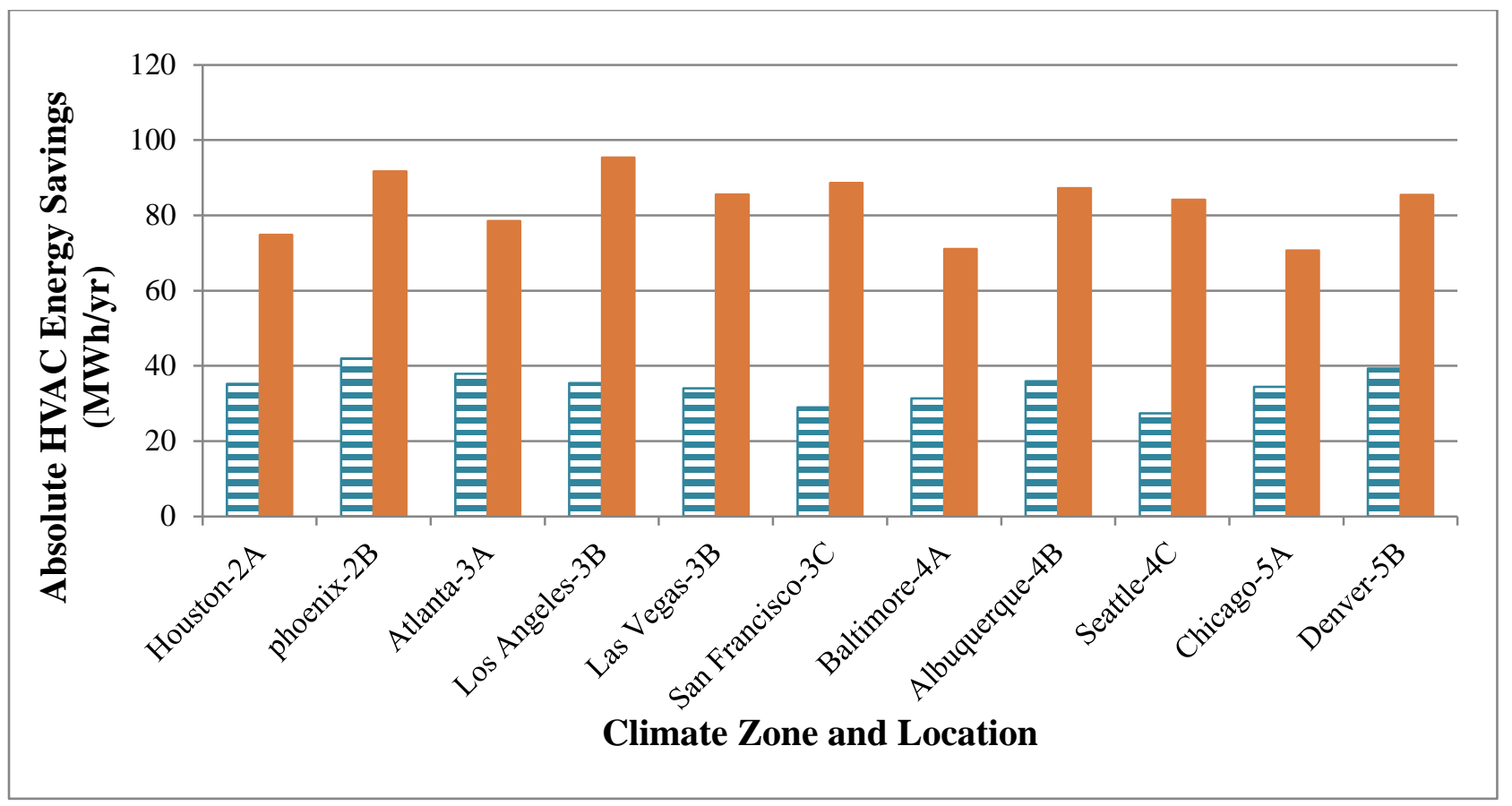

Figure 10: HVAC Energy Savings from the Use of Multi-speed Supply-Fan Control (Case 3) Compared to the Base Case with Constant-Speed Fan Control (Case 1)

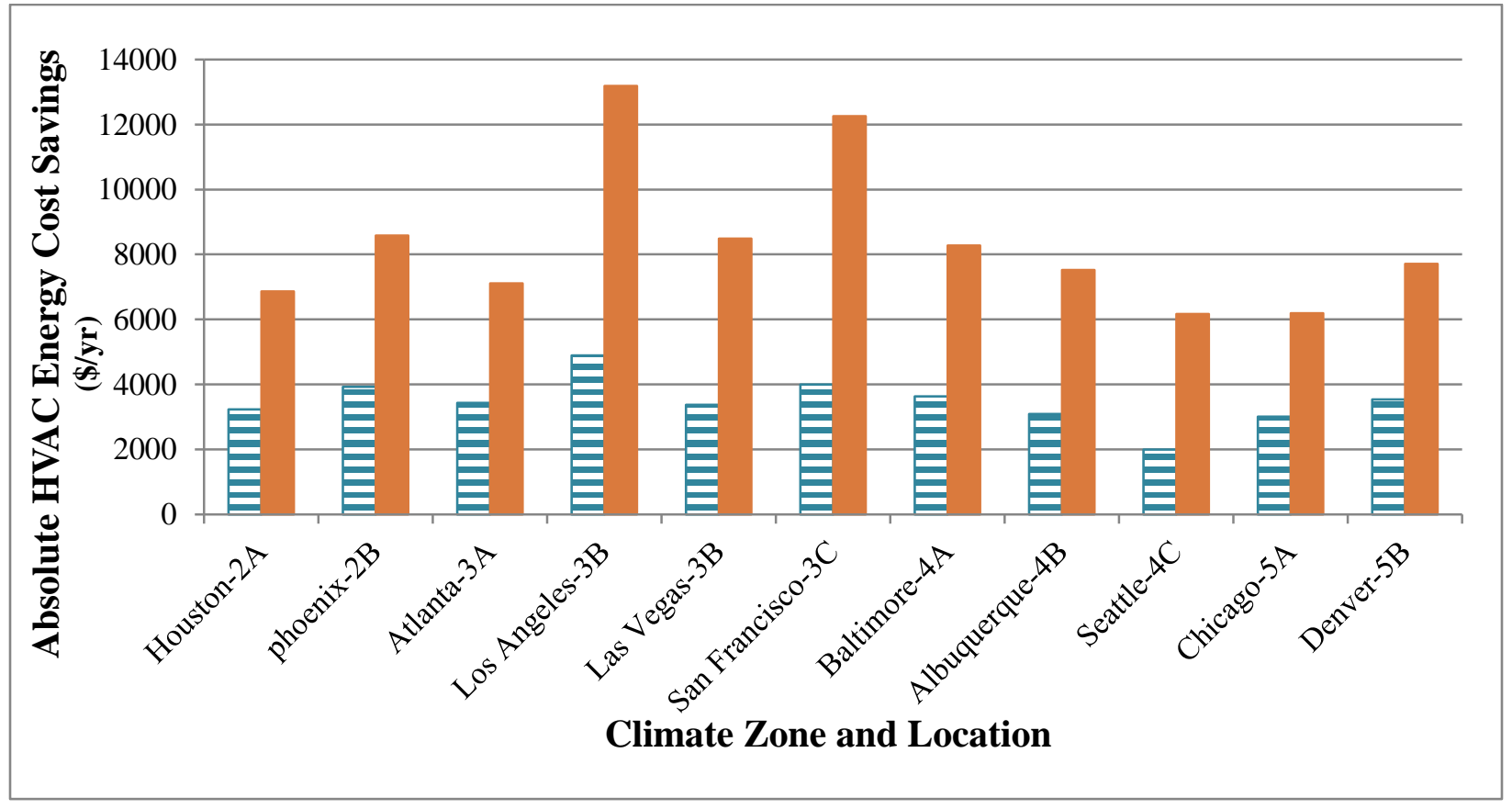

Figure 11: HVAC Cost Savings from the Use of Multi-speed Supply-Fan Control (Case 3) Compared to the Base Case with Constant-Speed Fan Control (Case 1) 


\subsubsection{Demand Controlled Ventilation}

Case 4 differs from the baseline only by the presence of DCV. Thus, comparing Case 4 with the baseline determines the impact of DCV on HVAC energy consumption and energy cost, as shown in Figure 12 through Figure 14.

- DCV achieves between $10 \%$ and $27 \%$ of HVAC energy and cost savings in the retail building, while it achieves up to 10\% of HVAC energy and cost savings in the medium office building. The difference in savings between the two building types is mostly attributed to their different occupancy profiles. Figure 15 shows the weekday occupancy profiles. For most occupied hours, the office building has a more constant and higher occupancy ratio than the stand-alone retail building. A stable ventilation requirement close to the peak design limits the potential of energy savings from DCV.

- $\quad$ DCV seems to be more effective in the cold climates and less beneficial in mild climates. In mild climates, the outdoor-air temperature is close to the return-air temperature during much of the occupied period. Therefore, the amount of outdoor air exceeding ventilation requirements brought in by the system has less impact on energy consumption in mild climates than it has in colder climates.

- $\quad$ For the office building, DCV even increases HVAC energy consumption in San Francisco. This is because reducing the outdoor-air flow causes more cooling energy when the system is in cooling mode, and the outdoor-air condition is favorable for economizing. A detailed investigation of the results shows that in San Francisco, Case 4 saves about $2.8 \mathrm{MWh} / \mathrm{yr}$ heating energy and increases about 7.1 MWh/yr cooling energy in comparison with the base case. The saved heating energy is not sufficient to overcome the increased cooling energy, leading to total energy increase.

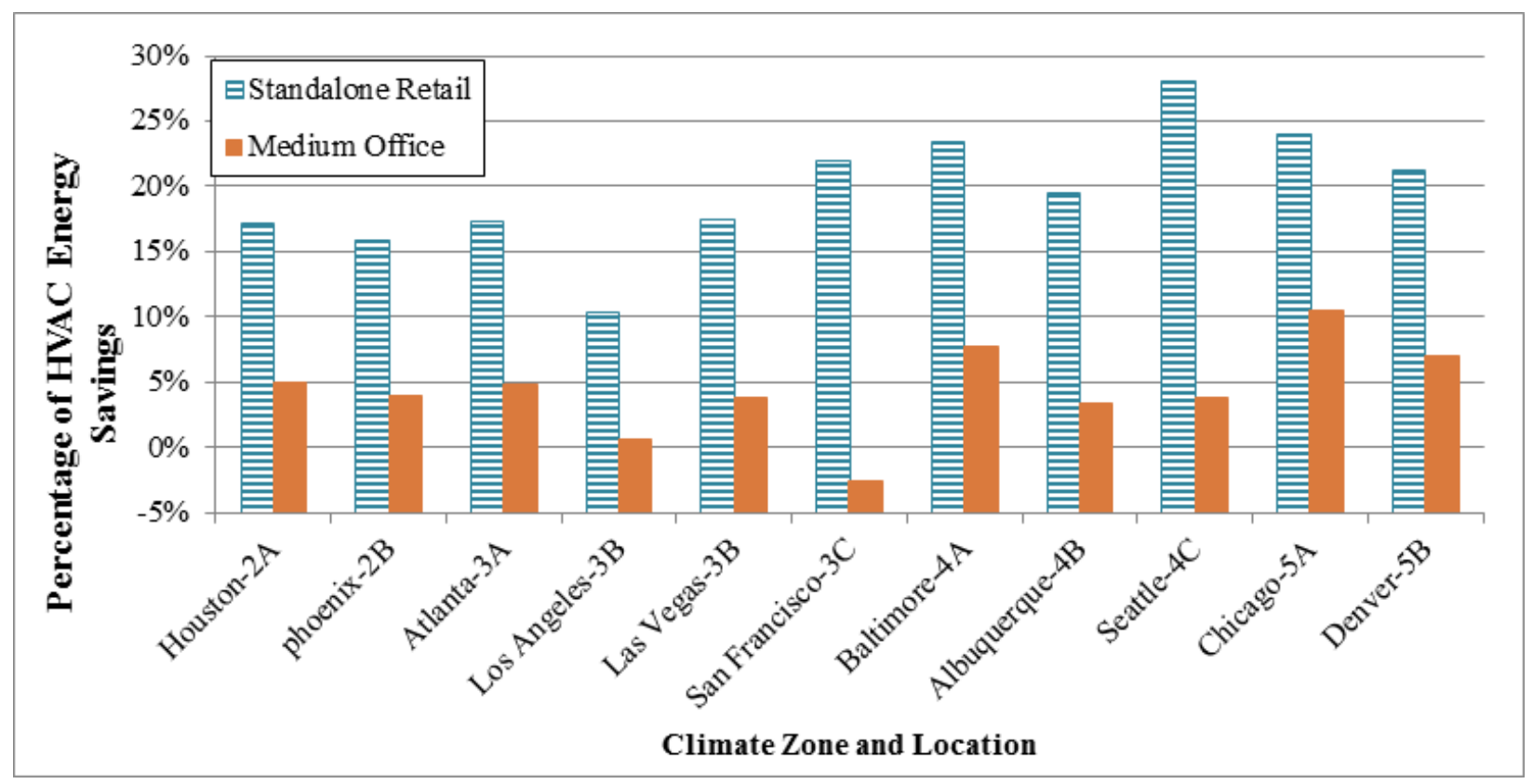

Figure 12: Percent HVAC Energy and Cost Savings from the Use of DCV Control (Case 4) Compared to the Baseline with no DCV Control (Case 1) 


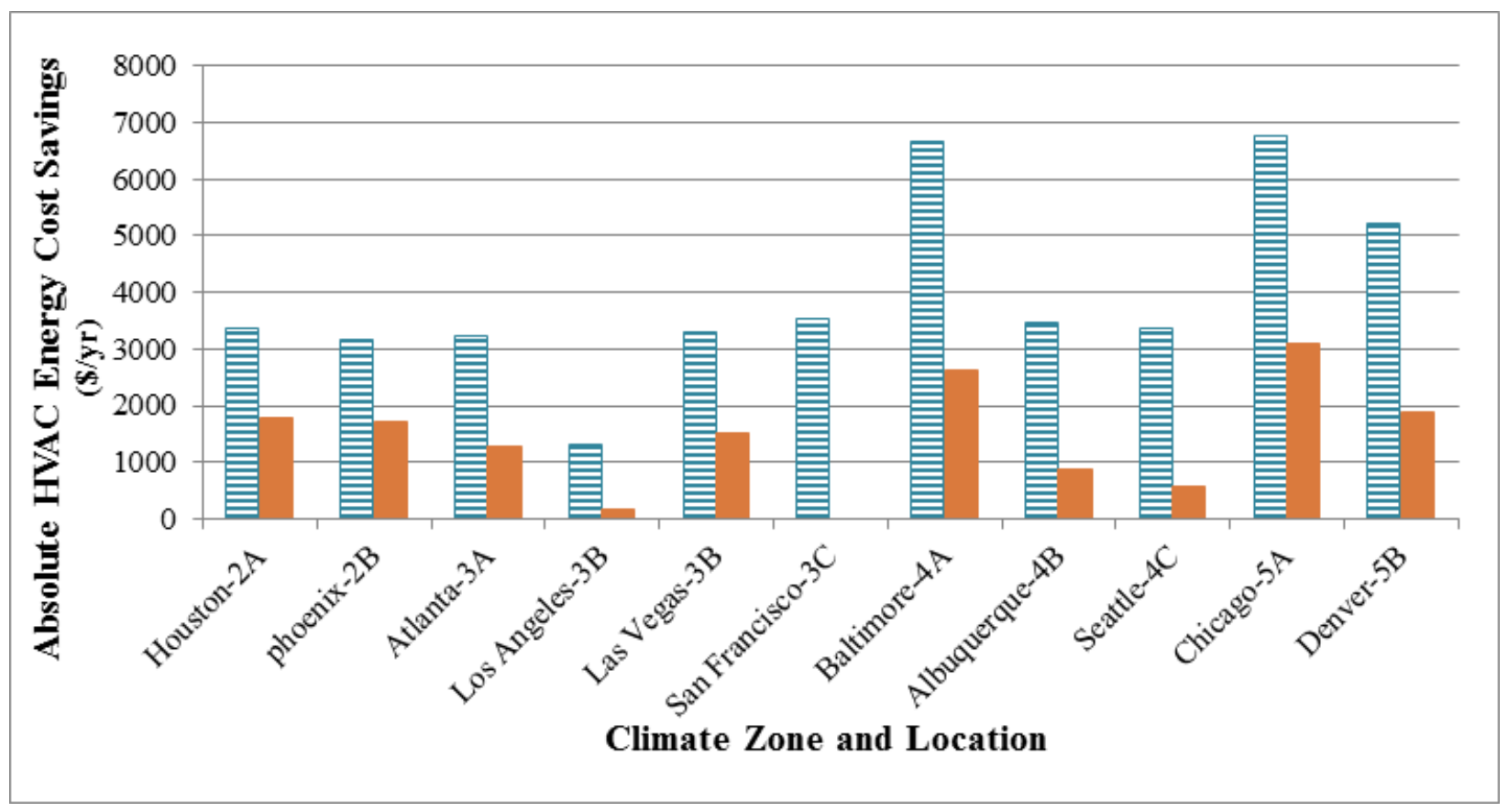

Figure 13: HVAC Energy Savings from the Use of DCV Control (Case 4) Compared to the Baseline with no DCV Control (Case 1)

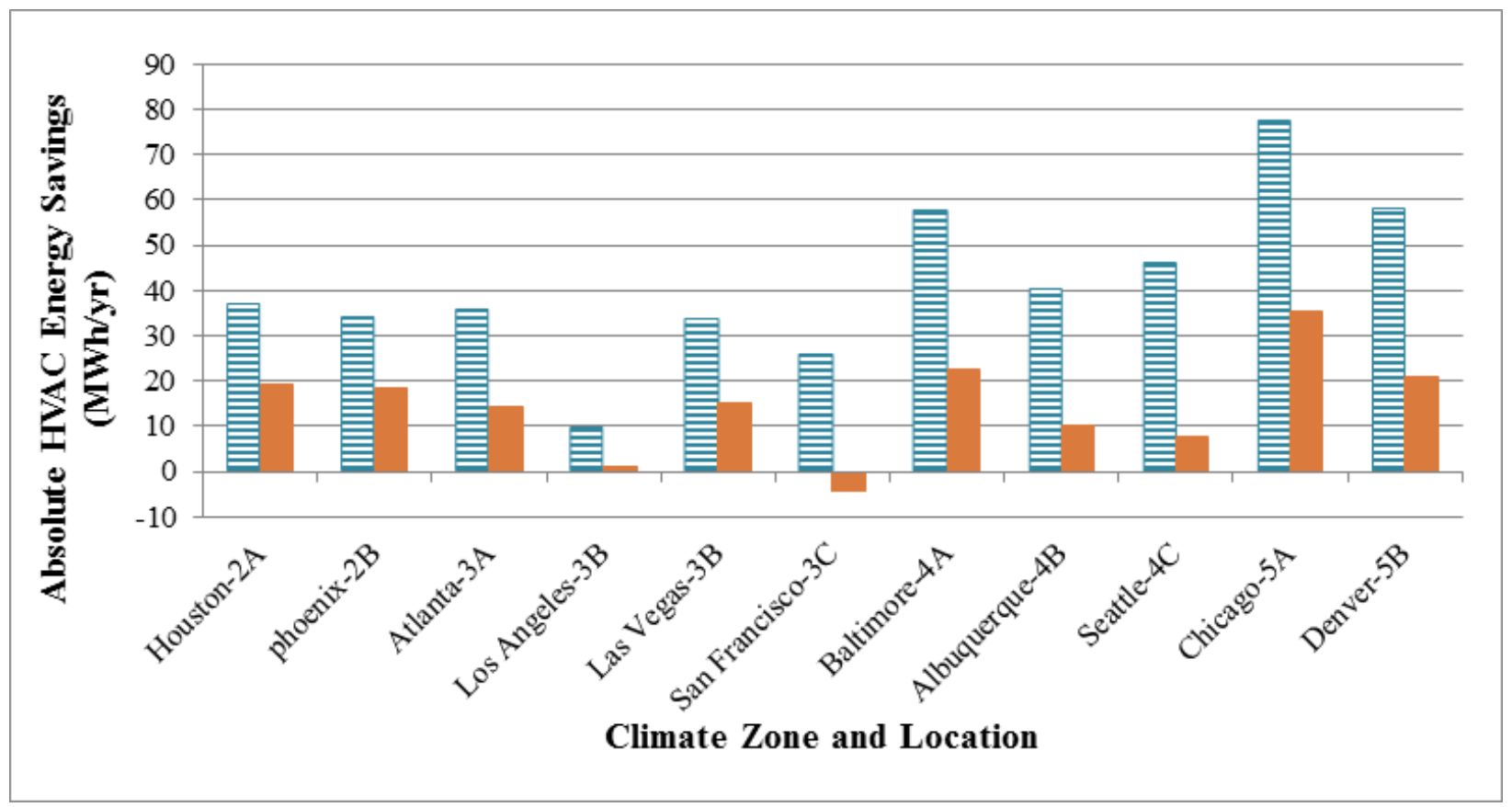

Figure 14: HVAC Energy Cost Savings from the Use of DCV Control (Case 4) Compared to the Baseline with no DCV Control (Case 1) 


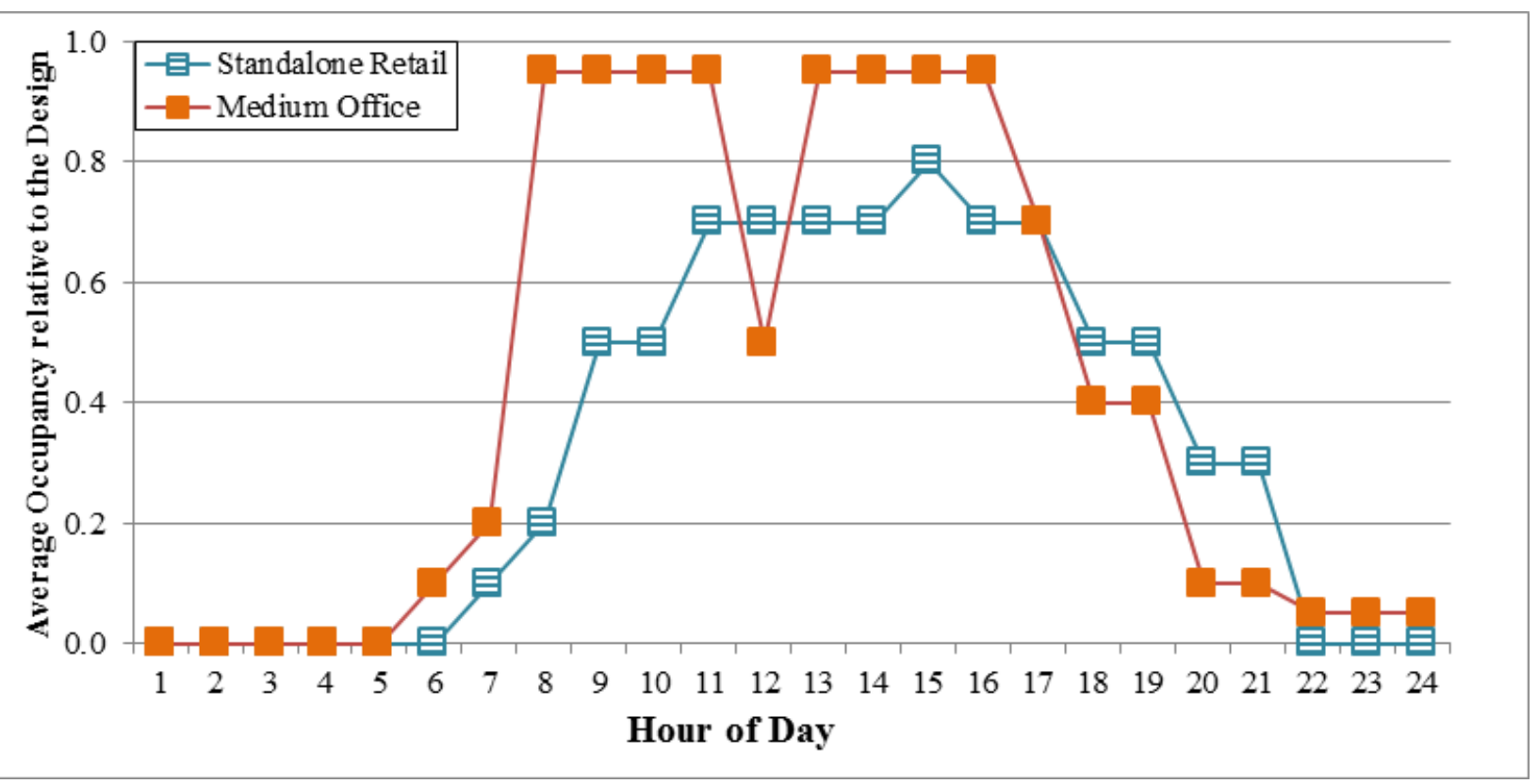

Figure 15: Weekday Occupancy Schedules for the Four Building Types

- Because the retail building has many hours with much lower occupancy than the peak, it benefits from DCV control for both heating and cooling. All the climates have over $30 \%$ heating energy savings in Retail, and most of them have over 10\% cooling energy savings. (Appendix B)

- The absolute energy savings range from $9.6 \mathrm{MWh} / \mathrm{yr}$ to $77 \mathrm{MWh} / \mathrm{yr}$ for the retail building and 1.2 MWh/yr to $35 \mathrm{MWh} / \mathrm{yr}$ for the office building. The annual energy cost savings are in the range between $\$ 1,336 / \mathrm{yr}$ and $\$ 6,765 / \mathrm{yr}$ for the retail building. For office, except San Francisco, the energy savings ranges from $1.2 \mathrm{MWh} / \mathrm{yr}$ to $35 \mathrm{MWh} / \mathrm{yr}$, the corresponding cost savings is $\$ 167$ to $\$ 3,100 /$ year.

\subsubsection{Summary}

All three individual control strategies achieve energy and cost savings. Figure 16 illustrates the range of percent savings across all 11 locations for the 2 building types. Overall, replacement of constant-speed fan control with multi-speed fan control yields the most energy savings: between $10 \%$ and $37 \%$ for the stand-alone retail building and $19 \%$ and $53 \%$ for the medium office building. DCV controls also yield energy and cost savings, especially for the retail building in colder climates. The percent HVAC energy and cost savings from DCV controls range between $10 \%$ and $28 \%$ for the retail building and up to $10 \%$ savings for the office building. In comparison with multi-speed fan and DCV controls, an integrated airside economizer has relatively small energy and cost savings.

Figure 17 and Figure 18 show the ranges of absolute total energy and cost savings from each individual control strategy. Multi-speed fan use results in energy savings in the range between 27.3 MWh/yr and $42 \mathrm{MWh} / \mathrm{yr}$ for the retail building, and in the range between $71 \mathrm{MWh} / \mathrm{yr}$ and $95 \mathrm{MWh} / \mathrm{yr}$ for the medium office building. DCV use results in energy savings up to 77 $\mathrm{MWh} / \mathrm{yr}$ for the retail stand-alone, and up to $35 \mathrm{MWh} / \mathrm{yr}$ for medium office building. The energy cost savings from multi-speed fan controls range between $\$ 2,000 / \mathrm{yr}$ and $\$ 4,895 / \mathrm{yr}$ for the retail building and between $\$ 6,172 / \mathrm{yr}$ and $\$ 13,188 / \mathrm{yr}$ for the office building. 

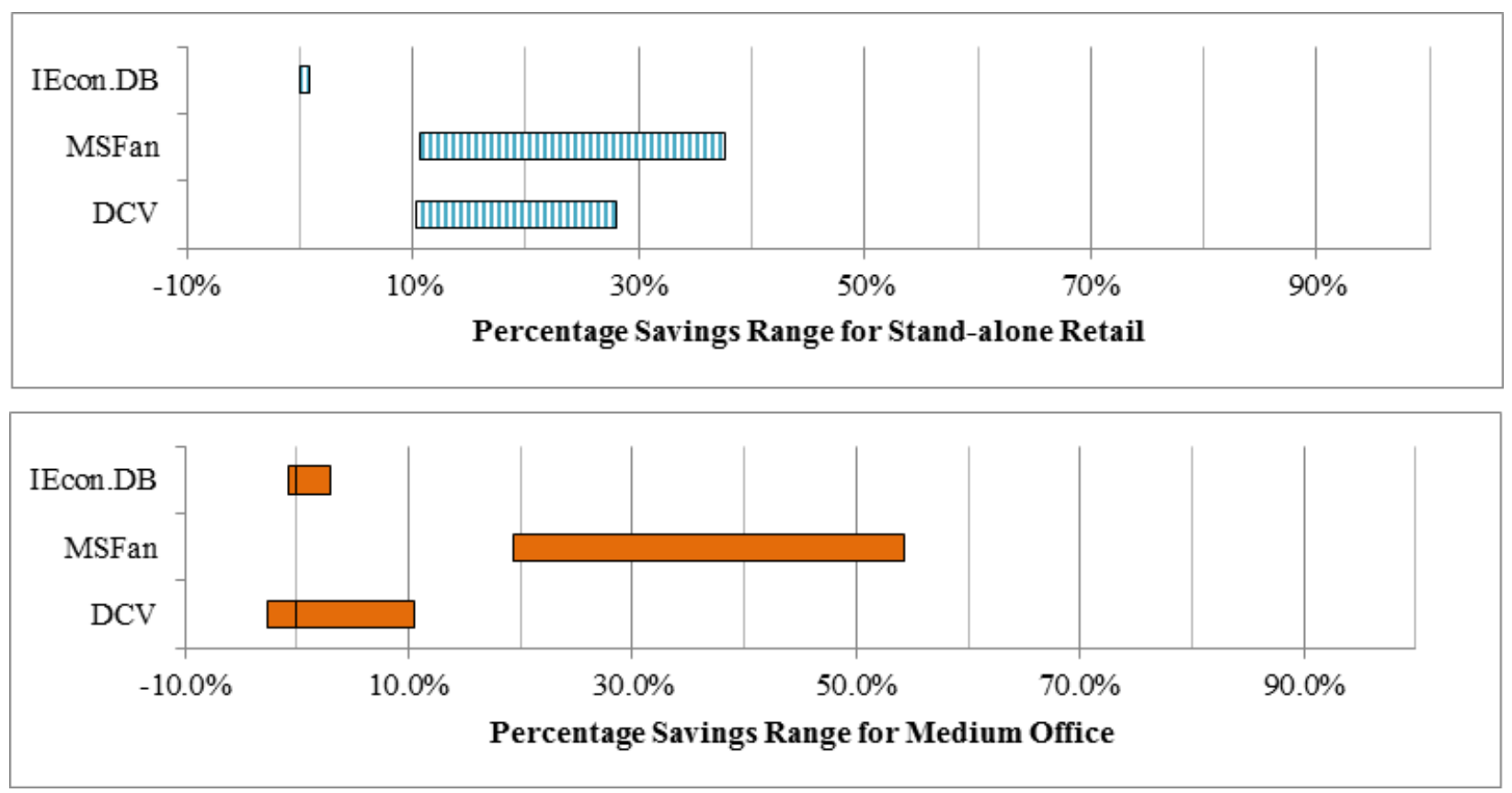

Figure 16: Range of Percentage Savings from Individual Control Strategies Across All 11 Locations for the two Building Types
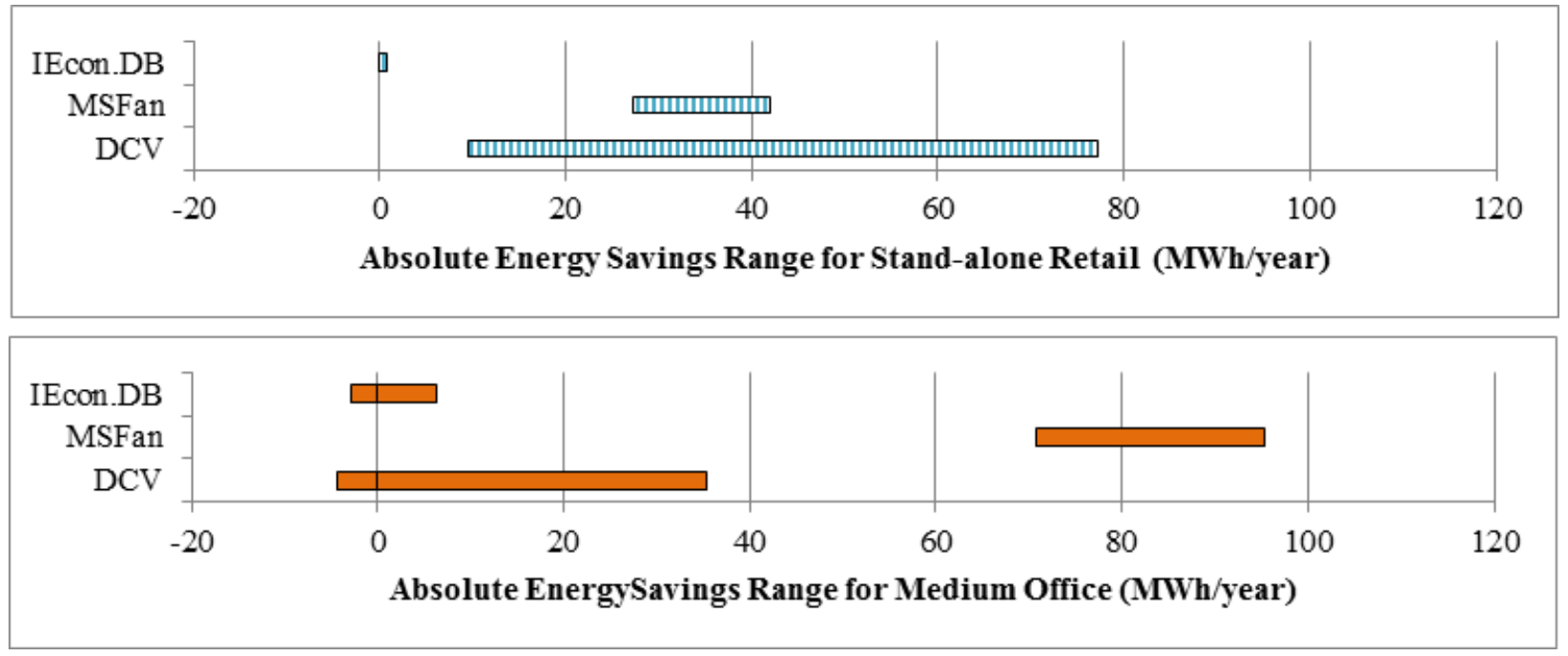

Figure 17: Range of Absolute Energy Savings from Individual Control Strategies Across All 11 Locations for the two Building Types 

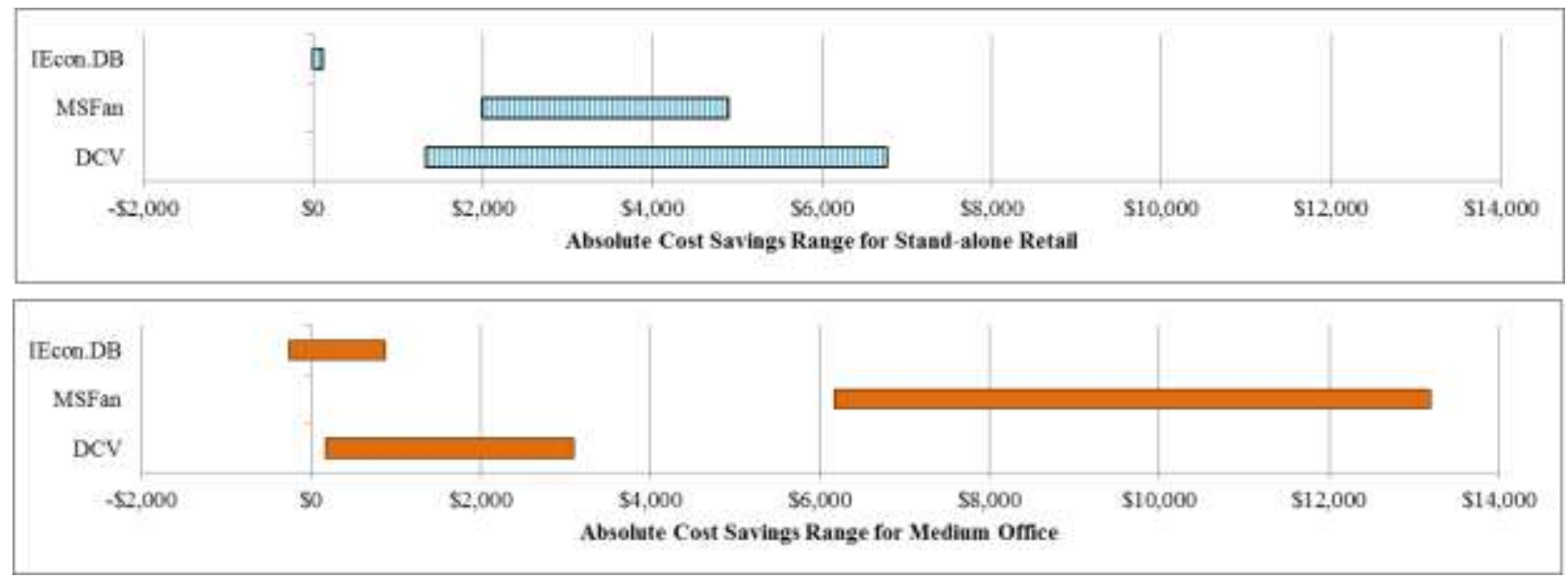

Figure 18: Range of Absolute Energy Cost Savings from Individual Control Strategies Across All 11 Locations on the Two Building Prototypes

\subsection{Energy and Cost Savings from Combined Control Strategies}

As stated in Section 5.2, two individual control strategies, multi-speed fan control and DCV, showed significant reduction in HVAC energy, while using of an integrated economizer had smaller impact. Therefore, only the combined control strategies of multi-speed fan control and DCV (Case 5: NIEcon.MSFan.DCV1) is discussed in detail in this section. However, the range of savings from all combinations is provided.

For the two building types, Figure 19 to Figure 22 presents the HVAC energy consumption and cost for Case 5 and the baseline. The percentage numbers in each figure indicate the difference between the baseline and Case 5. The following conclusions can be drawn from these figures:

- Combining multi-speed fan control and DCV results in greater than 35\% savings (both energy and cost) for the retail building across all the locations, with the maximum savings of $51 \%$. Saving in the office building range between $25 \%$ and $57 \%$ across the locations.

- Because of the interaction and synergies between multi-speed fan control and DCV, combining them may result in more savings than the sum of their individual savings. For example, for the medium office building in Seattle, multi-speed fan only (Case 3) has 42.6\% HVAC energy savings and DCV only (Case 4) has 3.8\% savings. In contrast, combining the above two control strategies (Case 5) achieves 53.8\% savings, which is $7.3 \%$ higher than the sum of the individual savings. The additional savings resulting from combining the two control strategies are because of the reduction in the amount of outdoorair intake; DCV increases the percentage of time the unit is in the ventilation mode, which then contributes to more savings from multi-speed fan control. The extra interaction savings could be observed for all the location in both building types, as shown in Appendix C.

- $\quad$ The annual electricity savings in the retail building range between $\$ 5,500 / \mathrm{yr}$ and $\$ 11,200 / y r$. Although the office building showed lower percentage savings, the absolute cost savings ranging between $\$ 7,800 / \mathrm{yr}$ and $\$ 14,000 / \mathrm{yr}$, which are higher than the retail building. The DCV control does not benefit the office building (Figure 22) as much as the retail building because of the flat occupancy profile in office building; therefore, the 
percent savings are lower than the retail building. But this package still results in cost savings of at least $25 \%$ across all the climate locations.

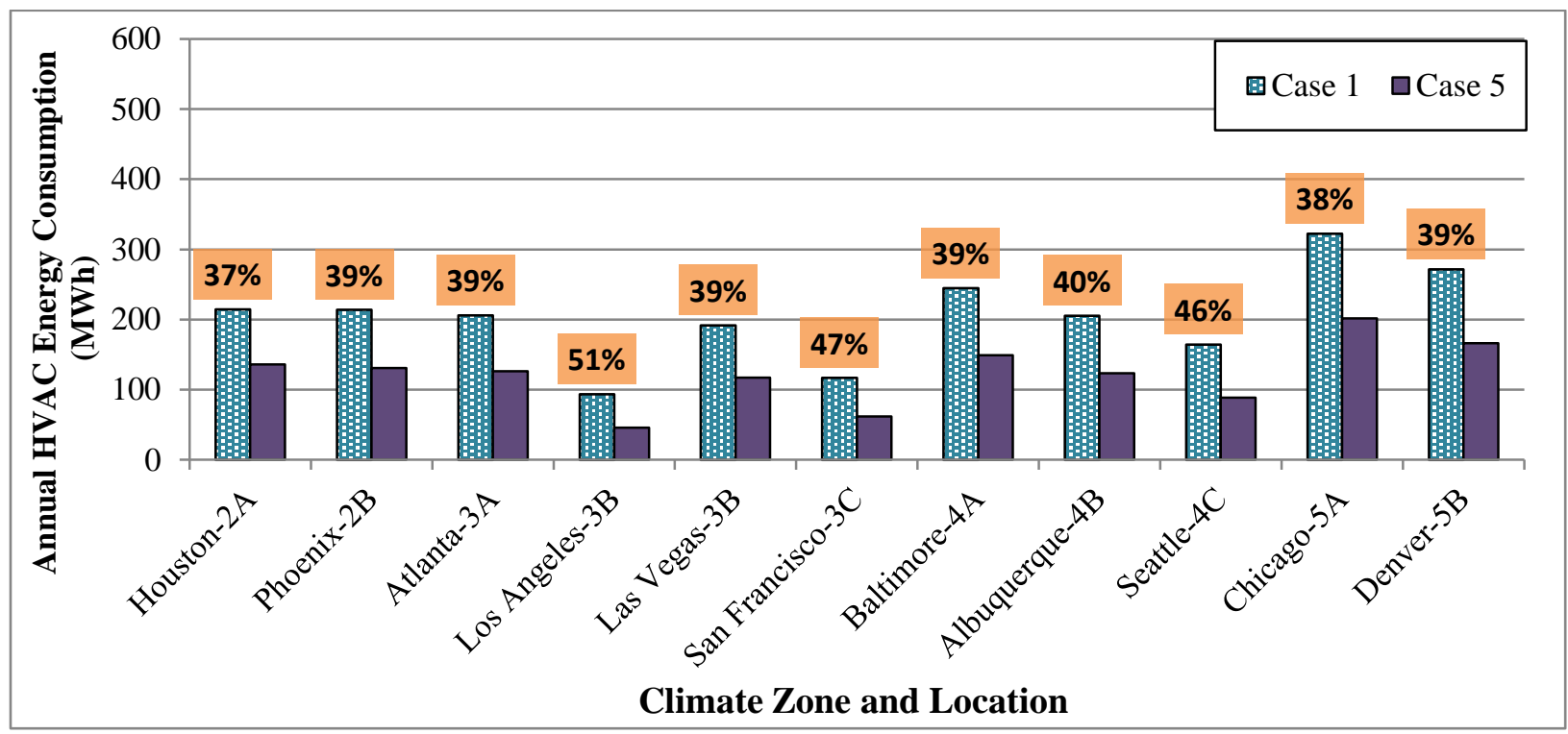

Figure 19: HVAC Energy Savings from Multi-speed Fan and DCV Controls for the Standalone Retail Building (Case 1 vs. Case 5)

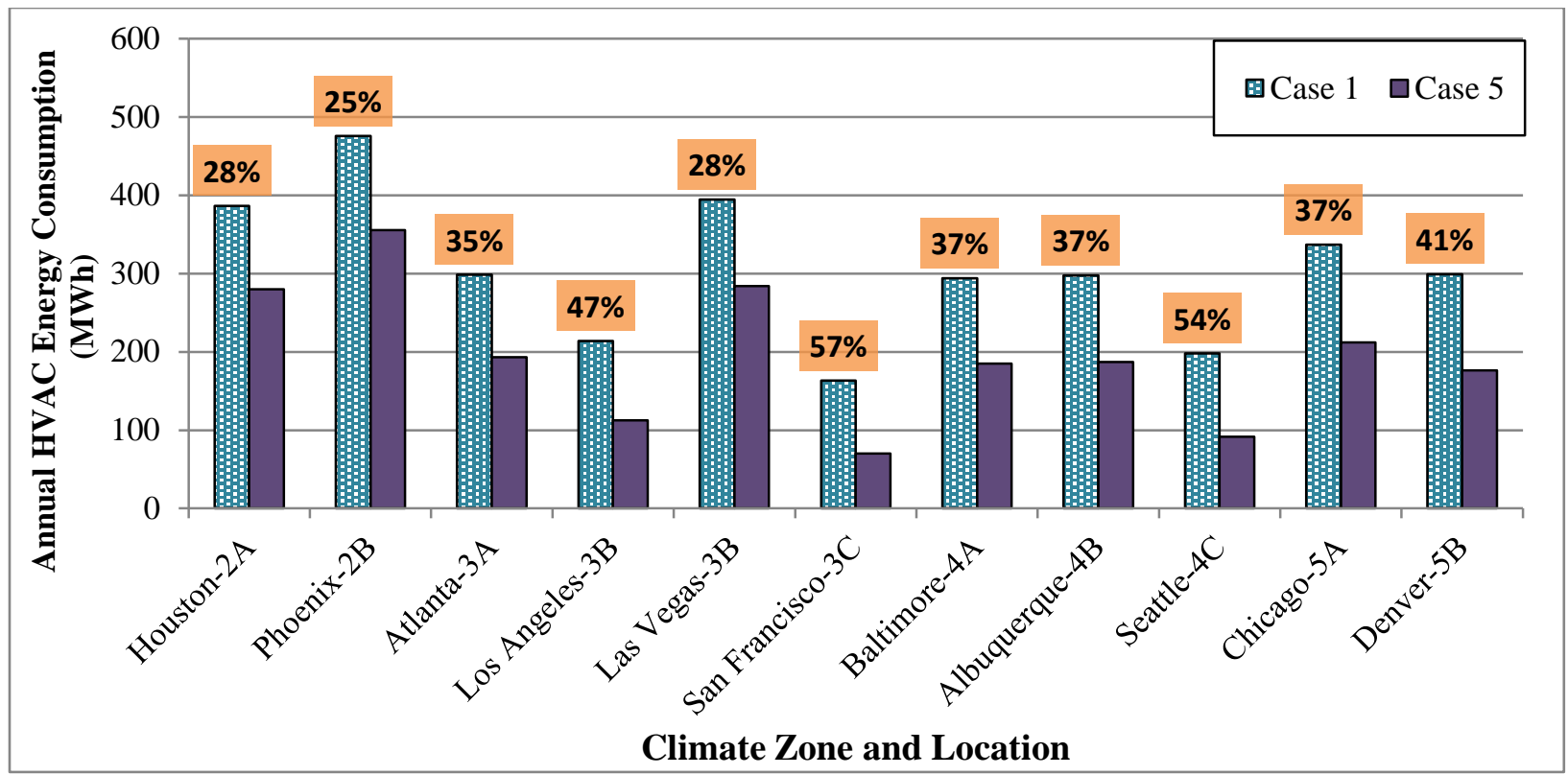

Figure 20: HVAC Energy Savings from Multi-speed Fan and DCV Controls for the Medium Office Building (Case 1 vs. Case 5) 


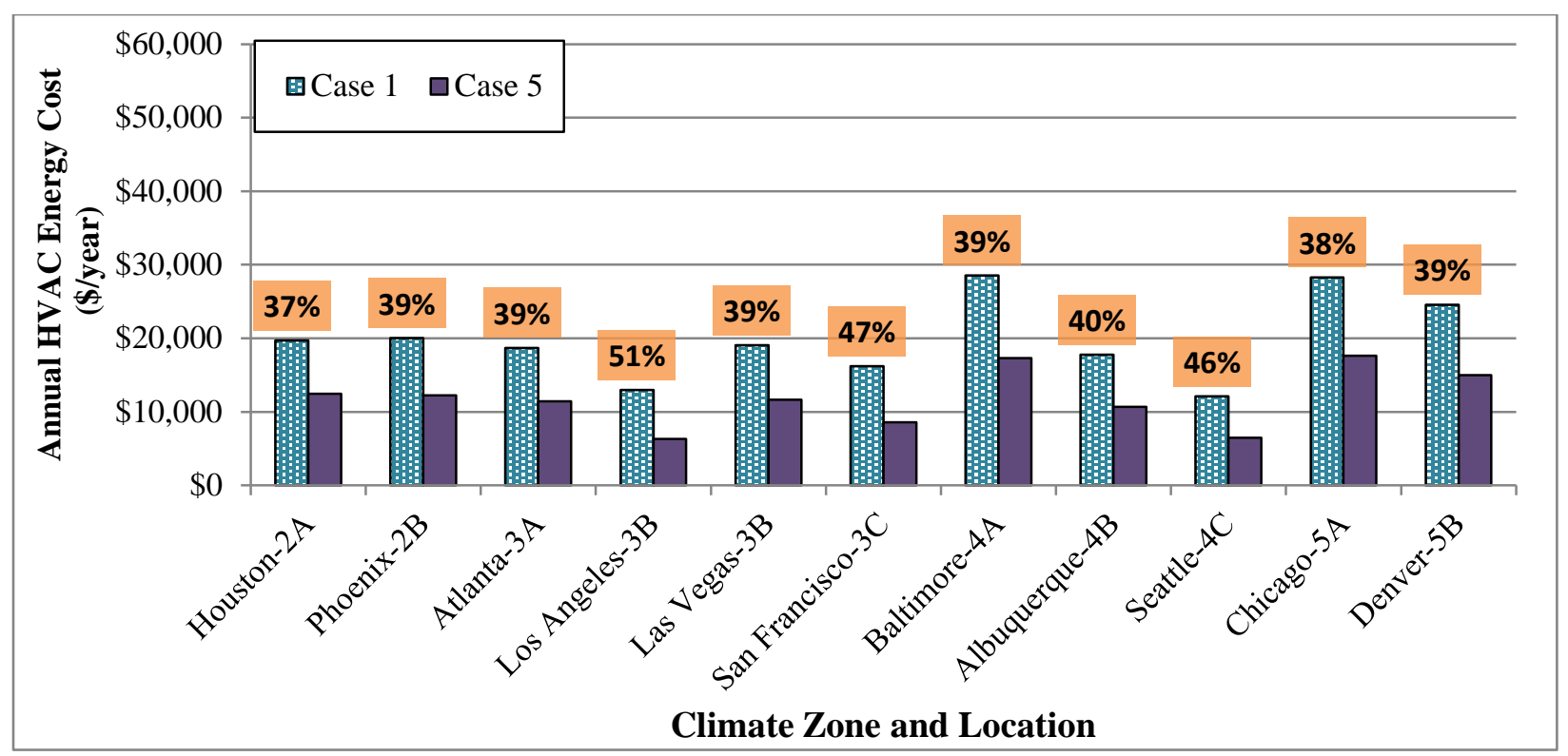

Figure 21: HVAC Cost Savings from Multi-speed Fan and DCV Controls for the Standalone Retail Building (Case 1 vs. Case 5)

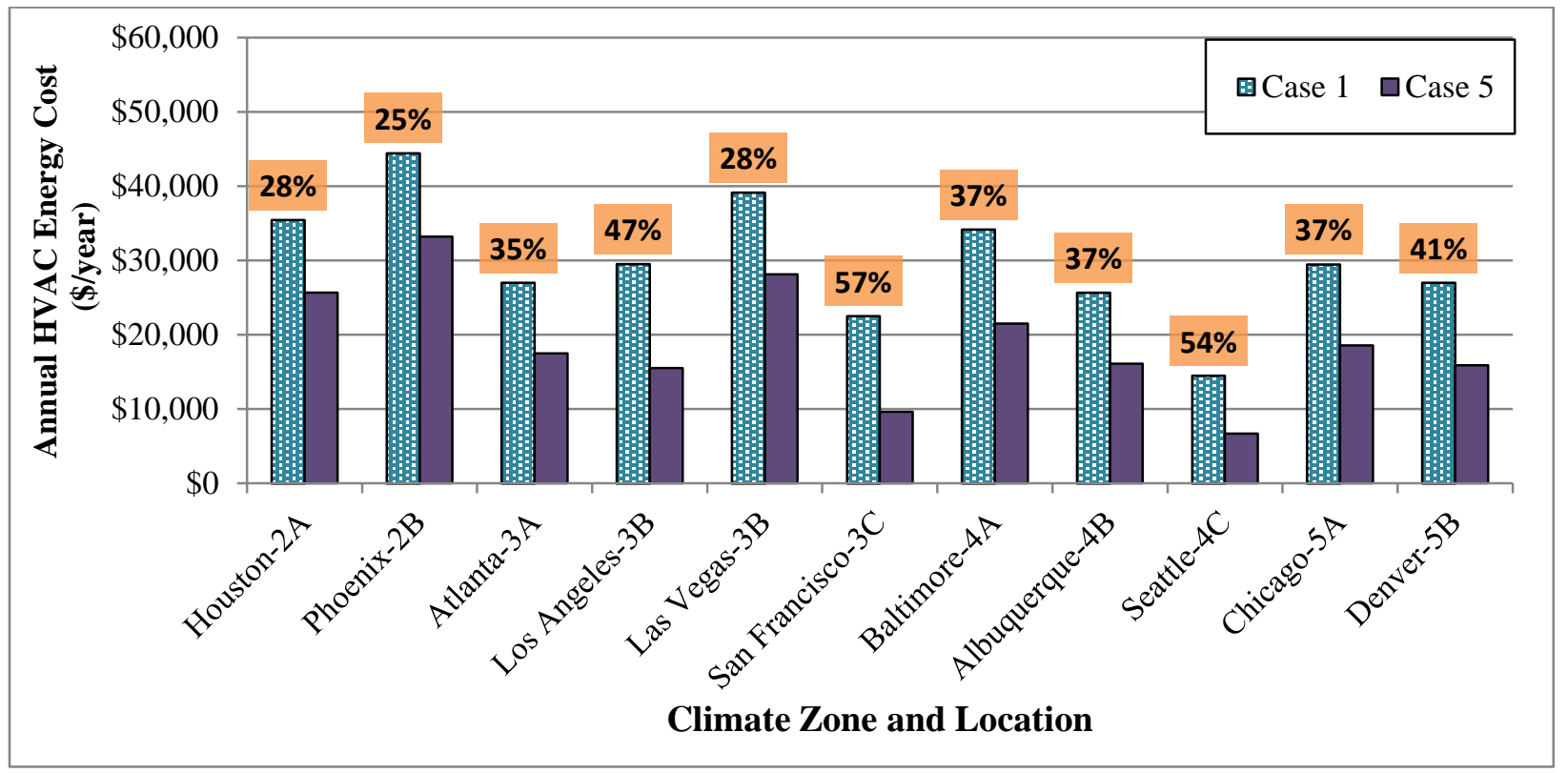

Figure 22: HVAC Cost Savings from Multi-speed Fan and DCV Controls for the Medium Office Building (Case 1 vs. Case 5)

Figure 23 shows the range of the percent savings for all combinations analyzed for this study together with the three individual control strategies. Adding an integrated economizer on top of other controls has negligible impact on energy and cost savings. For example, comparing Case 8 with Case 5 for the office building, enabling integrated economizer control only results in an additional $0 \%$ to $6.6 \%$ savings, which corresponds to $10.8 \mathrm{MWh} / \mathrm{yr}$ energy savings and $\$ 1,492 / \mathrm{yr}$ cost savings.

Detailed results for energy cost savings are provided in Appendix B (Table B-7 and Table B- 8). In all tables, the cost savings are shown as both absolute values and the percentages of the base 
case (Case 1). The difference between the tabulated cost savings for any two cases for a specific building type and location provides the average annual HVAC energy cost savings when changing from one combination of packaged-unit control strategies to another.
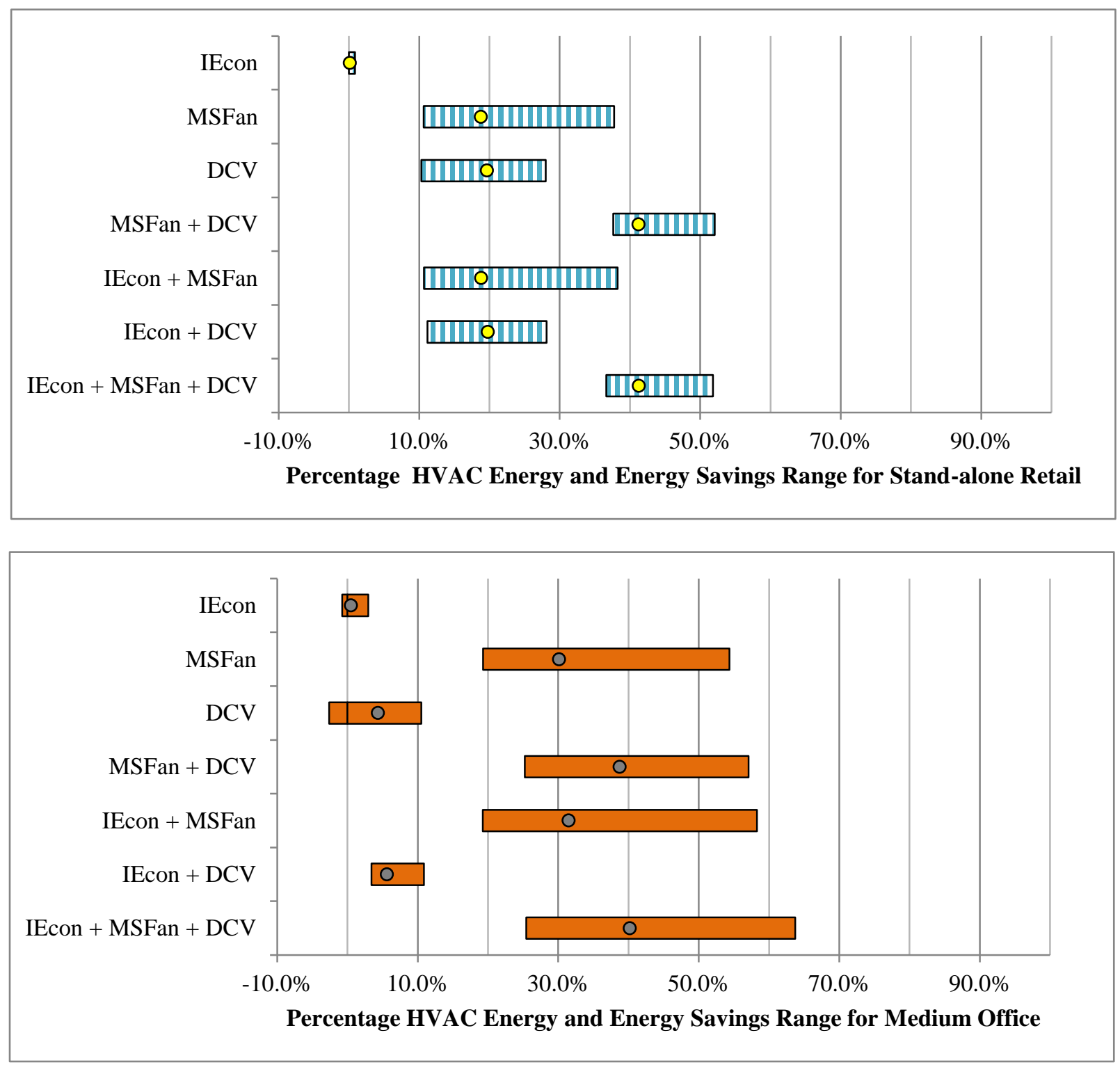

Figure 23: Percentage Savings Range for combinations of each case for all locations 


\section{Controller Cost Analysis}

One major objective of this study is to encourage the development of a cost-effective controller that saves significant energy for packaged heat pumps on existing buildings. The maximum installed cost of advanced controllers that will yield a specific simple payback period is important for potential users to evaluate the financial merits of installing advanced controllers but also for vendors and developers in pricing their advanced control products. Because an addon controller is usually associated with each packaged unit, the total energy cost savings for a whole building needs to be normalized before calculating the maximum acceptable controller installed cost. Based on the cost savings per unit and the assumed simple payback period, the maximum total installed cost per controller can be calculated by using Equation 2. Tables in Appendix D list the results that achieve a 3-year simple payback period for different cases covering all 8 advanced control combinations, 11 locations, and 2 building types. The results are based on the numbers of packaged units specified for the prototype buildings in Table 2 ( 4 for the stand-alone retail building, 15 for the medium office building). In addition, all packaged units on the building are assumed to be retrofitted with the advanced controller so that the total savings possible for the building are achieved.

Controllers with different combinations of advanced control capabilities are likely to have different manufacturing and installation costs. Controllers with greater functionality will likely cost more. On the other hand, the examined control strategies have different degrees of impact on energy cost savings, as discussed in Section 5. Controllers with greater functionality (actually, the best combination of functionality) provide greater energy and cost savings. Therefore, analysis of the savings provided by a controller relative to its cost is important. We examine this by determining the maximum total installed cost per controller that yields specific simple payback periods for controllers with different combinations of control functionality.

Figure 23 in Section 5 indicates that both multi-speed fan control and DCV yield significant energy and cost savings. Therefore, the following four scenarios are considered:

- Scenario 1: the advanced controller with only multi-speed supply-fan control (Case 3) is retrofit to an existing packaged unit having a base case controller with only non-integrated differential dry-bulb economizer (Case 1).

- Scenario 2: the advanced controller with only DCV (Case 4) is retrofit to an existing packaged unit having a base case controller (Case 1)

- Scenario 3: the advanced controller with both multi-speed fan control and DCV (Case 5) is retrofit to an existing packaged unit having a base case controller (Case 1).

- $\quad$ Scenario 4: the advanced controller with an integrated differential dry-blub economizer control, multi-speed supply-fan control, and DCV (Case 8) is retrofit to an existing packaged unit having a base case controller (Case 1).

\subsection{3-Year Simple Payback}

The maximum total installed costs per advanced controller for the above four scenarios that provides a 3-year payback period are compared in Figure 24 and Figure 25 for the two building types (The results are also provided in Table D-1 and Table D-2 in Appendix D). The dots on these two figures are the maximum total installed cost per controller for each of the four selected scenarios. The grey bar is the range of the controller cost for all the 4 scenarios. 


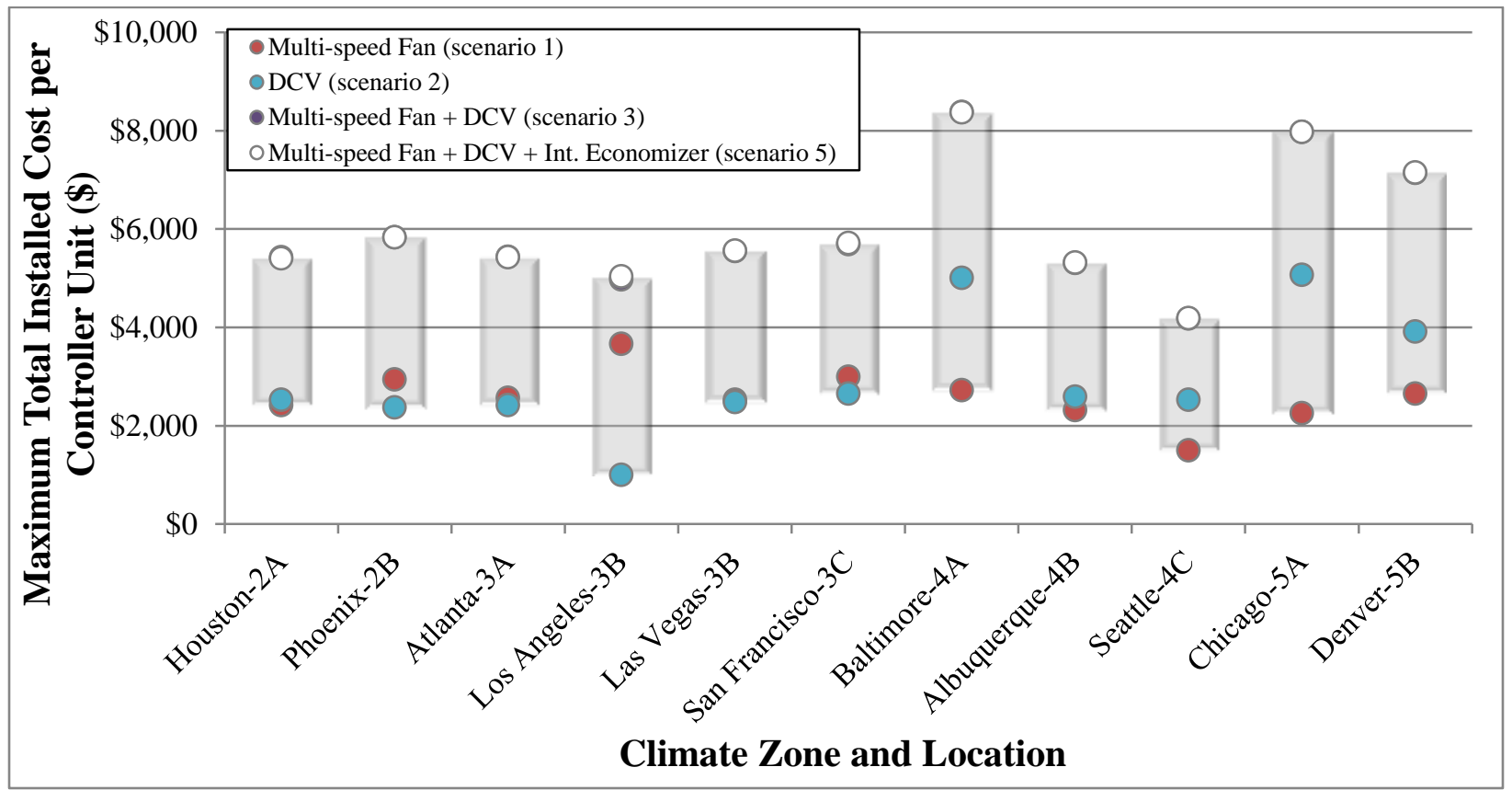

Figure 24: Maximum Total Installed Cost per Controller Unit to Achieve a Payback Period of 3 Years for the Stand-alone Retail

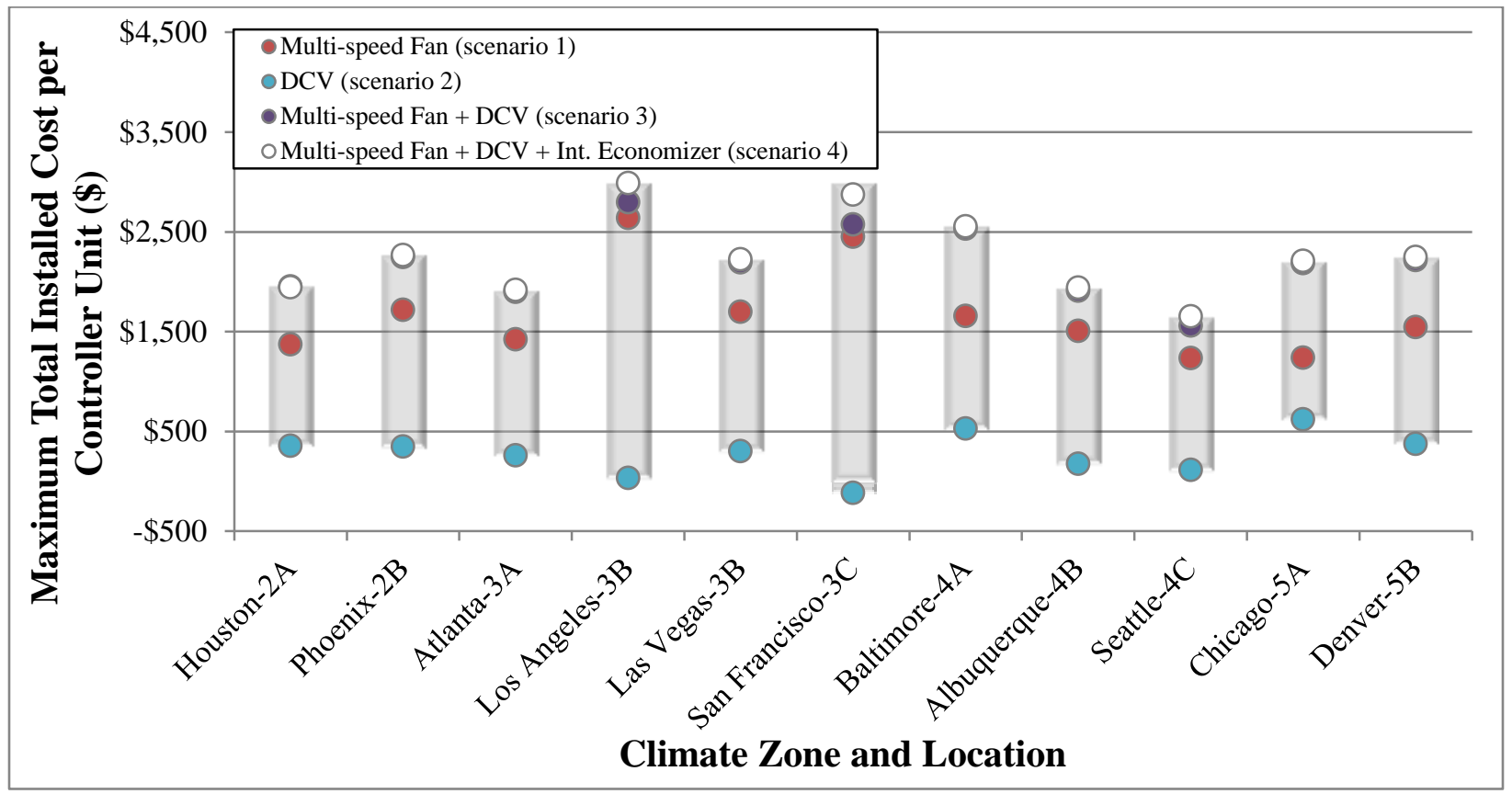

Figure 25: Maximum Total Installed Cost per Controller Unit to Achieve a Payback Period of 3 Years for the Medium Office

These figures show that the maximum total installed controller cost per packaged unit providing a 3-year payback period varies with the four scenarios. For both building types, Scenarios 3 and 4 have the largest maximum cost per controller for all 11 locations. Combining multi-speed fan control with DCV (Scenario 3) shows almost the same maximum total installed costs as the full 
control package (Scenario 4). These two scenarios have slightly different maximum controller cost only in Los Angeles (3A) and San Francisco (3C) for the medium office building. This observation is consistent with the discussion in Section 5. For the medium office building, Scenario 1 with multi-speed fan control achieves a much higher maximum controller cost than Scenario 2 with DCV for all 11 locations. However, for the retail building, these two scenarios have minor differences in their maximum controller costs for most locations.

For a given scenario, the maximum controller cost differs largely with system capacities. The retail building has much larger heat pump capacities than the medium office building. Thus, the maximum acceptable controller cost is much higher in the retail building. For example, Scenario 4 in Baltimore (4A) allows over $\$ 8,374$ controller cost to achieve a full economic pay back within 3 years for the retail building while it allows only $\$ 2,553$ for the office building.

Electricity prices also have a large impact on the calculated maximum controller costs. Higher controller costs are usually seen in the locations with high electricity prices. For example, for the medium office building, Scenario 4 has the maximum controller cost of \$2,986 in Los Angeles and $\$ 2,872$ in San Francisco, where the electricity prices are high. In contrast, Scenario 4 has the maximum controller cost of $\$ 1,652$ in Seattle, where the electricity price is low.

Figure 26 and Figure 27 show the range of the maximum acceptable installed cost to achieve 3year payback across all 11 locations for both building types. For multi-speed fan control alone (Scenario 1), the controller cost is about half of that from the full package. In the retail building, the maximum installed cost per unit for adding multi-speed fan control ranges from $\$ 2,200$ to $\$ 3,600$, except for Seattle with a lower acceptable cost at about $\$ 1,500$. In the medium office building, the maximum installed cost per unit for adding multi-speed fan control ranges from $\$ 1,200$ to $\$ 2,600$.

For DCV only (Scenario 2), the maximum installed cost per unit ranges from $\$ 2,400$ to $\$ 5,000$, except for Los Angeles with a lower acceptable cost at about \$1,000. In the medium office building, the maximum installed cost per unit for DCV only ranges from 0 to $\$ 600$ in Chicago. However, adding DCV only is not cost effective in mild climates such as Los Angeles and San Francisco because the maximum acceptable cost is around 0 .

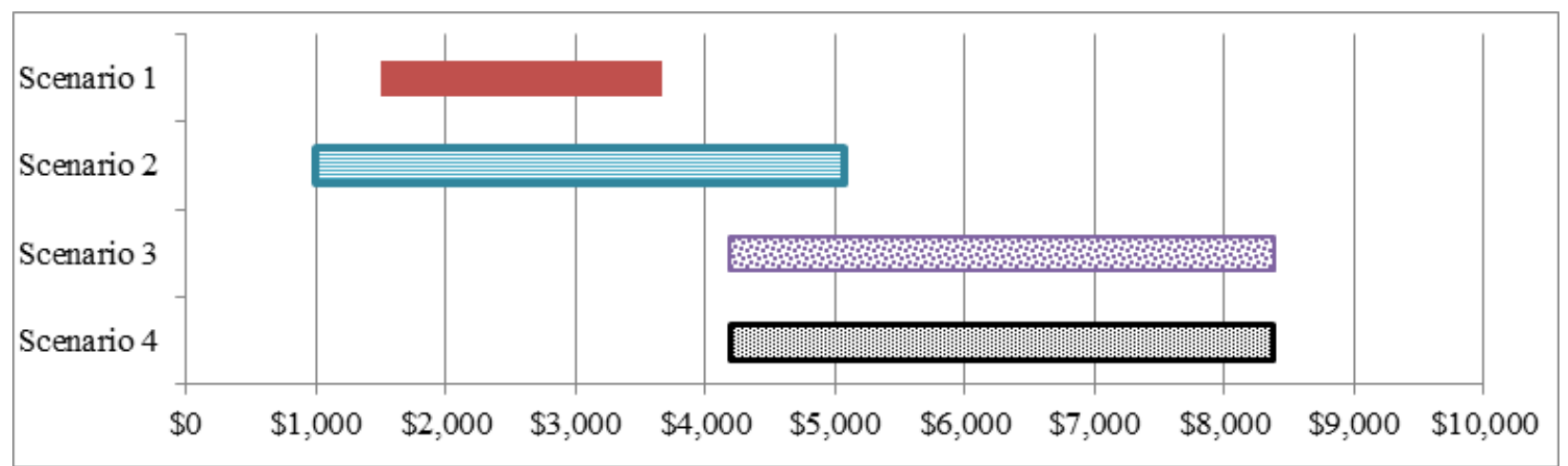

Figure 26: Range of Maximum Total Installed Cost per Controller Unit to Achieve 3-year Payback for Stand-alone Retail 


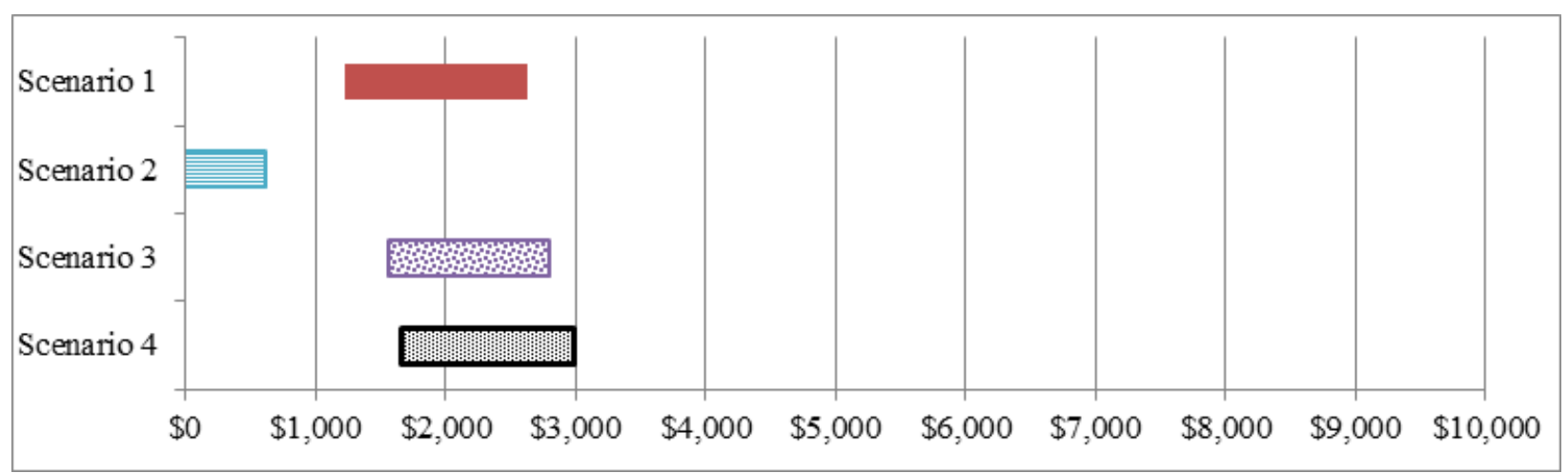

Figure 27: Range of Maximum Total Installed Cost per Controller Unit to Achieve 3-year Payback for Medium Office

\subsection{5-Year Simple Payback}

Based on the results in Table D-1 and Table D-2 that are calculated from the simple payback period of 3 years and the blended utility rates in the year of 2010 (Table 7), the maximum installed cost per controller can be easily calculated for other payback periods and utility rates. For example, for the medium office building in Houston, if the maximum total installed controller cost assuming a 3-year simple payback period at the original utility rate is known to be $\$ 1,943$ for Scenario 4 retrofit, the controller cost for 5-year simple payback at the original utility rate is equal to $\$ 1,943 / 3 \times 5=\$ 3,238$; the cost for 5 -year simple payback at $5 \%$ increased rate equals $\$ 3,238 \times(1+0.05)=\$ 3,400$.

In comparison with the results for 3-year payback shown previously, the acceptable cost for 5year payback is $66 \%$ higher. The full package (Scenario 4) can afford a maximum initial cost of $\$ 7000 /$ unit to $\$ 14,000 /$ unit for the retail and $\$ 2,800 /$ unit to $\$ 5,000 /$ unit for the office building. See Figure 28 and Figure 29 for details. 


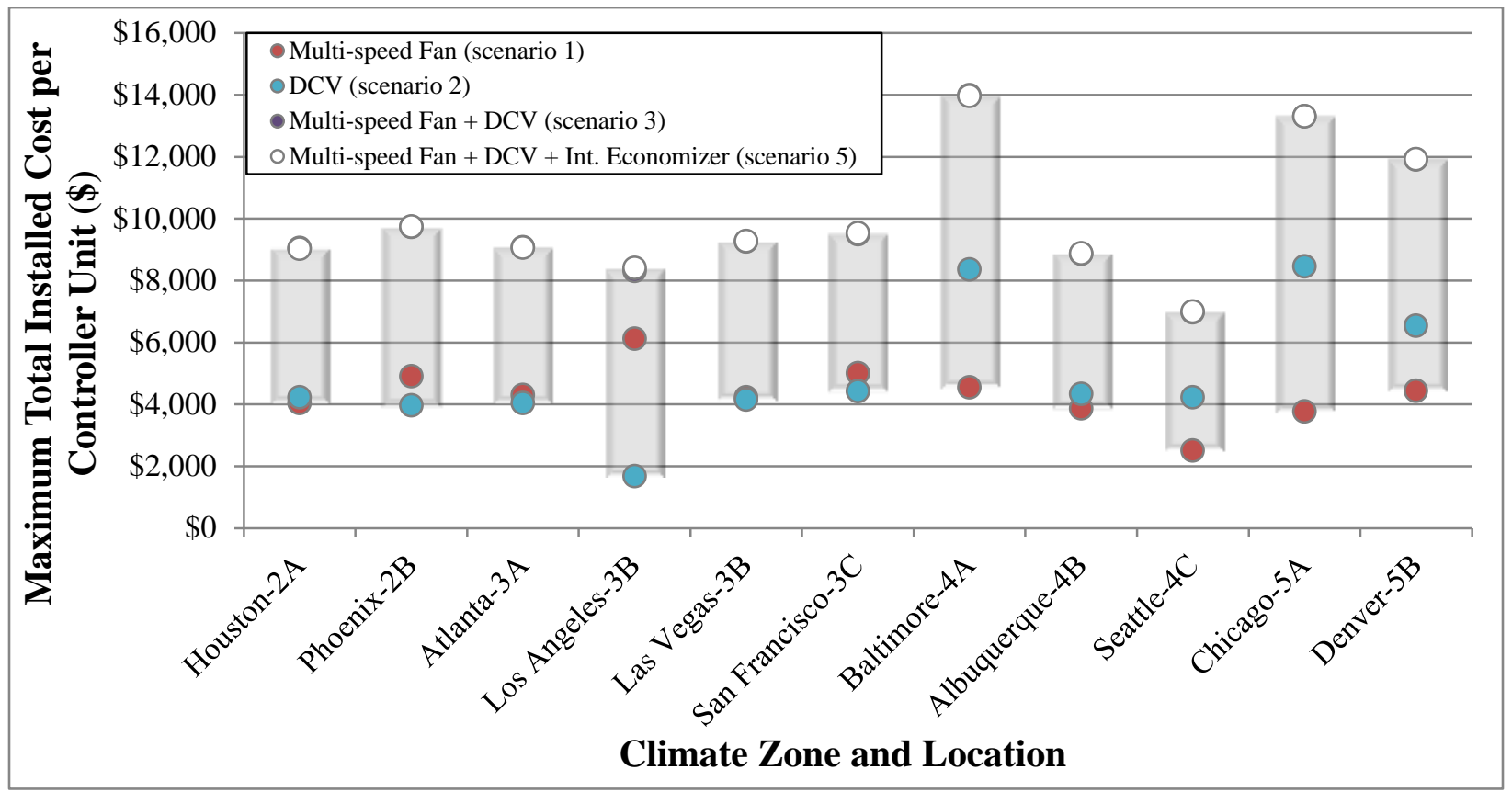

Figure 28: Maximum Total Installed Cost per Controller Unit to Achieve a Payback Period of 5 Years for the Stand-alone Retail

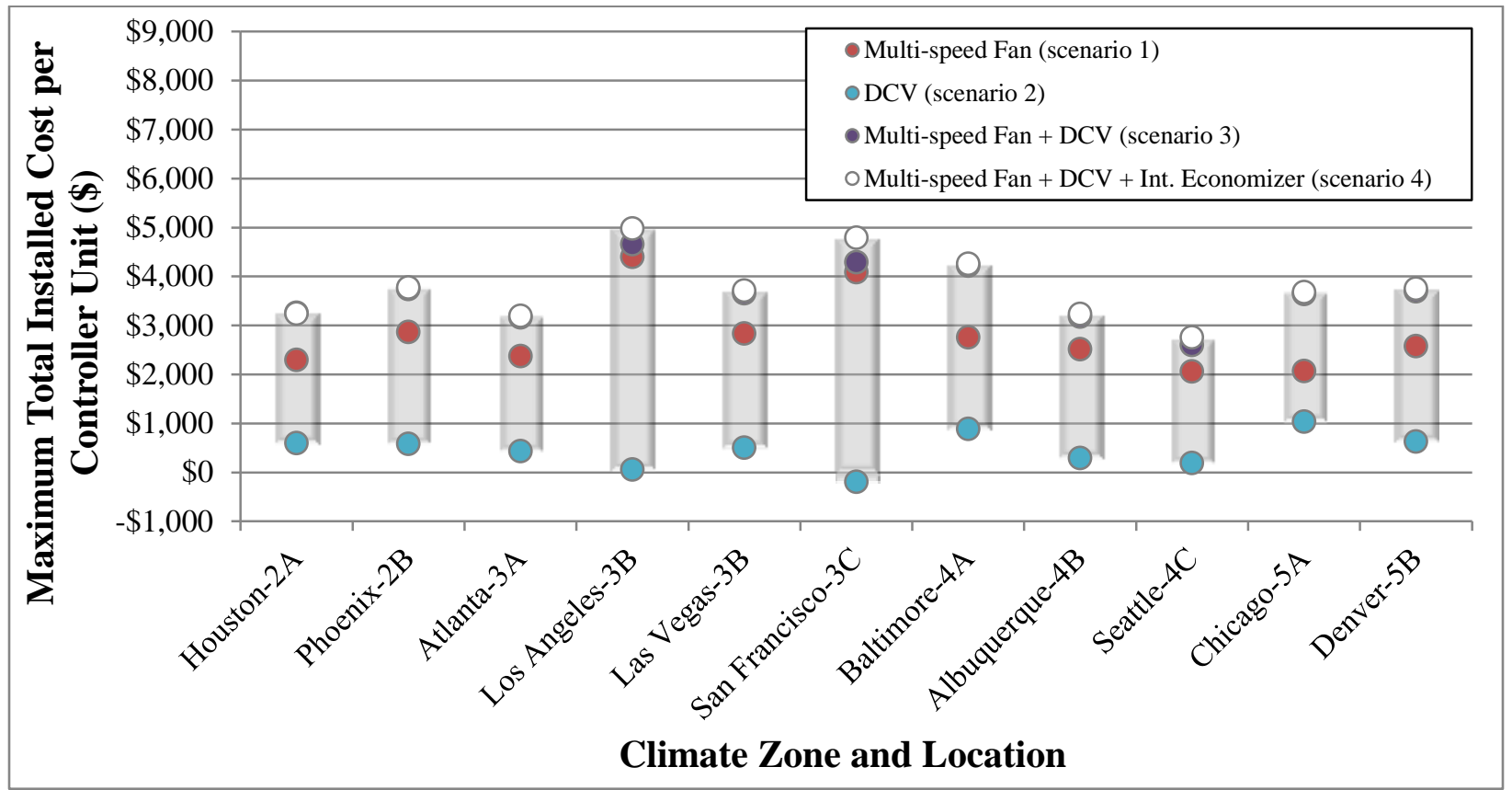

Figure 29: Maximum Total Installed Cost per Controller Unit to Achieve a Payback Period of 5 Years for the Medium Office 


\section{Summary and Future Planned Work}

The summary of the energy savings and economics of advanced control strategies for packaged heat pumps and the recommend future work is presented in this section.

\subsection{Summary}

The results based on simulations presented in Section 5 and 6 shows that advanced control combining an integrated airside economizer, DCV and multi-speed fan result in significant energy and cost savings across all locations and building types. The maximum percentage of HVAC energy savings relative to the base case is more than $50 \%$ for both building types. The maximum saving occurs in Los Angeles (3B) for the stand-alone retail building and San Francisco (3C) for the medium office. The smallest percentage savings is about $37 \%$ in Houston (2A) for the retail, and $26 \%$ in Phoenix (2B) for the medium office. The average energy saving for this full package is $41 \%$ in retail building and $40 \%$ in medium office building across 11 locations.

The annual absolute HVAC energy savings relative to the base case lies in the ranges between 48 $\mathrm{MWh} / \mathrm{yr}$ to $121 \mathrm{MWh} / \mathrm{yr}$ for the retail, and $104 \mathrm{MWh} / \mathrm{yr}$ to $126 \mathrm{MWh} / \mathrm{yr}$ for the medium office. The maximum savings for both building types occur in Denver (5B). The average absolute savings across the 11 locations is about $82 \mathrm{MWh} / \mathrm{yr}$ for the retail, and $113 \mathrm{MWh} / \mathrm{yr}$ for the medium office.

Combining the three control strategies results in significant electricity cost savings ranging between $\$ 5,600 / \mathrm{yr}$ and $\$ 11,170 / \mathrm{yr}$ for the retail and $\$ 8,260 / \mathrm{yr}$ and $\$ 14,930 / \mathrm{yr}$ for the medium office. The maximum absolute cost savings relative to the base case occur for Baltimore (4A) for the retail and Los Angeles (3B) for the medium office. The average percentage cost savings across the 11 locations is about $\$ 8,000 / y r$ for the retail, and $\$ 11,300 / y r$ for the office building.

Among all three advanced controls investigated, the integrated economizer control has the smallest energy and cost impact. Removing integrated economizer option from the full control package does not have a big impact on the magnitude of energy and cost savings. With the combination of multi-speed fan control and DCV, the percent energy and cost saving ranges between $37 \%$ and $51 \%$ for the retail and from $25 \%$ and $57 \%$ for the medium office. The average of percentage savings across all 11 locations is $41 \%$ for the retail and $39 \%$ for the medium office, which is about $0 \%$ and $1.4 \%$ less than the impact from the full package combining all three control strategies.

The control package combining only DCV and multi-speed fan yields energy savings between 48 to $122 \mathrm{MWh}$ for the retail building and 93 to $125 \mathrm{MWh}$ for the office building. The same control package yields energy cost savings between $\$ 5,575 / \mathrm{yr}$ and $\$ 11,184 / \mathrm{yr}$ for the retail building, and $\$ 7,795 / y r$ to $\$ 13,977 / y r$ for the office building. Except for the office building in Los Angeles and San Francisco, the control package combining only DCV and multi-speed fan achieves almost the same energy and savings as the full package control.

The maximum installed cost per controller that can achieve a 3-year simple payback varies with the building type. If the controller incorporates all considered control strategies (Case 8), the maximum total installed cost varies in the range between $\$ 4,200 /$ unit and $\$ 8,400 /$ unit for the retail building, and between $\$ 1,650$ /unit and $\$ 3,000 /$ unit for the office building. Advanced controllers with the complete set of control features corresponding to Cases 8 will need to have a 
total cost less than these values to provide savings that justify the investment by building owners in the absence of any incentives.

\subsection{Future Work}

Bringing retrofitable advanced control packages rapidly to the mass market to realize the large energy and cost savings potential found in this study will likely require additional information and further development of the technology. Some key needs identified by the project team include the following.

- The energy savings estimated with simulations in this study should be validated with field tests of retrofitable controllers for packaged units that are beginning to enter the marketplace. Testing can be used to validate overall energy savings as well as savings from individual control strategies and specific combinations of control strategies.

- If the cost of advanced controllers on the market exceeds the maximum cost for a payback period commonly found acceptable by building owners, additional technological innovation may be required to lower the cost of advanced controllers to acceptable levels. This technology development may be best performed in government-industry collaborations (e.g., national laboratories with building controller manufacturers).

- Development of a guide or software tool for building owners and managers to assist them in making decisions to install advanced controllers may be important to accelerate the market penetration of advanced controllers, which based on this study can save considerable energy (approximately $25 \%$ to $60 \%$ of the energy consumption of rooftop units over a broad range of U.S. climates).

- In addition to the measures considered (airside economizer, multiple supply-fan speed control, and DCV), other advanced control technologies applicable to packaged rooftop units should be evaluated. Such technologies include optimal start times, closing outdoorair dampers during morning warm up or cool down periods, and fully variable-speed control of the supply fan, condenser fan and compressor.

- The impact assessment was made for a single set of predefined values for the key control parameters (Table 6). Because these values are likely to vary in field applications, it is worthwhile to investigate the impact on energy and cost savings of using different parameter values. The control parameters could even be optimized. 


\section{References}

ASHRAE. 1999. ASHRAE Standard 62.1-1999: Ventilation for Acceptable Indoor Air Quality. American Society of Heating, Refrigerating and Air-Conditioning Engineers Inc., Atlanta, GA.

ASHRAE. 2010. ASHRAE Standard 62.1-2010: Ventilation for Acceptable Indoor Air Quality. American Society of Heating, Refrigerating and Air-Conditioning Engineers Inc., Atlanta, GA.

Brandemuehl M.J. and J.E. Braun. 1999. The impact of demand-controlled and economizer ventilation strategies on energy use in buildings. ASHRAE Transactions 105(2): 39-50.

Deru, M., K. Field, D. Studer, K. Benne, B. Griffith, P. Torcellini, B. Liu, M. Halverson, D. Winiarski, M. Yazdazian, J. Huang, and D. Crawley. 2011. U.S. Department of Energy Commercial Reference Building Models of the National Building Stock. NREL/TP-550046861, National Renewable Energy Laboratory, Golden, CO.

DOE. Department of Energy. 2010. EnergyPlus Energy Simulation Software, (version 7.1), US Department of Energy, Washington, DC.

EIA. Energy Information Administration. 2003. Commercial Buildings Energy Consumption Survey 2003. U.S. Department of Energy, Washington, D.C. Last accessed in July 2011 at http://www.eia.doe.gov/emeu/cbecs/contents.html.

EIA. Energy Information Administration. 2011. Electricity and Natural Gas Prices. Last accessed in July 2011 at http://www.eia.gov/electricity/data.cfm\#sales and http://www.eia.gov/dnav/ng/ng_pri_sum_dcu_nus_m.htm.

Field, K., M. Deru, and D. Studer. 2010. Using DOE commercial reference buildings for simulation studies. Proceedings of the 4th National Conference of IBPSA-USA, pp. 85-93. New York, NY.

Fumo, N., P. Mago, and R. Luck. 2010. Methodology to estimate building energy consumption using EnergyPlus benchmark models. Energy and Buildings 42 (12): 2331-2337.

Roth, K.W., J. Dieckmann, and J. Brodrick. 2003. Demand control ventilation. ASHRAE Journal 45(7): 91-92.

Stanke, D. 2006. System operation: dynamic reset operations. ASHRAE Journal 48(12): 18-32.

Taylor, S.T. and C.H. Cheng. 2010. Economizer high limit controls and why enthalpy economizers don't work. ASHRAE Journal 52(11): 12-28.

Wang W., S. Katipamula, Y. Huang, and M.R .Brambley. 2011. Energy Savings and Economics of Advanced Control Strategies for Packaged Air-Conditioning Units with Gas Heat. PNNL20955, Pacific Northwest National Laboratory, Richland, WA. 


\section{Appendix A \\ Prototype Building Characteristics}


Table A- 1: Key Geometric, Envelope, HVAC, Water Heating and Internal Load Characteristics for the Stand-alone Retail Building Prototype

\begin{tabular}{|c|c|}
\hline \multicolumn{2}{|l|}{ Geometry } \\
\hline Floor area & $25,000 \mathrm{ft}^{2}$ \\
\hline Aspect ratio & 1.3 \\
\hline Number of floor & 1 \\
\hline Window-to-wall ratio & $7.1 \%$ \\
\hline Floor-to-ceiling height & $20 \mathrm{ft}$ \\
\hline \multicolumn{2}{|l|}{ Envelope } \\
\hline Exterior wall & Steel-frame wall (R-value: 2.4 to 22 ) \\
\hline Roof & Insulation entirely above deck (R-value: 10 to 33 ) \\
\hline Window & $\begin{array}{l}\text { U-value } 0.52 \text { to } 1.03 \text {; } \\
\text { SHGC (solar heat gain coefficient) } 0.04 \text { to } 0.11 \text {; } \\
\text { VT (visible transmittance) } 0.02 \text { to } 0.1\end{array}$ \\
\hline Foundation & 4-in. concrete slab-on-grade floor \\
\hline \multicolumn{2}{|l|}{ HVAC } \\
\hline Type & Single-zone packaged heat pump system \\
\hline Heating & Heat pump with electrical resistance for supplemental heating \\
\hline Cooling & Heat pump (3.23 to 3.7 coefficient of performance - COP) \\
\hline Ventilation & $\begin{array}{l}0.3 \mathrm{cfm} / \mathrm{ft}^{2} \text { in cashier and two sales zones; } \\
0.15 \mathrm{cfm} / \mathrm{ft}^{2} \text { in storage zone. }\end{array}$ \\
\hline System schedule & $\begin{array}{l}7 \text { am-10 pm (weekdays) } \\
7 \text { am-11 pm (Sat.) } 9 \text { am-10 pm (Sun.) } \\
\end{array}$ \\
\hline Cooling set point and setback & $75^{\circ} \mathrm{F} / 86^{\circ} \mathrm{F}$ \\
\hline Heating set point and setback & $70^{\circ} \mathrm{F} / 60^{\circ} \mathrm{F}$ \\
\hline \multicolumn{2}{|l|}{ Internal Load } \\
\hline Occupancy density & $\begin{array}{l}300 \mathrm{ft}^{2} / \text { per person in storage zone } \\
\text { (total } 323 \text { persons in the building) } \\
67 \mathrm{ft}^{2} / \text { per person in four other zones }\end{array}$ \\
\hline Lighting & $\begin{array}{l}1.2 \mathrm{~W} / \mathrm{ft}^{2} \text { in storage zone } \\
3.4 \mathrm{~W} / \mathrm{ft}^{2} \text { in four other zones }\end{array}$ \\
\hline Plug equipment & $\begin{array}{l}0.3 \mathrm{~W} / \mathrm{ft}^{2} \text { in two sales zones; } \\
0.7 \mathrm{~W} / \mathrm{ft}^{2} \text { in storage zone; } \\
2.0 \mathrm{~W} / \mathrm{ft}^{2} \text { in cashier zone. }\end{array}$ \\
\hline
\end{tabular}


Table A- 2: Key Geometric, Envelope, HVAC, Water Heating and Internal Load Characteristics for the Medium Office Building Prototype

\begin{tabular}{|c|c|}
\hline \multicolumn{2}{|l|}{ Geometry } \\
\hline Floor area & $53,682 \mathrm{ft}^{2}$ \\
\hline Aspect ratio & 1.5 \\
\hline Number of floor & 3 \\
\hline Window-to-wall ratio & $48 \%$ \\
\hline Floor-to-ceiling height & $9 \mathrm{ft}$ \\
\hline \multicolumn{2}{|l|}{ Envelope } \\
\hline Exterior wall & Steel-frame wall (R-value: 2.4 to 22 ) \\
\hline Roof & Insulation entirely above deck (R-value: 10 to 33 ) \\
\hline Window & $\begin{array}{l}\text { U-value } 0.52 \text { to } 1.03 \\
\text { SHGC } 0.04 \text { to } 0.11 \\
\text { VT } 0.02 \text { to } 0.1\end{array}$ \\
\hline Foundation & 4-in. concrete slab-on-grade floor with carpet \\
\hline \multicolumn{2}{|l|}{ HVAC } \\
\hline Type & Single-zone packaged heat pump system \\
\hline Heating & Heat pump with electrical resistance for supplemental heating \\
\hline Cooling & Heat pump (3.23 to $3.7 \mathrm{COP})$ \\
\hline Ventilation & $\begin{array}{l}0.3 \mathrm{cfm} / \mathrm{ft}^{2} \text { in cashier and two sales zones; } \\
0.15 \mathrm{cfm} / \mathrm{ft}^{2} \text { in storage zone. }\end{array}$ \\
\hline System schedule & $\begin{array}{l}7 \text { am-10 pm (weekdays) } \\
7 \text { am-11 pm (Sat.) } 9 \text { am-10 pm (Sun.) }\end{array}$ \\
\hline Cooling set point and setback & $75^{\circ} \mathrm{F} / 86^{\circ} \mathrm{F}$ \\
\hline Heating set point and setback & $70^{\circ} \mathrm{F} / 60^{\circ} \mathrm{F}$ \\
\hline \multicolumn{2}{|l|}{ Internal Load } \\
\hline Occupancy density & $200 \mathrm{ft}^{2} /$ per person (268 full occupancy) \\
\hline Lighting & $1.6 \mathrm{~W} / \mathrm{ft}^{2}$ \\
\hline Plug equipment & $1.0 \mathrm{~W} / \mathrm{ft}^{2}$ \\
\hline Elevator & 2 elevators, 20 house power each, $91 \%$ motor efficiency \\
\hline
\end{tabular}


Appendix B

\section{Tables of HVAC Energy Uses}


Table B-1: HVAC Energy Uses Break Down for the Stand-alone Retail Building in Climate Zones 2A, 2B, 3A and 3B

Unit: MWh/year

\begin{tabular}{|c|c|c|c|c|c|c|c|c|c|}
\hline $\begin{array}{c}\text { Case } \\
\text { No }\end{array}$ & Case Name & $\begin{array}{c}\text { Fan } \\
\text { Energy }\end{array}$ & $\begin{array}{l}\text { Cooling } \\
\text { Energy }\end{array}$ & $\begin{array}{l}\text { Heating } \\
\text { Energy }\end{array}$ & $\begin{array}{c}\text { Total } \\
\text { HVAC } \\
\text { Energy }\end{array}$ & $\begin{array}{c}\text { Fan } \\
\text { Energy }\end{array}$ & $\begin{array}{l}\text { Cooling } \\
\text { Energy }\end{array}$ & $\begin{array}{l}\text { Heating } \\
\text { Energy }\end{array}$ & $\begin{array}{c}\text { Total } \\
\text { HVAC } \\
\text { Energy }\end{array}$ \\
\hline & & \multicolumn{4}{|c|}{ Houston-2A } & \multicolumn{4}{|c|}{ Phoenix-2B } \\
\hline 1 & NIEcon.SSFan.DCV0 & 66 & 111 & 38 & 215 & 67 & 120 & 27 & 214 \\
\hline 2 & IEcon.SSFan.DCV0 & 66 & 111 & 38 & 215 & 67 & 120 & 27 & 214 \\
\hline 3 & NIEcon.MSFan.DCV0 & 27 & 110 & 42 & 179 & 25 & 115 & 32 & 172 \\
\hline 4 & NIEcon.SSFan.DCV1 & 66 & 88 & 24 & 178 & 67 & 96 & 17 & 180 \\
\hline 5 & NIEcon.MSFan.DCV1 & 22 & 86 & 27 & 136 & 20 & 90 & 21 & 131 \\
\hline 6 & IEcon.MSFan.DCV0 & 27 & 110 & 42 & 180 & 25 & 115 & 32 & 172 \\
\hline 7 & IEcon.SSFan.DCV1 & 66 & 88 & 24 & 178 & 67 & 96 & 17 & 180 \\
\hline 8 & IEcon.MSFan.DCV1 & 22 & 86 & 27 & 136 & 20 & 90 & 21 & 131 \\
\hline & & \multicolumn{4}{|c|}{ Atlanta-3A } & \multicolumn{4}{|c|}{ Los Angeles-3B } \\
\hline 1 & NIEcon.SSFan.DCV0 & 72 & 53 & 82 & 206 & 56 & 14 & 24 & 94 \\
\hline 2 & IEcon.SSFan.DCV0 & 72 & 53 & 82 & 206 & 56 & 13 & 24 & 93 \\
\hline 3 & NIEcon.MSFan.DCV0 & 26 & 53 & 90 & 168 & 14 & 15 & 29 & 58 \\
\hline 4 & NIEcon.SSFan.DCV1 & 72 & 46 & 53 & 171 & 56 & 14 & 15 & 84 \\
\hline 5 & NIEcon.MSFan.DCV1 & 22 & 45 & 59 & 126 & 13 & 14 & 18 & 46 \\
\hline 6 & IEcon.MSFan.DCV0 & 26 & 53 & 90 & 168 & 14 & 14 & 29 & 58 \\
\hline 7 & IEcon.SSFan.DCV1 & 72 & 46 & 53 & 171 & 56 & 13 & 15 & 83 \\
\hline 8 & IEcon.MSFan.DCV1 & 22 & 45 & 59 & 126 & 13 & 14 & 18 & 45 \\
\hline
\end{tabular}


Table B-2: HVAC Energy Uses Break Down for the Stand-alone Retail Building in Climate Zones 3B, 3C, 4A and 4B

Unit: MWh/year

\begin{tabular}{|c|c|c|c|c|c|c|c|c|c|}
\hline $\begin{array}{l}\text { Case } \\
\text { No }\end{array}$ & Case Name & $\begin{array}{c}\text { Fan } \\
\text { Energy }\end{array}$ & $\begin{array}{l}\text { Cooling } \\
\text { Energy }\end{array}$ & $\begin{array}{l}\text { Heating } \\
\text { Energy }\end{array}$ & $\begin{array}{c}\text { Total } \\
\text { HVAC } \\
\text { Energy }\end{array}$ & $\begin{array}{c}\text { Fan } \\
\text { Energy }\end{array}$ & $\begin{array}{l}\text { Cooling } \\
\text { Energy }\end{array}$ & $\begin{array}{l}\text { Heating } \\
\text { Energy }\end{array}$ & $\begin{array}{c}\text { Total } \\
\text { HVAC } \\
\text { Energy }\end{array}$ \\
\hline & & \multicolumn{4}{|c|}{ Las Vegas-3B } & \multicolumn{4}{|c|}{ San Francisco-3C } \\
\hline 1 & NIEcon.SSFan.DCV0 & 62 & 82 & 48 & 192 & 48 & 3 & 66 & 117 \\
\hline 2 & IEcon.SSFan.DCV0 & 62 & 82 & 48 & 192 & 48 & 3 & 66 & 117 \\
\hline 3 & NIEcon.MSFan.DCV0 & 25 & 79 & 54 & 158 & 16 & 3 & 68 & 88 \\
\hline 4 & NIEcon.SSFan.DCV1 & 62 & 65 & 32 & 159 & 48 & 3 & 40 & 91 \\
\hline 5 & NIEcon.MSFan.DCV1 & 20 & 61 & 36 & 117 & 13 & 3 & 46 & 62 \\
\hline 6 & IEcon.MSFan.DCV0 & 25 & 78 & 54 & 158 & 16 & 3 & 68 & 88 \\
\hline 7 & IEcon.SSFan.DCV1 & 62 & 65 & 32 & 158 & 48 & 3 & 40 & 91 \\
\hline 8 & IEcon.MSFan.DCV1 & 20 & 61 & 36 & 117 & 13 & 3 & 46 & 62 \\
\hline & & \multicolumn{4}{|c|}{ Baltimore-4A } & \multicolumn{4}{|c|}{ Albuquerque-4B } \\
\hline 1 & NIEcon.SSFan.DCV0 & 69 & 40 & 135 & 245 & 70 & 34 & 101 & 206 \\
\hline 2 & IEcon.SSFan.DCV0 & 69 & 40 & 135 & 245 & 70 & 34 & 101 & 206 \\
\hline 3 & NIEcon.MSFan.DCV0 & 30 & 40 & 145 & 214 & 30 & 31 & 109 & 170 \\
\hline 4 & NIEcon.SSFan.DCV1 & 69 & 34 & 85 & 188 & 70 & 30 & 65 & 166 \\
\hline 5 & NIEcon.MSFan.DCV1 & 24 & 32 & 92 & 149 & 25 & 27 & 72 & 124 \\
\hline 6 & IEcon.MSFan.DCV0 & 30 & 39 & 145 & 214 & 30 & 31 & 109 & 170 \\
\hline 7 & IEcon.SSFan.DCV1 & 69 & 34 & 85 & 188 & 70 & 30 & 65 & 165 \\
\hline 8 & IEcon.MSFan.DCV1 & 24 & 33 & 92 & 149 & 25 & 27 & 72 & 123 \\
\hline
\end{tabular}


Table B-3: HVAC Energy Uses Break Down for the Stand-alone Retail Building in Climate Zones 4C, 5A and 5B

Unit: MWh/year

\begin{tabular}{|c|c|c|c|c|c|c|c|c|c|}
\hline $\begin{array}{c}\text { Case } \\
\text { No }\end{array}$ & Case Name & $\begin{array}{c}\text { Fan } \\
\text { Energy }\end{array}$ & $\begin{array}{l}\text { Cooling } \\
\text { Energy }\end{array}$ & $\begin{array}{l}\text { Heating } \\
\text { Energy }\end{array}$ & $\begin{array}{c}\text { Total } \\
\text { HVAC } \\
\text { Energy }\end{array}$ & $\begin{array}{c}\text { Fan } \\
\text { Energy }\end{array}$ & $\begin{array}{l}\text { Cooling } \\
\text { Energy }\end{array}$ & $\begin{array}{l}\text { Heating } \\
\text { Energy }\end{array}$ & $\begin{array}{c}\text { Total } \\
\text { HVAC } \\
\text { Energy }\end{array}$ \\
\hline & & \multicolumn{4}{|c|}{ Seattle-4C } & \multicolumn{4}{|c|}{ Chicago-5A } \\
\hline 1 & NIEcon.SSFan.DCV0 & 54 & 5 & 105 & 165 & 85 & 27 & 211 & 323 \\
\hline 2 & IEcon.SSFan.DCV0 & 54 & 5 & 105 & 164 & 85 & 27 & 211 & 323 \\
\hline 3 & NIEcon.MSFan.DCV0 & 23 & 5 & 110 & 137 & 37 & 26 & 226 & 288 \\
\hline 4 & NIEcon.SSFan.DCV1 & 54 & 5 & 59 & 118 & 85 & 23 & 137 & 246 \\
\hline 5 & NIEcon.MSFan.DCV1 & 17 & 5 & 67 & 88 & 30 & 22 & 149 & 201 \\
\hline 6 & IEcon.MSFan.DCV0 & 23 & 5 & 110 & 137 & 37 & 26 & 226 & 288 \\
\hline 7 & IEcon.SSFan.DCV1 & 54 & 5 & 59 & 118 & 85 & 23 & 138 & 245 \\
\hline 8 & IEcon.MSFan.DCV1 & 17 & 4 & 67 & 88 & 30 & 22 & 149 & 201 \\
\hline & & \multicolumn{4}{|c|}{ Denver-5B } & & & & \\
\hline 1 & NIEcon.SSFan.DCV0 & 85 & 21 & 166 & 272 & & & & \\
\hline 2 & IEcon.SSFan.DCV0 & 85 & 21 & 166 & 272 & & & & \\
\hline 3 & NIEcon.MSFan.DCV0 & 35 & 18 & 179 & 233 & & & & \\
\hline 4 & NIEcon.SSFan.DCV1 & 85 & 18 & 110 & 214 & & & & \\
\hline 5 & NIEcon.MSFan.DCV1 & 29 & 15 & 122 & 166 & & & & \\
\hline 6 & IEcon.MSFan.DCV0 & 35 & 18 & 179 & 233 & & & & \\
\hline 7 & IEcon.SSFan.DCV1 & 85 & 18 & 110 & 214 & & & & \\
\hline 8 & IEcon.MSFan.DCV1 & 29 & 15 & 122 & 166 & & & & \\
\hline
\end{tabular}


Table B-4: HVAC Energy Uses Break Down for the Medium Office in Climate Zones 2A, 2B, 3A and 3B

Unit: MWh/year

\begin{tabular}{|c|c|c|c|c|c|c|c|c|c|}
\hline $\begin{array}{l}\text { Case } \\
\text { No }\end{array}$ & Case Name & $\begin{array}{c}\text { Fan } \\
\text { Energy }\end{array}$ & $\begin{array}{l}\text { Cooling } \\
\text { Energy }\end{array}$ & $\begin{array}{l}\text { Heating } \\
\text { Energy }\end{array}$ & $\begin{array}{c}\text { Total } \\
\text { HVAC } \\
\text { Energy }\end{array}$ & $\begin{array}{c}\text { Fan } \\
\text { Energy }\end{array}$ & $\begin{array}{l}\text { Cooling } \\
\text { Energy }\end{array}$ & $\begin{array}{l}\text { Heating } \\
\text { Energy }\end{array}$ & $\begin{array}{c}\text { Total } \\
\text { HVAC } \\
\text { Energy }\end{array}$ \\
\hline & & \multicolumn{4}{|c|}{ Houston-2A } & \multicolumn{4}{|c|}{ Phoenix-2B } \\
\hline 1 & NIEcon.SSFan.DCV0 & 159 & 212 & 15 & 386 & 180 & 288 & 7 & 475 \\
\hline 2 & IEcon.SSFan.DCV0 & 158 & 216 & 15 & 389 & 179 & 287 & 7 & 473 \\
\hline 3 & NIEcon.MSFan.DCV0 & 79 & 212 & 20 & 311 & 92 & 280 & 12 & 384 \\
\hline 4 & NIEcon.SSFan.DCV1 & 157 & 198 & 11 & 367 & 178 & 273 & 6 & 457 \\
\hline 5 & NIEcon.MSFan.DCV1 & 72 & 194 & 14 & 280 & 85 & 262 & 8 & 355 \\
\hline 6 & IEcon.MSFan.DCV0 & 79 & 213 & 20 & 312 & 91 & 277 & 12 & 380 \\
\hline 7 & IEcon.SSFan.DCV1 & 157 & 199 & 11 & 367 & 178 & 272 & 6 & 456 \\
\hline 8 & IEcon.MSFan.DCV1 & 72 & 194 & 14 & 280 & 85 & 261 & 8 & 354 \\
\hline & & \multicolumn{4}{|c|}{ Atlanta-3A } & \multicolumn{4}{|c|}{ Los Angeles-3B } \\
\hline 1 & NIEcon.SSFan.DCV0 & 152 & 115 & 31 & 298 & 159 & 51 & 3 & 213 \\
\hline 2 & IEcon.SSFan.DCV0 & 151 & 117 & 31 & 299 & 158 & 46 & 3 & 207 \\
\hline 3 & NIEcon.MSFan.DCV0 & 62 & 117 & 40 & 220 & 55 & 57 & 6 & 118 \\
\hline 4 & NIEcon.SSFan.DCV1 & 151 & 111 & 22 & 284 & 159 & 52 & 2 & 212 \\
\hline 5 & NIEcon.MSFan.DCV1 & 56 & 110 & 27 & 193 & 52 & 57 & 4 & 112 \\
\hline 6 & IEcon.MSFan.DCV0 & 62 & 116 & 40 & 218 & 53 & 50 & 6 & 109 \\
\hline 7 & IEcon.SSFan.DCV1 & 151 & 111 & 22 & 284 & 158 & 46 & 2 & 206 \\
\hline 8 & IEcon.MSFan.DCV1 & 56 & 109 & 27 & 192 & 51 & 51 & 4 & 106 \\
\hline
\end{tabular}


Table B-5: HVAC Energy Uses Break Down for the Medium Office in Climate Zones 3B, 3C, 4A and 4B

Unit: MWh/year

\begin{tabular}{|c|c|c|c|c|c|c|c|c|c|}
\hline $\begin{array}{c}\text { Case } \\
\text { No }\end{array}$ & Case Name & $\begin{array}{c}\text { Fan } \\
\text { Energy }\end{array}$ & $\begin{array}{l}\text { Cooling } \\
\text { Energy }\end{array}$ & $\begin{array}{l}\text { Heating } \\
\text { Energy }\end{array}$ & $\begin{array}{c}\text { Total } \\
\text { HVAC } \\
\text { Energy }\end{array}$ & $\begin{array}{c}\text { Fan } \\
\text { Energy }\end{array}$ & $\begin{array}{l}\text { Cooling } \\
\text { Energy }\end{array}$ & $\begin{array}{l}\text { Heating } \\
\text { Energy }\end{array}$ & $\begin{array}{c}\text { Total } \\
\text { HVAC } \\
\text { Energy }\end{array}$ \\
\hline & & \multicolumn{4}{|c|}{ Las Vegas-3B } & \multicolumn{4}{|c|}{ San Francisco-3C } \\
\hline 1 & NIEcon.SSFan.DCV0 & 169 & 210 & 15 & 394 & 136 & 19 & 9 & 163 \\
\hline 2 & IEcon.SSFan.DCV0 & 168 & 210 & 15 & 393 & 136 & 16 & 9 & 160 \\
\hline 3 & NIEcon.MSFan.DCV0 & 82 & 206 & 21 & 309 & 37 & 22 & 15 & 74 \\
\hline 4 & NIEcon.SSFan.DCV1 & 168 & 201 & 11 & 379 & 136 & 26 & 6 & 167 \\
\hline 5 & NIEcon.MSFan.DCV1 & 75 & 194 & 15 & 284 & 33 & 27 & 9 & 70 \\
\hline 6 & IEcon.MSFan.DCV0 & 81 & 203 & 21 & 305 & 36 & 17 & 15 & 68 \\
\hline 7 & IEcon.SSFan.DCV1 & 167 & 199 & 11 & 378 & 136 & 16 & 6 & 157 \\
\hline 8 & IEcon.MSFan.DCV1 & 75 & 192 & 15 & 282 & 33 & 17 & 9 & 59 \\
\hline & & \multicolumn{4}{|c|}{ Baltimore-4A } & \multicolumn{4}{|c|}{ Albuquerque-4B } \\
\hline 1 & NIEcon.SSFan.DCV0 & 146 & 89 & 59 & 294 & 166 & 95 & 36 & 297 \\
\hline 2 & IEcon.SSFan.DCV0 & 145 & 90 & 59 & 294 & 164 & 97 & 36 & 297 \\
\hline 3 & NIEcon.MSFan.DCV0 & 58 & 91 & 74 & 223 & 66 & 96 & 48 & 210 \\
\hline 4 & NIEcon.SSFan.DCV1 & 145 & 86 & 40 & 271 & 164 & 96 & 27 & 287 \\
\hline 5 & NIEcon.MSFan.DCV1 & 51 & 86 & 49 & 185 & 59 & 94 & 34 & 187 \\
\hline 6 & IEcon.MSFan.DCV0 & 58 & 89 & 74 & 221 & 65 & 95 & 48 & 207 \\
\hline 7 & IEcon.SSFan.DCV1 & 145 & 86 & 40 & 270 & 164 & 95 & 27 & 286 \\
\hline 8 & IEcon.MSFan.DCV1 & 51 & 85 & 49 & 184 & 59 & 92 & 34 & 185 \\
\hline
\end{tabular}


Table B-6: HVAC Energy Uses Break Down for the Medium Office in Climate Zones 4C, 5A and 5B

Unit: MWh/year

\begin{tabular}{|c|c|c|c|c|c|c|c|c|c|}
\hline $\begin{array}{c}\text { Case } \\
\text { No }\end{array}$ & Case Name & $\begin{array}{c}\text { Fan } \\
\text { Energy }\end{array}$ & $\begin{array}{l}\text { Cooling } \\
\text { Energy }\end{array}$ & $\begin{array}{l}\text { Heating } \\
\text { Energy }\end{array}$ & $\begin{array}{c}\text { Total } \\
\text { HVAC } \\
\text { Energy }\end{array}$ & $\begin{array}{c}\text { Fan } \\
\text { Energy }\end{array}$ & $\begin{array}{l}\text { Cooling } \\
\text { Energy }\end{array}$ & $\begin{array}{l}\text { Heating } \\
\text { Energy }\end{array}$ & $\begin{array}{c}\text { Total } \\
\text { HVAC } \\
\text { Energy }\end{array}$ \\
\hline & & \multicolumn{4}{|c|}{ Seattle-4C } & \multicolumn{4}{|c|}{ Chicago-5A } \\
\hline 1 & NIEcon.SSFan.DCV0 & 144 & 19 & 35 & 198 & 157 & 69 & 111 & 337 \\
\hline 2 & IEcon.SSFan.DCV0 & 144 & 18 & 35 & 197 & 156 & 69 & 111 & 336 \\
\hline 3 & NIEcon.MSFan.DCV0 & 41 & 21 & 52 & 114 & 62 & 69 & 135 & 266 \\
\hline 4 & NIEcon.SSFan.DCV1 & 144 & 24 & 22 & 190 & 156 & 68 & 78 & 301 \\
\hline 5 & NIEcon.MSFan.DCV1 & 35 & 25 & 32 & 91 & 52 & 67 & 93 & 212 \\
\hline 6 & IEcon.MSFan.DCV0 & 40 & 19 & 52 & 111 & 61 & 69 & 135 & 265 \\
\hline 7 & IEcon.SSFan.DCV1 & 144 & 18 & 22 & 184 & 155 & 67 & 78 & 300 \\
\hline 8 & IEcon.MSFan.DCV1 & 34 & 19 & 32 & 85 & 52 & 66 & 93 & 211 \\
\hline & & \multicolumn{4}{|c|}{ Denver-5B } & & & & \\
\hline 1 & NIEcon.SSFan.DCV0 & 162 & 63 & 74 & 299 & & & & \\
\hline 2 & IEcon.SSFan.DCV0 & 162 & 62 & 74 & 297 & & & & \\
\hline 3 & NIEcon.MSFan.DCV0 & 59 & 62 & 92 & 214 & & & & \\
\hline 4 & NIEcon.SSFan.DCV1 & 162 & 62 & 54 & 278 & & & & \\
\hline 5 & NIEcon.MSFan.DCV1 & 51 & 60 & 66 & 176 & & & & \\
\hline 6 & IEcon.MSFan.DCV0 & 58 & 60 & 92 & 210 & & & & \\
\hline 7 & IEcon.SSFan.DCV1 & 162 & 60 & 55 & 277 & & & & \\
\hline 8 & IEcon.MSFan.DCV1 & 51 & 58 & 66 & 175 & & & & \\
\hline
\end{tabular}


Table B-7: HVAC Total Energy Cost for the Stand-alone Retail Building

Unit: \$/year

\begin{tabular}{|l|c|c|c|c|c|c|c|c|}
\hline Case No. & 1 & 2 & 3 & 4 & 5 & 6 & 7 & 8 \\
\hline Control Package & Baseline & IEcon & MSFan & DCV & MSFan+DCV & IEcon+MSFan & IEcon+DCV & $\begin{array}{c}\text { Full } \\
\text { Package }\end{array}$ \\
\hline Houston-2A & 19,707 & 19,705 & 16,477 & 16,332 & 12,468 & 16,480 & 16,342 & 12,492 \\
\hline Phoenix-2B & 20,014 & 19,997 & 16,089 & 16,850 & 12,236 & 16,079 & 16,841 & 12,229 \\
\hline Atlanta-3A & 18,686 & 18,675 & 15,255 & 15,456 & 11,434 & 15,254 & 15,456 & 11,443 \\
\hline Los Angeles-3B & 12,973 & 12,861 & 8,078 & 11,637 & 6,335 & 8,014 & 11,521 & 6,253 \\
\hline Las Vegas-3B & 19,045 & 19,033 & 15,671 & 15,728 & 11,636 & 15,665 & 15,720 & 11,630 \\
\hline San Francisco-3C & 16,157 & 16,134 & 12,160 & 12,620 & 8,566 & 12,146 & 12,581 & 8,535 \\
\hline Baltimore-4A & 28,514 & 28,489 & 24,877 & 21,832 & 17,331 & 24,865 & 21,834 & 17,349 \\
\hline Albuquerque-4B & 17,753 & 17,735 & 14,659 & 14,292 & 10,665 & 14,648 & 14,276 & 10,654 \\
\hline Seattle-4C & 12,061 & 12,046 & 10,059 & 8,684 & 6,486 & 10,050 & 8,667 & 6,472 \\
\hline Chicago-5A & 28,269 & 28,255 & 25,262 & 21,504 & 17,633 & 25,255 & 21,495 & 17,629 \\
\hline Denver-5B & 24,548 & 24,532 & 21,002 & 19,324 & 15,022 & 20,993 & 19,314 & 15,014 \\
\hline
\end{tabular}


Table B- 8: HVAC Total Energy Cost for the Medium Office Building

Unit: \$/year

\begin{tabular}{|l|c|c|c|c|c|c|c|c|}
\hline Case No. & 1 & 2 & 3 & 4 & 5 & 6 & 7 & 8 \\
\hline Control Package & Baseline & IEcon & MSFan & DCV & MSFan+DCV & IEcon+MSFan & IEcon+DCV & Full Package \\
\hline Houston-2A & 35,448 & 35,707 & 28,581 & 33,673 & 25,694 & 28,621 & 33,717 & 25,733 \\
\hline Phoenix-2B & 44,459 & 44,290 & 35,876 & 42,731 & 33,230 & 35,530 & 42,654 & 33,138 \\
\hline Atlanta-3A & 26,995 & 27,098 & 19,887 & 25,708 & 17,500 & 19,722 & 25,675 & 17,414 \\
\hline Los Angeles-3B & 29,522 & 28,642 & 16,334 & 29,354 & 15,545 & 15,047 & 28,503 & 14,591 \\
\hline Las Vegas-3B & 39,125 & 38,948 & 30,635 & 37,615 & 28,160 & 30,265 & 37,487 & 28,004 \\
\hline San Francisco-3C & 22,535 & 22,153 & 10,283 & 23,125 & 9,669 & 9,398 & 21,769 & 8,176 \\
\hline Baltimore-4A & 34,175 & 34,208 & 25,904 & 31,533 & 21,522 & 25,707 & 31,453 & 21,409 \\
\hline Albuquerque-4B & 25,658 & 25,642 & 18,133 & 24,779 & 16,121 & 17,875 & 24,661 & 15,951 \\
\hline Seattle-4C & 14,494 & 14,416 & 8,321 & 13,936 & 6,699 & 8,118 & 13,485 & 6,234 \\
\hline Chicago-5A & 29,493 & 29,452 & 23,303 & 26,394 & 18,566 & 23,179 & 26,283 & 18,453 \\
\hline Denver-5B & 26,994 & 26,843 & 19,277 & 25,115 & 15,919 & 18,974 & 24,964 & 15,757 \\
\hline
\end{tabular}




\section{Appendix C Tables of Energy and Energy Cost Savings}


Table C- 1: Total HVAC Energy Savings Compared to Case 1 for the Stand-alone Retail Building

\begin{tabular}{|c|c|c|c|c|c|c|c|c|c|c|c|c|c|c|}
\hline Case No. & \multicolumn{2}{|c|}{2} & \multicolumn{2}{|c|}{3} & \multicolumn{2}{|c|}{4} & \multicolumn{2}{|c|}{5} & \multicolumn{2}{|c|}{6} & \multicolumn{2}{|c|}{7} & \multicolumn{2}{|c|}{8} \\
\hline $\begin{array}{l}\text { Advanced } \\
\text { Control Package }\end{array}$ & \multicolumn{2}{|c|}{ IEcon } & \multicolumn{2}{|c|}{ MSFan } & \multicolumn{2}{|c|}{$\mathrm{DCV}$} & \multicolumn{2}{|c|}{ MSFan+DCV } & \multicolumn{2}{|c|}{ IEcon+MSFan } & \multicolumn{2}{|c|}{ IEcon+DCV } & \multicolumn{2}{|c|}{ Full Package } \\
\hline & $\begin{array}{c}\text { Abs. } \\
\text { [MWh] }\end{array}$ & $\begin{array}{l}\text { Rel. } \\
{[\%]}\end{array}$ & $\begin{array}{c}\text { Abs. } \\
{[\mathrm{MWh}]}\end{array}$ & $\begin{array}{c}\text { Rel. } \\
{[\%]}\end{array}$ & $\begin{array}{c}\text { Abs. } \\
\text { [MWh] }\end{array}$ & $\begin{array}{l}\text { Rel. } \\
{[\%]}\end{array}$ & $\begin{array}{c}\text { Abs. } \\
\text { [MWh] }\end{array}$ & $\begin{array}{l}\text { Rel. } \\
{[\%]}\end{array}$ & $\begin{array}{c}\text { Abs. } \\
{[\mathrm{MWh}]}\end{array}$ & $\begin{array}{l}\text { Rel. } \\
{[\%]}\end{array}$ & $\begin{array}{c}\text { Abs. } \\
{[\mathrm{MWh}]}\end{array}$ & $\begin{array}{l}\text { Rel. } \\
{[\%]}\end{array}$ & $\begin{array}{c}\text { Abs. } \\
\text { [MWh] }\end{array}$ & $\begin{array}{l}\text { Rel. } \\
{[\%]}\end{array}$ \\
\hline Houston-2A & 0.0 & 0.0 & 35.2 & 16.4 & 36.8 & 17.1 & 78.8 & 36.7 & 35.1 & 16.4 & 36.6 & 17.1 & 78.6 & 36.6 \\
\hline Phoenix-2B & 0.2 & 0.1 & 42.0 & 19.6 & 33.8 & 15.8 & 83.1 & 38.9 & 42.1 & 19.7 & 33.9 & 15.9 & 83.2 & 38.9 \\
\hline Atlanta-3A & 0.1 & 0.1 & 37.9 & 18.4 & 35.7 & 17.3 & 80.1 & 38.8 & 37.9 & 18.4 & 35.7 & 17.3 & 80.0 & 38.8 \\
\hline Los Angeles-3B & 0.8 & 0.9 & 35.4 & 37.7 & 9.7 & 10.3 & 48.0 & 51.2 & 35.9 & 38.2 & 10.5 & 11.2 & 48.6 & 51.8 \\
\hline Las Vegas-3B & 0.1 & 0.1 & 34.0 & 17.7 & 33.4 & 17.4 & 74.7 & 38.9 & 34.1 & 17.7 & 33.5 & 17.5 & 74.7 & 38.9 \\
\hline San Francisco-3C & 0.2 & 0.1 & 28.9 & 24.7 & 25.6 & 21.9 & 54.9 & 47.0 & 29.0 & 24.8 & 25.9 & 22.1 & 55.1 & 47.2 \\
\hline Baltimore-4A & 0.2 & 0.1 & 31.3 & 12.8 & 57.4 & 23.4 & 96.2 & 39.2 & 31.4 & 12.8 & 57.4 & 23.4 & 96.0 & 39.2 \\
\hline Albuquerque-4B & 0.2 & 0.1 & 35.9 & 17.4 & 40.1 & 19.5 & 82.1 & 39.9 & 36.0 & 17.5 & 40.3 & 19.6 & 82.3 & 40.0 \\
\hline Seattle-4C & 0.2 & 0.1 & 27.3 & 16.6 & 46.1 & 28.0 & 76.1 & 46.2 & 27.4 & 16.7 & 46.3 & 28.1 & 76.2 & 46.3 \\
\hline Chicago-5A & 0.2 & 0.1 & 34.3 & 10.6 & 77.3 & 23.9 & 121.5 & 37.6 & 34.4 & 10.7 & 77.4 & 24.0 & 121.5 & 37.6 \\
\hline Denver-5B & 0.2 & 0.1 & 39.3 & 14.4 & 57.9 & 21.3 & 105.5 & 38.8 & 39.4 & 14.5 & 58.0 & 21.3 & 105.6 & 38.8 \\
\hline
\end{tabular}


Table C- 2: Total HVAC Energy Savings Compared to Case 1 for the Medium Office Building

\begin{tabular}{|c|c|c|c|c|c|c|c|c|c|c|c|c|c|c|}
\hline Case No. & \multicolumn{2}{|c|}{2} & \multicolumn{2}{|c|}{3} & \multicolumn{2}{|c|}{4} & \multicolumn{2}{|c|}{5} & \multicolumn{2}{|c|}{6} & \multicolumn{2}{|c|}{7} & \multicolumn{2}{|c|}{8} \\
\hline $\begin{array}{l}\text { Advanced } \\
\text { Control Package }\end{array}$ & \multicolumn{2}{|c|}{ IEcon } & \multicolumn{2}{|c|}{ MSFan } & \multicolumn{2}{|c|}{$\mathrm{DCV}$} & \multicolumn{2}{|c|}{ MSFan+DCV } & \multicolumn{2}{|c|}{ IEcon+MSFan } & \multicolumn{2}{|c|}{ IEcon+DCV } & \multicolumn{2}{|c|}{ Full Package } \\
\hline & $\begin{array}{c}\text { Abs. } \\
{[\mathrm{MWh}]}\end{array}$ & $\begin{array}{l}\text { Rel. } \\
{[\%]}\end{array}$ & $\begin{array}{c}\text { Abs. } \\
{[\mathrm{MWh}]}\end{array}$ & $\begin{array}{l}\text { Rel. } \\
{[\%]}\end{array}$ & $\begin{array}{c}\text { Abs. } \\
{[\mathrm{MWh}]}\end{array}$ & $\begin{array}{l}\text { Rel. } \\
{[\%]}\end{array}$ & $\begin{array}{c}\text { Abs. } \\
{[\mathrm{MWh}]}\end{array}$ & $\begin{array}{l}\text { Rel. } \\
{[\%]}\end{array}$ & $\begin{array}{c}\text { Abs. } \\
{[\mathrm{MWh}]}\end{array}$ & $\begin{array}{l}\text { Rel. } \\
{[\%]}\end{array}$ & $\begin{array}{c}\text { Abs. } \\
\text { [MWh] }\end{array}$ & $\begin{array}{l}\text { Rel. } \\
{[\%]}\end{array}$ & $\begin{array}{c}\text { Abs. } \\
\text { [MWh] }\end{array}$ & $\begin{array}{l}\text { Rel. } \\
{[\%]}\end{array}$ \\
\hline Houston-2A & -2.8 & -0.7 & 74.8 & 19.4 & 19.3 & 5.0 & 106.2 & 27.5 & 74.4 & 19.3 & 18.9 & 4.9 & 105.8 & 27.4 \\
\hline Phoenix-2B & 1.8 & 0.4 & 91.8 & 19.3 & 18.5 & 3.9 & 120.0 & 25.3 & 95.4 & 20.1 & 19.3 & 4.1 & 121.0 & 25.5 \\
\hline Atlanta-3A & -1.1 & -0.4 & 78.5 & 26.3 & 14.2 & 4.8 & 104.9 & 35.2 & 80.3 & 26.9 & 14.6 & 4.9 & 105.8 & 35.5 \\
\hline Los Angeles-3B & 6.4 & 3.0 & 95.4 & 44.7 & 1.2 & 0.6 & 101.1 & 47.3 & 104.7 & 49.0 & 7.4 & 3.5 & 108.0 & 50.6 \\
\hline Las Vegas-3B & 1.8 & 0.5 & 85.6 & 21.7 & 15.2 & 3.9 & 110.5 & 28.0 & 89.3 & 22.6 & 16.5 & 4.2 & 112.1 & 28.4 \\
\hline San Francisco-3C & 2.8 & 1.7 & 88.6 & 54.4 & -4.3 & -2.6 & 93.0 & 57.1 & 95.0 & 58.3 & 5.5 & 3.4 & 103.8 & 63.7 \\
\hline Baltimore-4A & -0.3 & -0.1 & 71.1 & 24.2 & 22.7 & 7.7 & 108.8 & 37.0 & 72.8 & 24.8 & 23.4 & 8.0 & 109.8 & 37.4 \\
\hline Albuquerque- $4 \mathrm{~B}$ & 0.2 & 0.1 & 87.2 & 29.3 & 10.2 & 3.4 & 110.5 & 37.2 & 90.2 & 30.3 & 11.6 & 3.9 & 112.5 & 37.8 \\
\hline Seattle-4C & 1.1 & 0.5 & 84.2 & 42.6 & 7.6 & 3.8 & 106.3 & 53.8 & 87.0 & 44.0 & 13.8 & 7.0 & 112.7 & 57.0 \\
\hline Chicago-5A & 0.5 & 0.1 & 70.7 & 21.0 & 35.4 & 10.5 & 124.8 & 37.0 & 72.1 & 21.4 & 36.7 & 10.9 & 126.1 & 37.4 \\
\hline Denver-5B & 1.7 & 0.6 & 85.5 & 28.6 & 20.8 & 7.0 & 122.7 & 41.0 & 88.8 & 29.7 & 22.5 & 7.5 & 124.5 & 41.6 \\
\hline
\end{tabular}


Table C-3: HVAC Energy Cost Savings Compared to Case 1 for the Stand-alone Retail Building

\begin{tabular}{|c|c|c|c|c|c|c|c|c|c|c|c|c|c|c|}
\hline \multirow{3}{*}{$\begin{array}{l}\text { Case No. } \\
\text { Advanced } \\
\text { Control Package }\end{array}$} & \multicolumn{2}{|c|}{2} & \multicolumn{2}{|c|}{3} & \multicolumn{2}{|c|}{4} & \multicolumn{2}{|c|}{5} & \multicolumn{2}{|c|}{6} & \multicolumn{2}{|c|}{7} & \multicolumn{2}{|c|}{8} \\
\hline & \multicolumn{2}{|c|}{ IEcon } & \multicolumn{2}{|c|}{ MSFan } & \multicolumn{2}{|c|}{ DCV } & \multicolumn{2}{|c|}{ MSFan.+DCV } & \multicolumn{2}{|c|}{ IEcon+MSFan } & \multicolumn{2}{|c|}{ IEcon+DCV } & \multicolumn{2}{|c|}{ Full Package } \\
\hline & $\begin{array}{c}\text { Abs. } \\
{[\$]}\end{array}$ & $\begin{array}{l}\text { Rel. } \\
{[\%]}\end{array}$ & $\begin{array}{c}\text { Abs. } \\
{[\$]}\end{array}$ & $\begin{array}{l}\text { Rel. } \\
{[\%]}\end{array}$ & $\begin{array}{c}\text { Abs. } \\
{[\$]}\end{array}$ & $\begin{array}{l}\text { Rel. } \\
{[\%]}\end{array}$ & $\begin{array}{l}\text { Abs. } \\
{[\$]}\end{array}$ & $\begin{array}{l}\text { Rel. } \\
\text { [\%] }\end{array}$ & $\begin{array}{l}\text { Abs. } \\
{[\$]}\end{array}$ & $\begin{array}{l}\text { Rel. } \\
{[\%]}\end{array}$ & $\begin{array}{l}\text { Abs. } \\
{[\$]}\end{array}$ & $\begin{array}{l}\text { Rel. } \\
{[\%]}\end{array}$ & $\begin{array}{l}\text { Abs. } \\
{[\$]}\end{array}$ & $\begin{array}{l}\text { Rel. } \\
{[\%]}\end{array}$ \\
\hline Houston-2A & 2 & 0.0 & 3,230 & 16.4 & 3,375 & 17.1 & 7,239 & 36.7 & 3,227 & 16.4 & 3,365 & 17.1 & 7,215 & 36.6 \\
\hline Phoenix-2B & 18 & 0.1 & 3,925 & 19.6 & 3,165 & 15.8 & 7,778 & 38.9 & 3,935 & 19.7 & 3,173 & 15.9 & 7,785 & 38.9 \\
\hline Atlanta-3A & 11 & 0.1 & 3,431 & 18.4 & 3,230 & 17.3 & 7,252 & 38.8 & 3,432 & 18.4 & 3,230 & 17.3 & 7,243 & 38.8 \\
\hline Los Angeles-3B & 113 & 0.9 & 4,895 & 37.7 & 1,336 & 10.3 & 6,638 & 51.2 & 4,960 & 38.2 & 1,452 & 11.2 & 6,720 & 51.8 \\
\hline Las Vegas-3B & 12 & 0.1 & 3,374 & 17.7 & 3,317 & 17.4 & 7,408 & 38.9 & 3,380 & 17.7 & 3,325 & 17.5 & 7,415 & 38.9 \\
\hline San Francisco-3C & 23 & 0.1 & 3,997 & 24.7 & 3,537 & 21.9 & 7,591 & 47.0 & 4,011 & 24.8 & 3,576 & 22.1 & 7,622 & 47.2 \\
\hline Baltimore-4A & 26 & 0.1 & 3,638 & 12.8 & 6,682 & 23.4 & 11,184 & 39.2 & 3,649 & 12.8 & 6,681 & 23.4 & 11,165 & 39.2 \\
\hline Albuquerque-4B & 17 & 0.1 & 3,093 & 17.4 & 3,461 & 19.5 & 7,087 & 39.9 & 3,105 & 17.5 & 3,476 & 19.6 & 7,098 & 40.0 \\
\hline Seattle-4C & 16 & 0.1 & 2,002 & 16.6 & 3,377 & 28.0 & 5,575 & 46.2 & 2,011 & 16.7 & 3,394 & 28.1 & 5,589 & 46.3 \\
\hline Chicago-5A & 15 & 0.1 & 3,008 & 10.6 & 6,766 & 23.9 & 10,636 & 37.6 & 3,015 & 10.7 & 6,774 & 24.0 & 10,640 & 37.6 \\
\hline Denver-5B & 15 & 0.1 & 3,546 & 14.4 & 5,223 & 21.3 & 9,525 & 38.8 & 3,554 & 14.5 & 5,233 & 21.3 & 9,533 & 38.8 \\
\hline
\end{tabular}


Table C-4: HVAC Energy Cost Savings Compared to Case 1 for the Medium Office Building

\begin{tabular}{|c|c|c|c|c|c|c|c|c|c|c|c|c|c|c|}
\hline Case No. & \multicolumn{2}{|c|}{2} & \multicolumn{2}{|c|}{3} & \multicolumn{2}{|c|}{4} & \multicolumn{2}{|c|}{5} & \multicolumn{2}{|c|}{6} & \multicolumn{2}{|c|}{7} & \multicolumn{2}{|c|}{8} \\
\hline $\begin{array}{l}\text { Advanced } \\
\text { Control Package }\end{array}$ & \multicolumn{2}{|c|}{ IEcon } & \multicolumn{2}{|c|}{ MSFan } & \multicolumn{2}{|c|}{ DCV } & \multicolumn{2}{|c|}{ MSFan+DCV } & \multicolumn{2}{|c|}{ IEcon+MSFan } & \multicolumn{2}{|c|}{ IEcon+DCV } & \multicolumn{2}{|c|}{ Full Package } \\
\hline & $\begin{array}{c}\text { Abs. } \\
{[\$]}\end{array}$ & $\begin{array}{l}\text { Rel. } \\
{[\%]}\end{array}$ & $\begin{array}{l}\text { Abs. } \\
{[\$]}\end{array}$ & $\begin{array}{l}\text { Rel. } \\
{[\%]}\end{array}$ & $\begin{array}{c}\text { Abs. } \\
{[\$]}\end{array}$ & $\begin{array}{l}\text { Rel. } \\
{[\%]}\end{array}$ & $\begin{array}{l}\text { Abs. } \\
{[\$]}\end{array}$ & $\begin{array}{l}\text { Rel. } \\
{[\%]}\end{array}$ & $\begin{array}{c}\text { Abs. } \\
{[\$]}\end{array}$ & $\begin{array}{l}\text { Rel. } \\
{[\%]}\end{array}$ & $\begin{array}{c}\text { Abs. } \\
{[\$]}\end{array}$ & $\begin{array}{l}\text { Rel. } \\
{[\%]}\end{array}$ & $\begin{array}{c}\text { Abs. } \\
{[\$]}\end{array}$ & $\begin{array}{l}\text { Rel. } \\
{[\%]}\end{array}$ \\
\hline Houston-2A & -259 & -0.7 & 6,867 & 19.4 & 1,775 & 5.0 & 9,754 & 27.5 & 6,828 & 19.3 & 1,731 & 4.9 & 9,715 & 27.4 \\
\hline Phoenix-2B & 168 & 0.4 & 8,583 & 19.3 & 1,728 & 3.9 & 11,229 & 25.3 & 8,929 & 20.1 & 1,804 & 4.1 & 11,321 & 25.5 \\
\hline Atlanta-3A & -102 & -0.4 & 7,109 & 26.3 & 1,287 & 4.8 & 9,495 & 35.2 & 7,273 & 26.9 & 1,321 & 4.9 & 9,581 & 35.5 \\
\hline Los Angeles-3B & 880 & 3.0 & 13,188 & 44.7 & 168 & 0.6 & 13,977 & 47.3 & 14,476 & 49.0 & 1,019 & 3.5 & 14,931 & 50.6 \\
\hline Las Vegas-3B & 177 & 0.5 & 8,491 & 21.7 & 1,511 & 3.9 & 10,966 & 28.0 & 8,860 & 22.6 & 1,639 & 4.2 & 11,121 & 28.4 \\
\hline San Francisco-3C & 383 & 1.7 & 12,252 & 54.4 & -590 & -2.6 & 12,867 & 57.1 & 13,138 & 58.3 & 766 & 3.4 & 14,359 & 63.7 \\
\hline Baltimore-4A & -34 & -0.1 & 8,271 & 24.2 & 2,642 & 7.7 & 12,653 & 37.0 & 8,468 & 24.8 & 2,722 & 8.0 & 12,766 & 37.4 \\
\hline Albuquerque-4B & 16 & 0.1 & 7,525 & 29.3 & 879 & 3.4 & 9,537 & 37.2 & 7,783 & 30.3 & 997 & 3.9 & 9,707 & 37.8 \\
\hline Seattle-4C & 78 & 0.5 & 6,173 & 42.6 & 557 & 3.8 & 7,795 & 53.8 & 6,375 & 44.0 & 1,009 & 7.0 & 8,259 & 57.0 \\
\hline Chicago-5A & 42 & 0.1 & 6,190 & 21.0 & 3,100 & 10.5 & 10,927 & 37.0 & 6,314 & 21.4 & 3,210 & 10.9 & 11,041 & 37.4 \\
\hline Denver-5B & 151 & 0.6 & 7,717 & 28.6 & 1,879 & 7.0 & 11,075 & 41.0 & 8,020 & 29.7 & 2,030 & 7.5 & 11,237 & 41.6 \\
\hline
\end{tabular}


Appendix D

\section{Tables of Maximum}

\section{Acceptable Controller Costs}


Table D-1: Maximum Controller Installed Cost per Unit Supporting Different Retrofits for the Stand-alone Retail Building Based on the Payback Period of 3 Years and the Original Utility Rates

Unit: \$/controller
\begin{tabular}{|l|c|c|c|c|c|c|c|}
\hline Case No. & 2 & 3 & 4 & 5 & 6 & 7 & 8 \\
\hline $\begin{array}{l}\text { Advanced Control } \\
\text { Package }\end{array}$ & IEcon & MSFan & DCV & MSFan+DCV & IEcon+MSFan & IEcon+DCV & Full Package \\
\hline Houston-2A & 2 & 2,422 & 2,531 & 5,429 & 2,420 & 2,524 & 5,411 \\
\hline Phoenix-2B & 13 & 2,944 & 2,373 & 5,834 & 2,951 & 2,380 & 5,839 \\
\hline Atlanta-3A & 8 & 2,573 & 2,423 & 5,439 & 2,574 & 2,422 & 5,432 \\
\hline Los Angeles-3B & 84 & 3,671 & 1,002 & 4,979 & 3,720 & 1,089 & 5,040 \\
\hline Las Vegas-3B & 9 & 2,530 & 2,487 & 5,556 & 2,535 & 2,494 & 5,561 \\
\hline San Francisco-3C & 17 & 2,997 & 2,653 & 5,693 & 3,008 & 2,682 & 5,716 \\
\hline Baltimore-4A & 19 & 2,728 & 5,012 & 8,388 & 2,737 & 5,011 & 8,374 \\
\hline Albuquerque-4B & 13 & 2,320 & 2,596 & 5,315 & 2,329 & 2,607 & 5,324 \\
\hline Seattle-4C & 12 & 1,502 & 2,533 & 4,181 & 1,508 & 2,546 & 4,192 \\
\hline Chicago-5A & 11 & 2,256 & 5,074 & 7,977 & 2,261 & 5,081 & 7,980 \\
\hline Denver-5B & 11 & 2,659 & 3,917 & 7,144 & 2,666 & 3,925 & 7,150 \\
\hline
\end{tabular}


Table D-2: Maximum Controller Installed Cost per Unit Supporting Different Retrofits for the Medium Office Building Based on the Payback Period of 3 Years and the Original Utility Rates

\begin{tabular}{|c|c|c|c|c|c|c|c|}
\hline Case No. & 2 & 3 & 4 & 5 & 6 & 7 & 8 \\
\hline $\begin{array}{l}\text { Advanced Control } \\
\text { Package }\end{array}$ & IEcon & MSFan & $\mathrm{DCV}$ & MSFan+DCV & IEcon+MSFan & IEcon+DCV & Full Package \\
\hline Houston-2A & - & 1,373 & 355 & 1,951 & 1,366 & 346 & 1,943 \\
\hline Phoenix-2B & 34 & 1,717 & 346 & 2,246 & 1,786 & 361 & 2,264 \\
\hline Atlanta-3A & - & 1,422 & 257 & 1,899 & 1,455 & 264 & 1,916 \\
\hline Los Angeles-3B & 176 & 2,638 & 34 & 2,795 & 2,895 & 204 & 2,986 \\
\hline Las Vegas-3B & 35 & 1,698 & 302 & 2,193 & 1,772 & 328 & 2,224 \\
\hline San Francisco-3C & 77 & 2,450 & -118 & 2,573 & 2,628 & 153 & 2,872 \\
\hline Baltimore-4A & - & 1,654 & 528 & 2,531 & 1,694 & 544 & 2,553 \\
\hline Albuquerque-4B & 3 & 1,505 & 176 & 1,907 & 1,557 & 199 & 1,941 \\
\hline Seattle-4C & 16 & 1,235 & 111 & 1,559 & 1,275 & 202 & 1,652 \\
\hline Chicago-5A & 8 & 1,238 & 620 & 2,185 & 1,263 & 642 & 2,208 \\
\hline Denver-5B & 30 & 1,543 & 376 & 2,215 & 1,604 & 406 & 2,247 \\
\hline
\end{tabular}




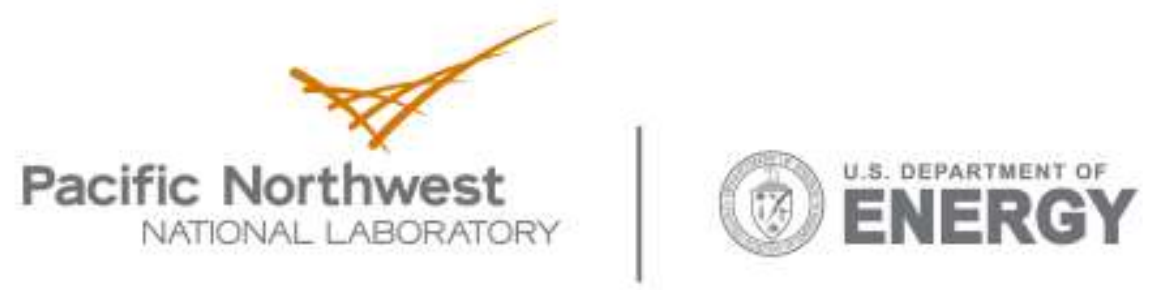

902 Battelle Boulevard

P.O. Box 999

Richland, WA 99352

1-888-375-PNNL (7665)

www.pnl.gov 